\title{
AN INDUSTRY STUDY OF THE UTILISATION OF PUBLIC R\&D
}

\section{TRACY BAILEY \\ GERRIT LOOTS}

LAUREN WILDSCHUT

\section{crest}

Centre for Research on Science and Technology 
C 


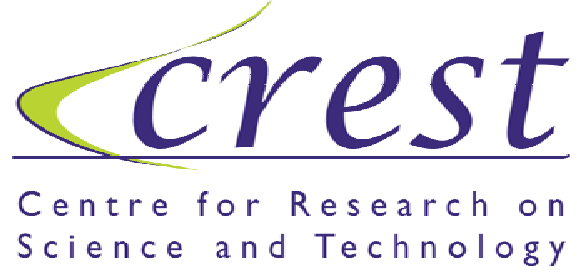

THE PRODUCTION AND UTILISATION OF KNOWLEDGE IN HIGHER EDUCATION INSTITUTIONS IN SOUTH AFRICA

Volume 3

\section{An industry study of the utilisation of public R\&D}

Tracy Bailey, Gerrit Loots \& Lauren Wildschut

(C)2005 Centre for Research on Science \& Technology, Stellenbosch University

All rights reserved 
The Production and Utilisation of Knowledge in Higher Education Institutions in South Africa (Volume 3): An Industry Study of the Utilisation of Public R\&D

Published by SUN PReSS, a division of AFRICAN SUN MeDIA, Stellenbosch 7600

www.africansunmedia.co.za

www.sun-e-shop.co.za

All rights reserved. Copyright $\odot 2005$ Centre for Research on Science \& Technology, Stellenbosch University

No part of this book may be reproduced or transmitted in any form or by any electronic, photographic or mechanical means, including photocopying and recording on record, tape or laser disk, on microfilm, via the Internet, by e-mail, or by any other information storage and retrieval system, without prior written permission by the publisher.

First edition 2005

ISBN: 978-1-919980-63-8

e-ISBN: $978-1-919980-71-3$

DOI: $10.18820 / 9781919980713$

Set in $11 / 13$ Lucida Sans Unicode

Cover design by Dewald van Zyl

Typesetting by Marthie van Niekerk

SUN PReSS is a division of AFRICAN SUN MeDIA, Stellenbosch University's publishing division.

SUN PReSS publishes academic, professional and reference works in print and electronic format. This publication may be ordered directly from http://www.sun-e-shop.co.za 


\section{CONTENTS}

Preface

Outline of Volume 3

Chapter I: Introduction

Chapter 2: The demand environment of company R\&D

2.I Market-push and market-pull ……............................................ 7

2.2 The 'innovation imperative' .................................................................. 9

2.3 The need for technological problem-solving .................................. 10

2.4 Technology-push and knowledge spillovers .................................... II

2.5 Aligning R\&D with regulations and industry standards ................ 12

2.6 The need to improve cost effectiveness ......................................... 13

2.7 The need for improved quality and performance .......................... 14

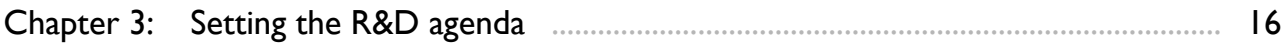

3.I Who makes an input into the R\&D agenda? ................................. 16

3.2 The nature of the inputs into the R\&D agenda ........................... 20

Chapter 4: Modes of knowledge production …........................................................... 26

4.I Different definitions of and emphases on 'research' and 'development' ........................................................................ 26

4.2 Experimental development ....................................................... 28

4.3 Applied research ........................................................................ 29

4.4 Basic fundamental and basic strategic research ............................ 31

Chapter 5: R\&D outsourcing and collaboration ….................................................. 34

5.I Motivations behind R\&D outsourcing and collaboration ............... 34

5.2 The nature of R\&D collaboration in general .................................. 36

5.3 Who do companies collaborate with around R\&D? ...................... 38

5.4 The nature of R\&D outsourcing …........................................... 42

5.5 Who do companies outsource their R\&D to? ............................... 43

Chapter 6: The outputs of company R\&D …................................................................ 47

6.I Non-epistemic outputs of company R\&D .................................... 47

6.2 Epistemic outputs of company R\&D: Knowledge, skills

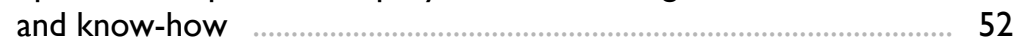

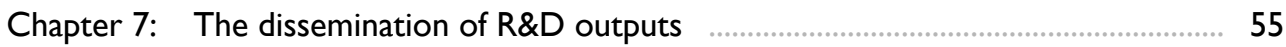

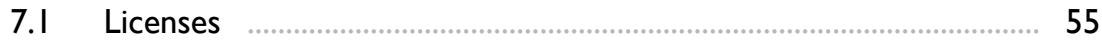

7.2 Patents

7.3 Design codes and standards …................................................. 57

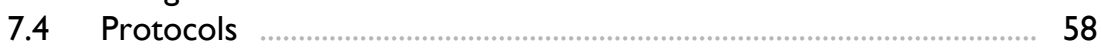

7.5 Internal reports and communication .......................................... 58

7.6 Feedback to and ongoing consultation with user groups and clients 


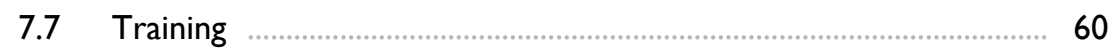

7.8 Forums, conferences and other networks ………........................... 61

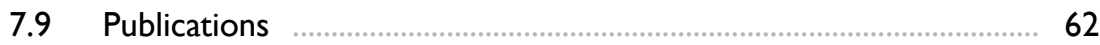

Chapter 8: The benefits and beneficiaries of company R\&D .

8.I The nature of the benefits of company R\&D ……......................... 64

8.2 The beneficiaries of company R\&D .......................................... 73

8.3 Instances of 'no utilisation' ............................................ 79

Chapter 9: Factors that limit R\&D and technology transfer .

9.I Lack of appropriately skilled human resources ……….................... 81

9.2 Inadequate financial resources …………..................................... 86

9.3 The lack of certain equipment and facilities locally …….................. 88

9.4 Inadequate sources of knowledge or information ………............. 88

9.5 Difficulties associated with technology transfer ............................ 91

9.6 Inadequate government incentives and support ........................... 92

9.7 Conflicting agendas of industry and academia around collaboration and outsourcing ...................................................... 94

9.8 Limited or stagnating local markets …………….......................... 96

9.9 Negative attitudes towards innovation/R\&D …………................... 96

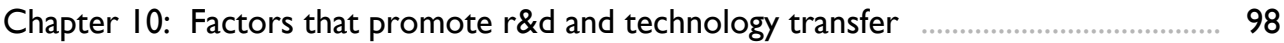

10.1 Adequate financial, human and knowledge resources .................... 98

10.2 Company geared towards innovation and R\&D ............................ 99

10.3 Good human resources management ….................................... 101

10.4 Evaluating the outcomes of company R\&D .............................. 10 I

10.5 The 'South African advantage' .............................................. 102

Chapter II: Concluding comments $\ldots$

List of references 


\section{PREFACE}

In June 2002, the Carnegie Corporation of New York awarded a substantial grant to CREST - then the Centre for Interdisciplinary Studies - to conduct research on the production and utilisation of research in higher education in South Africa.

In the original proposal to Carnegie, we described the context and rationale behind this project as follows:

With the advent of the new democracy in 1994, it was expected that the higher education institutions in the country would and should play a major role in the transformation of South African society. On the one hand, South African universities and technikons were expected to transform themselves; on the other hand, as major actors within the national system of innovation, it was also expected that they would make a significant contribution to the new society in various ways, including the production of relevant and useful knowledge.

The focus in the project is on the R\&D function of higher education institutions; on the knowledge produced by scientists and scholars at these institutions. In terms of this focus, the overarching aim of the proposed project is to analyse and assess to what extent South African universities and technikons are engaged in a transformative agenda in the production and utilisation of scientific knowledge.

Two major research questions will drive the project:

$<$ To what extent has the production of scientific knowledge at SA universities and technikons changed over the past seven years?

C To what extent is the knowledge produced at SA universities and technikons used, particularly in the interest of new national goals?

At the same time as we commenced our work on this project, the National Advisory Council on Innovation placed on tender a national study on the state of research utilisation in South Africa. CREST was awarded a grant to conduct a survey of public sector R\&D as well as a separate interview-based study of industry views on research utilisation. We subsequently integrated our work on the Carnegie project and the $\mathrm{NACl}$ commission into a two and a half year study. By the end of December 2004 we completed our research.

The findings of this study have been organised into six separate reports:

Volume I: A review of models of research utilisation

Volume 2: A survey of research utilisation

Volume 3: An industry study of the utilisation of public R\&D

Volume 4: The dynamic of knowledge production and utilisation: Fifteen case studies

Volume 5: The role of intermediary organisations in the utilisation of research

Volume 6: Knowledge for transformation: Modes of knowledge production and utilisation in post-apartheid South Africa 


\section{Outline of Volume 3}

Volume 3 in this series of studies on shifts in modes of knowledge production and utilisation is devoted to a study of the views of more than I00 R\&D managers of high R\&D intensive South African companies. Eight main themes are addressed in this study:

$<$ The demand environment of industry R\&D

$<$ Agenda-setting in industrial R\&D

$<$ A review of different modes of knowledge production

$<$ R\&D outsourcing and collaboration

$<$ The outputs of company R\&D

$<$ The dissemination of company R\&D

$<$ The benefits and beneficiaries of company R\&D

$<$ Factors that limits R\&D and technology transfer

$<$ Factors that promote R\&D and technology transfer

A study of this scope invariably relies on teamwork. We have been very fortunate to have a group of dedicated and hard-working individuals who have assisted in various aspects of the study. In particular, we would like to thank the following people:

$<$ Fran Ritchie who assisted with the administration of the industry interviews, for some of the transcriptions and post-editing, and for writing the fieldwork report on the industry interviews.

$<$ Desmarie Dreyer, Maryke Hunter-Hüsselman, Annette Mehnert, Moira Pogrund and Catherine Twycross for transcribing the interviews.

$<$ Marthie van Niekerk who provided general administrative support to the project.

TRACY BAILEY, GERRIT LOOTS and LAUREN WILDSCHUT

Stellenbosch 


\section{CHAPTER 1}

INTRODUCTION

The CREST study on research utilisation comprised two main empirical components: a questionnaire survey of research being conducted with universities, technikons and science councils (Volume 2) and a telephone survey of a sample of R\&D managers in one hundred and sixteen companies). This report is devoted to the telephone survey study.

Telephone interviews were conducted with major players across most sectors of the economy during the second half of 2002. In each case, an interview was conducted with the most senior person in charge of R\&D or Technology at the firm or company concerned. Although it was initially planned to interview 200 respondents, it soon became evident that this was not feasible within the time frame. Problems with outdated contact names, difficulties in setting up interviews and other related problems, meant that we had to suffice with a total of 116 completed telephone interviews of which II 3 were usable. A complete list of the 166 companies contacted organised by economic sector is presented in Table I.

Table I.I: List of companies per sector interviewed

\begin{tabular}{|l|l|}
\hline Agriculture, forestry, fishing \& hunting & $\begin{array}{l}\text { Chemicals: Petroleum refineries \& } \\
\text { products }\end{array}$ \\
\hline Astral Foods (Meadow Feeds) & Petro SA \\
\hline Capespan & Petro SA Mossgas \\
\hline Citrus Research Institute & Sasol - Sastech \\
\hline Kynoch Feeds & Chemicals: Rubber \& plastic products \\
\hline Mondi Forests Ltd & DPI Plastics \\
\hline Mondi Processes & Construction \\
\hline Pannar & Infraset (Grinaker - LTA) \\
\hline SAPPI & Murray \& Roberts \\
\hline Sugar Milling Research Institute & Electronic hardware, systems \& software \\
\hline Chemicals: Chemicals excluding drugs & Altech Defence Systems \\
\hline AECI African Explosives & Azisa \\
\hline AECI Aroma and Fine Chemicals & Digicore Technology \\
\hline AECI Bioproducts & Fuchs Electronics \\
\hline AECI Fibres (SA Nylon Spinners) & Grintek Communications \\
\hline AECI Specialty Chemicals (ChemServe) & Grintek Electronic Systems \\
\hline Eli Lilly Pty Ltd & Grintek Electronics \\
\hline
\end{tabular}




\begin{tabular}{|c|c|}
\hline Fine Chemicals Corporation & Huletts Aluminium \\
\hline Keyplan Engineers & Impro Technologies \\
\hline Lever Ponds & ISIS \\
\hline Novartis: Pharma & Nanoteq \\
\hline Plascon & Reutech Radar Systems \\
\hline Unilever & Siemens Telecommunications \\
\hline Chemicals: Drugs \& medicines & Spescom \\
\hline Aspen Pharmacare & Tellumat \\
\hline Aventis (Hoechst Marion \& Roussel) & Thales Advanced Engineering \\
\hline Bristol Meyers Squibb & $\begin{array}{l}\text { Fabricated metal products \& machinery: } \\
\text { Metal products }\end{array}$ \\
\hline Meyer Zall Laboratories & Aberdare Cables \\
\hline Pfizer Global R\&D & African Cables \\
\hline $\begin{array}{l}\text { Fabricated metal products \& } \\
\text { machinery: Aircraft }\end{array}$ & Columbus Stainless \\
\hline Denel Aviation & Dorbyl Engineering \\
\hline Denel Ordnance & Mitek \\
\hline $\begin{array}{l}\text { Fabricated metal products \& } \\
\text { machinery: Electrical machinery }\end{array}$ & South African Institute for Steel Construction \\
\hline Circuit Breaker Industries & $\begin{array}{l}\text { Fabricated metal products \& machinery: } \\
\text { Shipbuilding \& repairing }\end{array}$ \\
\hline Conlog & Dorbyl Engineering - Shipping \\
\hline Genwest \& Hansen & $\begin{array}{l}\text { Fabricated metal products \& machinery: } \\
\text { Radio, TV \& communication equipment }\end{array}$ \\
\hline Willards Batteries & Altech UEC Multimedia \\
\hline $\begin{array}{l}\text { Fabricated metal products \& } \\
\text { machinery: Motor vehicles }\end{array}$ & Altech Netstar \\
\hline Delta Motor Corporation & Eloptro \\
\hline Toyota & Grintek Avitronics \\
\hline Volkswagen of SA & Mining \\
\hline Manufacturing: Food, drink \& tobacco & Amplats Research Centre \\
\hline Anglovaal Industries (I\&J) & AngloGold Engineering \\
\hline Anglovaal Industries (National Brands Ltd) & AngloGold GeoChemistry \\
\hline Ceres & AngloGold Metallurgy \\
\hline Clover & De Beers \\
\hline Distillers Corp & De Beers Diamond Research Laboratory \\
\hline Illovo & Impala Platinum Exploration \& Projects \\
\hline
\end{tabular}




\begin{tabular}{|l|l|}
\hline Parmalat & Impala Platinum Metallurgy \\
\hline Pioneer Foods & Impala Platinum Mining \\
\hline Reckitt Benckiser (\& Colman) & Impala Platinum Refinery \\
\hline South African Breweries & ISCOR Mining Consulting Services \\
\hline Tiger Foods & Services \& infrastructure \\
\hline Tongaat-Hulett Sugar & Cell C \\
\hline Unilever Best Foods Robertson & ESKOM \\
\hline $\begin{array}{l}\text { Manufacturing: Paper, print \& } \\
\text { publishing }\end{array}$ & National Ports Authority \\
\hline Nampak - Megapak & Rand Water \\
\hline $\begin{array}{l}\text { Manufacturing: Textiles, apparel \& } \\
\text { leather }\end{array}$ & Vodacom \\
\hline Bergriver Textiles & Transport \\
\hline Breathetex Corporation & South African Airways \\
\hline Gelvenor Textiles & \\
\hline Kaytech & \\
\hline
\end{tabular}

The reporting of the results of the industry interviews has been guided by a number of research questions that are based on the adapted Bozeman model of technology transfer (Bailey \& Mouton 2005). The key findings of this part of the study will be presented under these same headings, viz.

$<$ What stimulates the demand for company R\&D?

$<$ Who and what informs the R\&D agenda?

$<$ Modes of knowledge production

$<$ R\&D outsourcing and collaboration

$<$ Dissemination of R\&D outputs

$<$ The nature and benefits of company R\&D

$<$ The beneficiaries of company R\&D

$<$ What promotes and inhibits R\&D, and particularly the utilisation of company R\&D?

The analysis and structure of this report are also guided by the Bozeman model as outlined in Bailey \& Mouton (2005). In addition to the themes outlined above, throughout this report the ideas and observations articulated by respondents, as well as conclusions drawn from the analysis of the data, about the factors which impact on the effective utilisation of R\&D outputs, are highlighted. The final chapter of the report gives voice to respondents' ideas about how to maximise utilisation of company R\&D.

Unlike public sector R\&D, which extends from the arts and humanities to science and technology, the R\&D undertaken by the companies interviewed for this study falls mainly within the science and technology domain, as well as market-related research and analysis. 
It is therefore more appropriate to use the term 'technology transfer' in the discussion of research utilisation in the industry setting. As Bailey \& Mouton (2005) highlight, there are various definitions of technology transfer, as well as a range of different models describing the innovation process, of which technology transfer forms an integral part. Two of the definitions of technology transfer cited by Bailey \& Mouton (2005:3I) are provided here as a point of departure:

Technology transfer is the process by which research and other new technologies are transferred into useful processes, products, and programs. Another way of saying the same thing is: technology transfer is the process by which a better way of doing something is put into use as quickly as possible. (Hodgkins 1989)

... all the activities leading to the appropriate adoption of a new product or procedure by any group of users. 'New' is used in a special sense as it means any improvement. over existing technologies or processes, not necessarily a chronologically recent invention. ... Technology transfer is not simply information dissemination; that is, it is not simply sending out information - whatever the form - and then passively awaiting its use. Technology transfer is a more active term. It implies interaction between technology sponsors and users and results in actual innovation. (Schmitt, Beimborn \& Mulroy 1985)

What neither of these definitions alludes to, however, is the enormous importance of 'tacit' or 'embedded' knowledge in the process of technology transfer. Kraak (1997, quoted in Bailey \& Mouton 2005:39) defines tacit knowledge as

... the experience employees across the occupational spectrum have acquired through years of employment in a given enterprise: their knowledge of the production environment, their ability to identify flaws in the production process and quality defects in the final product, their learning-by-doing and sharing of shop floor wisdom. ... It bears a critical relationship with the capacity to reconfigure existing production information, technological knowledge and expertise to yield new designs, new products and increased market share.

For the purposes of this study, therefore, technology transfer is taken to include the transfer and utilisation of the outputs of company R\&D, as well as the transfer of tacit knowledge and skills in the process.

Finally, the term 'R\&D' is used in this report to refer to what is really quite a diverse range of activities. Chapter 4 on modes of knowledge production explores this in detail. For now, it is useful to note that very few of the companies that we approached had what they termed an 'R\&D unit'. More often than not, their R\&D activities were described in different ways. In addition, especially in the larger companies or multinational corporations, the R\&D function was spread across a number of units or centres - the division depending on who the R\&D is for, and which part of the business operations it relates to (e.g. design, production, marketing or sales). 
Table I.2 provides a few examples of the nomenclature employed by companies to describe the R\&D function within the firm.

Table I.2: Nomenclature used by companies to describe the R\&D function

\begin{tabular}{|c|c|}
\hline $\begin{array}{l}\text { Agriculture, forestry, fishing \& } \\
\text { hunting }\end{array}$ & $\begin{array}{l}\text { - Technical Department } \\
\text { - R\&D Division }\end{array}$ \\
\hline Chemicals & $\begin{array}{l}\text { - New Business Development Unit } \\
\text { - R\&D Department } \\
\text { - Product Development Department } \\
\text { - Exploration \& Production Division } \\
\text { - Clinical Studying, Monitoring \& Management } \\
\text { - Global R\&D }\end{array}$ \\
\hline $\begin{array}{l}\text { Electronic hardware, systems \& } \\
\text { software }\end{array}$ & $\begin{array}{l}\text { - Developmental operations (translated from } \\
\text { Afrikaans) }\end{array}$ \\
\hline $\begin{array}{l}\text { Fabricated metal products \& } \\
\text { machinery }\end{array}$ & $\begin{array}{l}\text { - Engineering (translated from Afrikaans) } \\
\text { - Engineering Services } \\
\text { - Product Development \& Procurement Department } \\
\text { - Technology Advancement Group }\end{array}$ \\
\hline Manufacturing & $\begin{array}{l}\text { - Development Resource Group } \\
\text { - Quality management and research (translated from } \\
\text { Afrikaans) } \\
\text { - Technology Transfer \& Troubleshoot Group } \\
\text { - New Product Development }\end{array}$ \\
\hline Mining & $\begin{array}{l}\text { - Best Practice Department } \\
\text { - Mining Technologies } \\
\text { - Research Centre \& Process Technical Division } \\
\text { - New Technology Function } \\
\text { - Diamond Research Laboratory } \\
\text { - Mining Consulting Services }\end{array}$ \\
\hline Services \& infrastructure & $\begin{array}{l}\text { - Knowledgebase Centre } \\
\text { - Infrastructural Planning \& Development }\end{array}$ \\
\hline Transport & - Flight: Technical \& Performance \\
\hline
\end{tabular}

The following chapter focuses on the analysis and discussion of the industry interviews and begin with an exploration of the various internal and external demands that stimulate company R\&D. 
Bozeman's (2000) concept of 'demand environment' refers to the range of factors that stimulate the demand for R\&D in the first place. Within industry, the demand environment comprises both internal (to the company) and external factors which give rise to the need, or create a demand for companies to undertake some form of R\&D. These are not discrete categories, however. An internal factor such as the need to lower the costs of production is closely related to the external influences of the global economy.

The internal demand environment of most company R\&D includes a number of interrelated factors, for example:

$<$ The need to reduce the costs of production/operation and increase profit margins

$<$ The specific R\&D requirements within each department or unit, and

$<$ The drive to improve the quality of products, processes and overall performance.

According to Bozeman (2000:643), the external demand environment for technology, in particular, is normally conceptualised in terms of 'market-push' or 'market-pull'. In other words, the demand for technology, and thus R\&D, is either a response to an existing need for the transfer object, or to the potential for induced demand (Bozeman 2000:636). In this sense most, if not all, the R\&D in the companies we surveyed was to some extent responding directly to clients' needs and/or looking for new market opportunities. In addition to market forces, Bozeman (2000:643) also notes that the public sector can play a significant role in creating a demand for technological innovation (e.g. via government funding).

Another important element of the external demand environment of company R\&D is what we have termed the 'innovation imperative', that is, the increasing pressure for companies to innovate continually, in order to compete effectively in the global economy. A different kind of 'imperative' is that which is set by government and industry regulations and standards which can have a direct impact on the nature and direction of company R\&D.

In summary, the demand environment can be seen as comprising needs and expectations, new opportunities, and/or regulations and imperatives.

Finally, the demand environment can be analysed in terms of 'strong' and 'weak' forms of demand. Strong demands are demands that companies simply cannot ignore, if they intend to survive. Weak demands are those that companies can choose to ignore, which would be 'nice-to-haves', should the budget and the management allow it. Clearly, whether these internal and external factors represent a strong or weak form of demand for a company depends to some extent on the context, in particular, the company's main line of business and the function of the R\&D unit within the broader operations. 
Having said that, it is possible to plot the various internal and external aspects of the demand environment of company R\&D in general as follows:

Figure I.I: A demand environment matrix

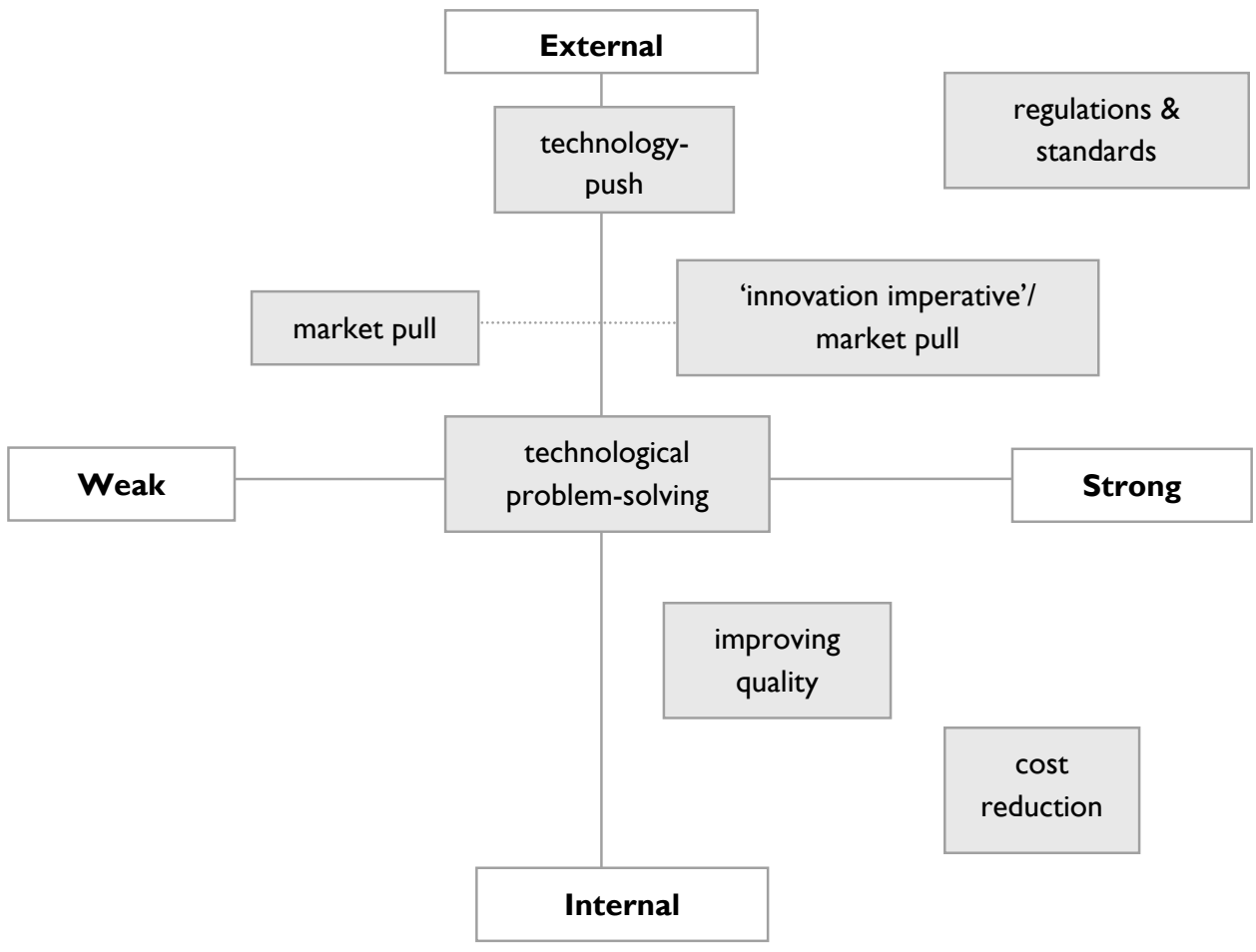

Significantly, very few companies appeared to have 'social responsibility' on their R\&D agenda. Pharmaceutical companies which develop drugs for tuberculosis and AIDS, or companies that develop technologies in safety and security, might be seen to be responding to a more social demand.

Selected quotations from the industry interviews, which speak to the nature of these various internal and external elements of the demand environment for company R\&D, are provided below.

\subsection{Market-push and market-pull}

All company R\&D is, to some extent or another, responsive to demands in the marketplace: either it is a direct response to the needs of clients and customers, or it is in anticipation of what client/customer needs are likely to be in the future. Here, one could distinguish between weaker forms of 'customer-driven' R\&D, such as decisions made on the basis of market analyses or market research, and stronger forms of 'client-driven' R\&D as exemplified in the input of clients and user groups through direct consultation. 
R\&D can also respond to changes in the application environment, that is, adapt to new conditions in the market within which the company operates.

Our focus is really on serving and keeping in touch with the marketplace and serving the needs of the market. (Electronic hardware, systems \& software: Altech Defence Systems)

I would say 50\% market driven. (Manufacturing: Bergriver Textiles)

It is very much focused on a particular problem or opportunity in the marketplace that we think we can exploit ...(Chemicals: AECI Specialty Chemicals)

... there is constant feedback in terms of what pressures there are in the market, what are the changes coming along the line and how we should adapt ourselves to make sure that we respond. (Manufacturing: Unilever Best Foods Robertson)

... there wouldn't just be, say, a technical $R \& D$ going on without having some sort of customer requirement. ... half of their $R \& D$ is related to the specific requirements that their customers have, that they develop new designs around. And the other half is more sort of in-house manufacturing efficiency, doing work on that. (Construction: Murray \& Roberts)

Obviously market-driven, from the point of view that we need to know what our customer wants. But a lot of innovations are developed outside of the customer base, so to speak. It then has to be marketed to them. We have, over the last few years, been developing electronic detonators, for instance, and that wasn't identified by the market. (Chemicals: $\mathrm{AECI}$ African Explosives)

Basically, a customer will come with a requirement and based on that requirement, we'll investigate what needs to be done and what technology is available, and we'll develop them into our product. Or, we will approach existing customers with new ideas for enhanced products, which then require additional development. (Electronic hardware, systems \& software: Thales Advanced Engineering)

Our strategy is to maybe get out of what are considered commodity-type businesses, where we cannot compete anymore with the bigger producers, particularly in the East, and we are focusing on specialised markets, but on a global scale. So, what is happening is as soon as we get into speciality markets, the products we're making are more difficult, therefore require a higher level of expertise and R\&D for that matter. That's why our research and development efforts or technology efforts are increasing year by year. (Chemicals: AECI Fibres - SA Nylon Spinners) 


\subsection{The 'innovation imperative'}

Many respondents indicated that innovation is an economic imperative - without it, a company will not be able to gain and maintain a competitive edge, or even just stay in the market. Significantly, R\&D plays a critical role in meeting this demand. (The extent to which R\&D is valued by companies in relation to this factor is discussed in Chapter 8.) Ensuring a competitive advantage means, amongst others, continually developing new, or improving existing product and process technologies, beating the competition by "being first to market", significantly reducing costs, and always thinking about the future - "what R\&D do we need to be doing now to ensure our survival in the future?"

We are continually bringing out new products. In this kind of industry, ... without R\&D we wouldn't be able to do it. It is vital to the future of the company. We have to keep innovating to make smaller, cheaper, more features. When new technologies come out like, for example, remote meter reading, we have to investigate it and implement it otherwise we will be left out of the market. (Fabricated metal products \& machinery: Conlog)

We tend to stay ahead more by just continually innovating. (Electronic hardware, systems \& software: Thales Advanced Engineering)

There are new developments in aviation all the time, and if you don't say ahead of the game, at the front of the game, you get left behind, and then you just don't become a player anymore. (Transport: SAA)

I think it is the classic business case: being first to market, being able to produce the product better than anybody else can, and of course the market acceptance - making sure that customers would prefer to buy it from us than from our competitors. (Electronic hardware, systems \& software: Grintek (2))

... the products have to remain at the forefront of technology to be competitive. (Chemicals: AECI African Explosives)

... our main aim is looking at innovative technology that will give our company competitive advantages ... (Agriculture, forestry, fishing \& hunting: Capespan)

... in order to keep up with the marketplace you do need to plan generational changes in a product. (Electronic hardware, systems \& software: Altech Defence Systems)

... we're keeping our eyes on what is happening to fuel cells around the world that threatens our current position. (Fabricated metal products \& machinery: Aberdare Cables)

The second is what we call a maintenance project. Generally that might be the competition has launched a new product and now we have to 
improve ours because there is a new benchmark being set. So that is product maintenance, which is all about improving the quality. (Manufacturing: Tiger Foods)

We typically find that our products have a life cycle of less than five years. That is sort of from breath-to-death kind of stuff. So, we continuously have to innovate and enhance the products. (Electronic hardware, systems \& software: Spescom)

... the idea is to make the company ultimately more competitive through cost efficiencies, or as I said earlier, new product development that competitors don't have. (Manufacturing: South African Breweries)

\subsection{The need for technological problem-solving}

Being innovative means developing new and unique products, or improving existing products and processes in innovative ways. This invariably presents a range of technical challenges which the R\&D function within the company is required to solve. Company $R \& D$ also engages in technological problem solving when conducting R\&D on behalf of clients.

Technological problem solving might involve:

$<$ Solving problems with products, e.g. prevention and cure of crop diseases, how to improve the structural integrity of a product, or how to make a product more environmentally friendly

$<$ Solving problems inherent in a process - "How could we do it better?"

$<$ Solving the problem of application in different contexts - "How do we apply this technology in a new/different context?"

... the overall expansion for Anglo Platinum at the moment has a huge technological requirement in terms of the characterisation of ores, and the performance of those ores, and also the generating of all the design information that you need for building plants, building operations. (Mining: Amplats Research Centre)

You know there is Utopia in gold mining that we must develop machinery that will break rock without having to drill and blast, which is what we're doing now. And we have been chasing that Utopia now for 35 years. (Mining: AngloGold Engineering)

Part of the benefits of having the in-house R\&D is that we can provide specialist consultancy to the operations. For instance we can say, "Don't do that or it will fail". We can prevent them from making bad investments. And to put value to those sort of contribution is very difficult. But that's what we are working on - trying to capture those contributions. (Mining: De Beers (I)) 
So it is driven by problems coming out of existing structures, typically which say, "What have we done wrong and how do we do it better?" (Fabricated metal products \& machinery: South African Institute for Steel Construction)

... problems which are difficult to solve for the development engineers - and that's when we go to the research department of our organisation, as how to analyse and come up with a solution for specific applications or problems. (Fabricated metal products \& machinery: Circuit Breaker Industries)

$R \& D$... also supports production from a troubleshooting point of view, investigations - if something goes wrong in production it will be referred back to R\&D and we will tell them how to proceed or what to do. (Chemicals: Fine Chemicals Corporation)

... there is a lot of problem solving. Cables can be used in many different circumstances and the number of permutations is not always regularly described in standard data. So we look at those special conditions, and then come up with solutions or applications or recommendations rather for the use of a particular size of cable. (Fabricated metal products \& machinery: African Cables)

The example is typical in the field. We found some of our products overseas have turned yellow in colour, so our R\&D section has resolved that. (Chemicals: PetroSA Mossgas)

... there've been a number of, let's call it, incremental advances that have taken place in respect of modified atmosphere packaging formats that have been developed by the unit to address particular weaknesses or issues relating to certain grape varieties ... (Agriculture, forestry, fishing \& hunting: Capespan)

... if there is a technical issue or a technical problem, it first of all comes to us, as the local or regional technical experts. If we can't resolve it, we will move it up a rung of our ladder to our development groups. If they can't resolve it, it becomes a fundamental science issue ... (Manufacturing: Reckitt Benckiser \& Coleman)

\subsection{Technology-push and knowledge spillovers}

The 'innovation imperative' compels companies to take note of the (especially new) technologies available on the market, to ensure that they are not left behind in the race for technological advance. Many respondents indicated that they direct significant amounts of energy to scanning the environment for new ideas (knowledge spillovers) and technology which could be applied locally.

... the OU market dictates how long on average they want the battery to last and the SA market is dictated by the country car allowance system which says that a car has one owner basically for between four to five years. 
So they have dictated that we design a battery that lasts four to five years. (Fabricated metal products \& machinery: Willard Batteries)

... on the software side, you just have to keep on improving, taking account of new technologies or new ways of doing things and thinking of things becoming available. (Fabricated metal products \& machinery: Mitek)

To a large extent we try to keep abreast of cutting edge technology as it is being developed internationally and then see to what extent it can be applied locally. (Chemicals: Keyplan Engineers)

Now what we've really done is look at the capabilities that are out there. Looked also at a lot of the current technologies that are in use and how we can leverage them as existing technologies. (Services \& infrastructure: Cell C)

\subsection{Aligning R\&D with regulations and industry standards}

Certain industries have to adhere to government/industry regulations or standards in order to be able to produce and sell their products or technologies. These regulations or standards make very explicit demands that the R\&D must respond to, or at least remain in line with. For example, R\&D in some industries (notably mining, pharmaceuticals and food manufacturing) seeks ways to achieve certain levels of safety. The pharmaceutical companies have ethical standards to maintain. Often, companies are required to register with or obtain accreditation from the relevant bodies.

We operate according to a specific non-conformance in our corrective action process, which is specified in our Quality Management and Food Safety system, that being that as soon as a problem is detected, corrective action would be taken to solve the problem, and only once the problem is completely solved would that corrective action request be signed off. That would often result, possibly, in either correcting an engineering aspect of the process or correcting details in either a process or a specification and resulting in an updated or a revised specification, or making improvements to the way a process flows. That would obviously be documented in terms of a corrective action request and filed for purposes of auditing by our internal and external auditors. (Manufacturing: Anglovaal Industries - National Brands Ltd)

... it's the engineering safety aspect of it. We have to keep ensuring that our product that we supply, and that we specify for them to use, is within engineering standards, is within SABS standards and that we are maintaining a level of safety out there. (Fabricated metal products \& machinery: Mitek)

Over the last three to four years, there has been a large move by the EU to restrict citrus coming in to the Union - almost like a trade barrier. So they have been more stringent about legislation ... and so we have had to keep that market open. We have been addressing items on things like citrus black 
spot, and just the fact that we've still kept that market open, has been a big success. (Agriculture, forestry, fishing \& hunting: Citrus Research Institute)

Now SIMRAC is a statutory organisation in this country - Safety in Mines Research Advisory Committee. They are there by statute to do mining safety research and mining companies are levied in relation to the number of accidents they are having and its about a R35 million-a-year programme. Its been running for the last 6 or 7 years. A lot of our research needs in rock engineering, in ventilation engineering, specifically issues around safety are all channelled through SIMRAC. (Mining: AngloGold Engineering)

We are guided by, first of all, international guidelines on clinical research that are put out. They have to keep on top of that in terms of appropriateness, ethics, morals and state of the art sort of processes in clinical research. ... So, because of the international guidelines, we are forced to stay at the forefront of knowledge, both from a process point of view and from a drug point of view, and technical point of view. (Chemicals: Eli Lilly Pty Ltd)

\subsection{The need to improve cost effectiveness}

A strong internal demand for many companies is the need for R\&D to find ways to reduce the costs of production, processes and operations. This is an important way of ensuring that one's company is competitive in the market.

It all aims to bring the cost of operation down the cost curve, which is a strategic objective of the company. (Mining: Amplats Research Centre)

... you should also have the ability to see some cost reductions and unit cost reductions in there. And that's the other part of it. I mean, at the end of the day, you need for projects to also make financial sense and business sense, because we're not a charity. We still need to stay in business. (Mining: Impala Platinum Mining)

... anybody can make sugar, but not everybody can make sugar efficiently. It is the costs reduction. We need to reduce costs because there is tremendous pressure on margins. There is a limit to how much sugar you can sell in South Africa and then what you don't sell in South Africa, you have to export. And the prices are not always predictable. (Manufacturing: Tongaat-Hulett Sugar)

... the products have become too expensive, either because the ingredients are expensive or the processes or equipment has got expensive or people have got expensive, so we have to bring the costs down by improving the process, or changing the ingredients, or something like that. (Manufacturing: Anglovaal Industries - I\&J) 
... most of our R\&D is on nationally reducing costs and doing work to improve equipment and processes, or raw materials, doing it differently so we could reduce costs. (Agriculture, forestry, fishing \& hunting: Mondi Processes)

It happens when we do this type of evaluation, that the source plants says to us, "Well if you don't take that part in the factory we will reduce the cost by $x$ Rand". We will go out to local suppliers and we have a department that continually scans this, they are forever doing feasibility studies. ... we then get to the point where we say, "Okay we can make this part cheaper than what we can import for", there's an entry cost of tooling development of a certain amount, half a million, million, whatever the complete cost is. With the saving we can achieve a payback and we have a criterion for payback. We will not localise anything that will payback of more than two years, okay. We will then have a look at that and decide that, yes, we are going to localise the component because of the economic advantage. (Fabricated metal products \& machinery: Delta Motor Corporation)

\subsection{The need for improved quality and performance}

Inherent in much of the R\&D undertaken by companies is the need for improvement: improving the quality of products, the performance of processes and systems, or the safety of staff, clients or consumers. Improvements lead to cost reduction and more of a competitive edge.

... when any company spends capital, you want to take the opportunity to improve your operations, and not merely to build more of the same. And that is very much part of our focus - to improve what we have, which is really part of the overall strategy that is bringing it down the cost curve. (Mining: Amplats Research Centre)

The second agenda is really driven from a supply chain and simplification process. How do we align things in the supply chain, how do we look for common specifications, in other words how do we look for simple processes and how do we simplify and harmonise, not only locally in the country, but regionally, and then again globally. (Chemicals: Unilever)

One third would be operational efficiency and about one-third would be improving safety. (Transport: SAA)

There are clearly many good reasons why companies pursue R\&D. Usually, company R\&D is a response to a combination of factors within the demand environment, although one or two - depending on the context - will predominate. Furthermore, many of these factors are interrelated. For instance, responding to the innovation imperative may well involve having to engage in technological problem solving, responding to technology-push or to customers and clients' needs. It might also involve the quest to improve the quality of products, processes and general performance. In other words, the respective demand factors are seldom mutually exclusive, but instead, are often mutually reinforcing. 
What must not be forgotten, of course, is that 'for-profit' private sector companies have two simple objectives: to stay in business and to make more money. In this sense, all the factors in the demand environment discussed above stem from this singular aim. However, as we will see later, not all companies have the resources necessary to respond to their demand environment.

The question is: how are the needs, regulations and opportunities in the demand environment identified, and then translated into an R\&D agenda? We asked respondents about who is involved in setting the research agenda, as well as the nature of the inputs made into the agenda-setting process. 
Who makes an input into the R\&D agenda, depends on whom the R\&D is intended for, that is, for the company to use internally, or on behalf of a client. Internally, R\&D responds to the strategic plan and to the specific needs of company staff - whether they are in design and engineering, production, marketing or sales. Externally, clients and customers, members of the wider industry, or specialists in the field might be invited to make an input into setting the R\&D agenda.

In addition to consulting specific individuals around the R\&D priorities, companies also engage in various activities that are designed to identify the factors in the demand environment that need to be taken into account and responded to. This usually involves some form of market analysis and environmental and technological scanning.

\subsection{Who makes an input into the R\&D agenda?}

\section{The company itself}

In general, the company plays a central role in setting its own R\&D agenda. Even in cases when a company or R\&D unit is working collaboratively with another company or institution, the company has a say in the R\&D agenda. This is to ensure that the agenda is closely related to the firm's strategic direction and planning, and that it will make good business sense at the end of the day.

There is considerable diversity in the ways in which people within the company are involved in the agenda-setting process. Overall, it usually involves more than one department or unit within the firm. Very often, marketing or new business units play an important role. Others might include production units/factories, and the finance people. The composition of the group often reflects the multiple purposes and users of company R\&D, as well as the multidisciplinary (Mode 2) nature of the projects. Input into the agenda is either done in a collective fashion, or each unit interacts with R\&D individually.

Occasionally, the agenda is set by an individual (e.g. an Executive Director, or head of the research unit). In some cases, Boards or Committees have the final say. For those South African companies that are part of a multinational corporation, the parent company usually plays a role in setting the R\&D agenda.

It is coordinated by what we call New Business Development. They identify opportunities; they then make decisions as to either source the intellectual property from other companies or to develop it in-house. (Chemicals: Aspen Pharmacare)

We see ourselves as a professional service consultant firm to the marketing department. They decide, they determine largely what, we would call, ad hoc research. ... So it is largely driven by the company's growth agenda and what innovation we need to do. (Chemicals: Lever Pond) 
... a need or problem would be identified within the factories.

(Manufacturing: Tongaat-Hulett Sugar)

Well, firstly, I think it is fair to say that we don't tackle any project unless it stands on three legs. There would be an R\&D leg, there would be a production leg and there would be a marketing leg. And there is a little forum that we run, where we meet and discuss projects, basically a think tank on new concepts. Then we put in place role players presenting the three legs. (Manufacturing: Pioneer Foods)

In terms of the actual projects and the innovations that we are going to implement in SA, that is decided by the South African team, with relevant information from around the globe. (Manufacturing: Unilever Best Foods Robertson)

The executive of the company decide on it in their strategic plan for the year. (Fabricated metal products \& machinery: African Cables)

We've got a small group of internal people, basically metallurgists, and one chemist and we look at the new products that need to be developed.

(Fabricated metal products \& machinery: Huletts Aluminium)

Okay, what happens there is that I actually collate and do the first filtering. Normally it is about $50 \%$ more or $100 \%$ more than we would require. Then I present that to the Board of Avitronics, plus we have senior management within Avitronics, and then they say, "Well look, this is a good way to go." So they basically filter what I give them and then we reduce it down to about $50 \%$ of my original input. (Electronic hardware, systems \& software: Grintek Avitronics)

It is very much an inclusive process within the organisation. What we tend to do is that we bring the organisation together every year and we develop a five-year business plan. It is a rolling five-year business plan that is very much based on technology for a competitive advantage, and, at the same time, in line with our strategic intent. What we do is we develop this fiveyear business plan (and it is a major document - six or seven hundred pages) and it goes into the nth detail about the potential of technologies and how we need to look at it. It goes out to the organisation and we actually get the top 200 managers and specialists in the organisation, and we sit down and brainstorm this document. They go away and they give us feedback online, and what we then do is we take this document and make the appropriate changes ... What we also do is that we have in excess of 800 projects, projects varying from $R 50000$ to $R 20$ million, and it is strongly driven by steering committees. We have about thirty steering committees a year that actually sit and review each and every project, with our customers. (I call our customers our line-groups within our organisation.) What we do is we look at the performance and, of course, quite clearly, at the end of the 
year, we have to see value and things like internal rates (we need to show a return on investment). We do that twice a year by internal or external audit on the projects, to see that in actual fact we are getting value. (Services \& infrastructure: Eskom)

The R\&D manager. It is important that he, in his position as that person, is a visionary individual, and that he interacts very closely with his team. He uses his team as a resource base all the time, particularly in terms of mapping the future. He also integrates across the division; what we gear up to do has to be in line to what our processors want. We've got to be driven by giving them the products that they need. So, he does involve them in his decision making as well. So it is intradivisional as well as interdivisional interaction in terms of the decision-making. I think also, importantly, with the research agenda is that there is discussion with the academics in our support research institutions in terms of that agenda, particularly because in the business of growing trees, you are really [not] consciously mapping this year or next year. You really have got to be mapping up to twenty years. You are looking after the future of the company, twenty years from now on. So it is critically important that he accesses those people. (Agriculture, forestry, fishing \& hunting: Mondi Forests Ltd)

\section{Multinationals}

Being an affiliate of a multinational organisation, obviously a lot of the clinical research and the $R \& D$ plan and strategy is determined at headquarters. And we have to align ourselves with that. But at the local affiliate level, we can (within that strategy and plan) decide which and what we are going to do that is in line with our own particular strategy here, also baseline provided and directed by headquarters. We essentially decide within that on our research agenda locally. (Chemicals: Eli Lilly Pty Ltd)

That is entirely orchestrated by them in the sense of the actual study, so the protocol are a given and the participation is where the choice is ours. (Chemicals: Aventis)

So the global innovation centre almost defines the agenda and what we do regionally, and locally is that we look at consumer fit. If there is a fit for our consumers we will then adapt that innovation and then apply them to SA. (Manufacturing: Unilever Best Foods Robertson)

\section{Contracting clients and customers}

Since the R\&D agenda is largely market-driven, real and potential customers, or clients who contract R\&D from the company, make an important input into the agenda.

Locally, we try to determine what the unmet needs of the consumer are and that defines our research, specifically. (Chemicals: Unilever) 
... when it is in our line of business and a customer has a specific need, then we run the sponsorship to the research for development to meet their specific requirements. (Electronic hardware, systems \& software: Grintek (3))

The company is very customer-orientated and typically work is defined after consultation with the markets or with customers. So, typically projects become projects in two ways; one is by direct request of a customer, which will result in our having to develop a new product or customise a product. The other main method is our anticipation of the needs of typical customers. (Electronic hardware, systems \& software: Fuchs Electronics)

It is a joint effort between the manufacturing unit - they do research as to what the key issues are and project proposals are then drawn up and agreed between the customer - or mill operating unit, or a marketing unit and then that is used as a framework to execute the research programme. (Agriculture, forestry, fishing \& hunting: SAPPI)

And we will also bring the marketers down here, because our R\&D is very market driven. We have to keep our feet on the ground here and make it very customer specific. I have mentioned our close contact with our customers. We get a lot of ideas from our customers. We are very close to all the municipalities in this country, you know, and ideas come from that relationship. (Fabricated metal products \& machinery: Aberdare Cables)

\section{Industry}

It is generally the case that industry makes an input into a company's R\&D agenda when the company represents or conducts research on behalf of industry members.

It is largely influenced by the growers. Our extension manager visits all the production areas in which they have sort of technical groups that report back saying, "These are our research priorities". On top of that, the actual project managers might bring up their own research requirements, because they may be more into the future than the growers. It is a combination of the growers and the experts in the field. (Agriculture, forestry, fishing \& hunting: Citrus Research Institute)

We are a department within the [company name] group of companies and as such, there are different companies that we service within the [company name] group. There are four main companies in the group and basically they give us their needs, which are prioritised needs ... (Agriculture, forestry, fishing \& hunting: Capespan)

We have an Advisory Research Committee with representation from each of the major sugar companies, and also with representation from the university and the CSIR, a small representation. Together with the sugar factories we draw up a proposed research programme, which is then debated and 
proved by the Advisory Research Committee. (Agriculture, forestry, fishing \& hunting: Sugar Milling Research Institute)

... there is obviously a Trust which is the body, The Wheat and Cereal Trust, and they would have a technical committee. And I serve on the technical committee and as do some of the other milling companies - it is a broad spectrum. We need to look at the interests of the whole spectrum from seed breeder right through to the final manufacturer of certain goods, and obviously there is something for upcoming farmers and that type of thing. (Manufacturing: Pioneer Foods)

\section{Specialist expertise}

Finally, where necessary, companies will seek expert input into the decision-making around the R\&D agenda.

We also have international services that we subscribe to, where it's more than just publication-driven. We have a team of people that we can draw on for their expertise in a particular area. (Services \& infrastructure: Cell C)

\subsection{The nature of the inputs into the R\&D agenda}

Typically, companies draw on ideas and information from a variety of sources when making decisions regarding the R\&D agenda. Internally, the R\&D agenda is aligned with the strategic plan and priorities of the company, as well as the budget available for R\&D activities. In terms of external demand, the existing and future needs of customers and clients are determined through market analyses. Other ideas are gleaned from scanning the environment, locally and internationally, for new technologies and knowledge that could be applied within the company - either to improve products or to commercialise locally. This is done by consulting journals and other literatures, searching the Internet, attending conferences, trade shows and other networking forums and, in some cases, even reverse engineering.

\section{Strategic needs}

... in conjunction with a number of my colleagues in production and in projects, as well as the executive in terms of longer term strategic needs of the company. (Mining: Amplats Research Centre)

The $R \& D$ agenda is determined from various forums. We've got a business development forum, which is run by our executives at Head Office. Obviously there the critical goals or strategic issues are identified, and then round that we have technical meetings, we explore these and we put plans in place to look at things that could help us with them. (Mining: Impala Platinum - Metallurgy)

... each of those strategic business units develop their own technology strategy, which is an outflow or is based on their business strategy. ... And 
we at R\&D were heavily involved in setting out this technology strategy. So this is to make sure that all the work that we are doing in R\&D is aligned with the technology strategy each of those SPUs use. From those four technology strategies for each business units we develop a [company name] technology strategy, in other words for the whole company, an overall one, if I can say that. And from now on, specifically from this year, all the work that we are doing is derived from the gaps identified in those technology strategies of each different unit. (Mining: Iscor Mining Consulting Services)

... our R\&D is very much driven by our strategic intent, and our strategic intent is very much to be an African service facility of global stature. ... So, we see technology, and in particular R\&D, as one of those key issues that can facilitate our competitive advantage. ... we have a technology roadmap which looks at the future, and we are talking about fifteen to twenty years, so we have a long-term view at the strategic level of what the focus areas are we need to go into. Built on that, we then put the five-year plan together, and that technology roadmap, first of all, is now part of our business planning process. It was built by our managing planning level. What we do is we go the next level down and we develop a five-year strategic direction plan, which then goes into the organisation. It really looks at the technology roadmap and makes it almost operational from an $R \& D$ perspective. (Services \& infrastructure: Eskom)

\section{Market analyses}

... we got in-house what's called a Technology Marketing function, which does some sort of strategic market analysis, and based on that we evaluate the relative merits of the ideas for projects we have, which we then translate into a R\&D portfolio project. (Mining: De Beers (I))

We have got a management team that determines the direction, which is dictated to a large extent by market research and market requirements, and then availability of technology. We have basically got a scouting function where we go out, we look at what is available, what is happening in the market, what will be the next demand. And then according to that we set up a programme, we work out the likelihood of projects, what the likelihood of successes are and what would be the benefits if we were to succeed. And then you work from there to basically determine which project falls next and what amount of attention it should deserve. (Chemicals: AECI Bioproducts)

What would happen is, let's say someone in marketing comes up with an idea for a new shampoo. They then will come to us and we will probably go and do some exploratory work, to go and talk to consumers qualitatively about what are the needs of shampoo. They will normally get it out of a habit and attitude study or some previous piece of research, but we will probably go and interrogate it further and they will give us a brief, a research brief. (Chemicals: Lever Pond) 
... we look at the IMF of what products are selling, where are they selling, what is the quantities that are sold. Saying maybe we can make a break through in that particular market with a blockbuster. You look wherever the need is. (Chemicals: Meyer Zall Laboratories)

There are inputs from everywhere possible, from market research, from market awareness, trends in other markets. (Manufacturing: Reckitt Benckiser \& Coleman)

Often it was very technology driven: people would go out and then find things that you could do with whatever product and to find at the end that there was no real market for it. We tried to turn that around in the last five years and say, well let's find something that there's a market demand for, and then try and find the technology fit to give us what's required to challenge that market. (Manufacturing: Illovo)

The marketing people give input as well of what they feel is required, and then afterwards, before we actually go and invest a large amount of money, they do market surveys for us. (Electronic hardware, systems \& software: Grintek Avitronics)

\section{Environmental scanning}

We have people part of whose job it is to make sure that they stay abreast of whatever is happening in certain product categories around the world, and they will read journals, they will read trade magazines, they will sit on the internet. I think we have identified seven or eight possible sources of innovation. People go to trade shows, people travel overseas, walk through supermarkets' shelves. (Manufacturing: Tiger Foods)

There are a lot of trade shows every year in all parts of the world, a lot of conferences, so from that point of view there is a lot of public domain knowledge where you can see what your competitors are doing and that is fairly characteristic of the defence industry. (Electronic hardware, systems \& software: Altech Defence Systems)

Then a recently created department is New Business, where we have a group of people looking at new opportunities, not only in polymers and fibres but a bit broader - really looking at what is happening in technology and if there is any competence we have at getting into something new and different. (Chemicals: AECI Fibres - SA Nylon Spinners)

... the products have to remain at the forefront of technology to be competitive. So with globalisation, a lot of information became available which we didn't have access to before, which has to be built into our product and services. (Chemicals: AECI African Explosives) 
We have international contacts. We don't work in isolation. We communicate all over the world; we meet with other technology bodies all over the world from time to time. So, we like to think we know what is going on. We make an effort to find out. (Chemicals: Plascon)

It is making sure we track international stuff and look at the application of that to our own processes. But also working in a number of areas from fairly cutting-edge or fairly new technology because we are upgrading existing technology. ... We might look at the pharmaceuticals what they are doing and find an application there. (Agriculture, forestry, fishing \& hunting: SAPPI)

Well we use anything that comes out of universities and in publications - we use literature to get ideas. (Agriculture, forestry, fishing \& hunting: Capespan)

\section{Journals, conference proceedings and the Internet}

Many firms reported subscribing to and/or consulting journals pertaining to their industry and their R\&D activities. Because of the multidisciplinary nature of much of the R\&D work, frequently a cross-section of these sources is used to inform the R\&D agenda and R\&D activities in general. Interestingly, companies do not only consult journals to look for research findings, but also to identify individuals or groups with particular expertise.

Increasingly though, companies are using the Internet as an important source of information, and it appears that the Internet is taking the place of more traditional sources, such as journals.

If you look at the journals we subscribe to, they cut across business, industry, clinical and medical. (Chemicals: Eli Lilly Pty Ltd)

... we would only be looking at research journals, like consumer research, not scientific journals. (Chemicals: Lever Pond)

Both scientific and academic mainly, occasionally industrial as well. (Mining: AngloGold - Geochemistry)

We certainly get all the papers that are presented regarding heavy ore conferences that they have once a year ... (Fabricated metal products \& machinery: Dorbyl Engineering (2))

I think we rely on mostly what we read in these journals in terms of building up a bigger picture of the environment we play in: who the market leaders are in certain areas, and where there are gaps ... (Electronic hardware, systems \& software: Nanoteq)

They play a role certainly in giving us information, but what we do on a local level is they actually can point us in the direction of an investigator. Say we have a new disease area that we have not worked in before, by 
reading the local scientific journals, we can see perhaps doctors or professors that are publishing in that area and it can point us to the people that we are looking for to do our trials. The other reason we would perhaps be reading scientific journals as well is that sometimes we pick up doctors writing to these journals on case reports. We can pick up that perhaps he has been giving a certain drug of ours to their patients and picked up an adverse effect that we didn't know about, or something like that. (Chemicals: Pfizer Global R\&D)

If you understand the way it works, journals are often the showcase of ideas and trends in ideas in the world and it is good to keep an eye on those. One must also recognise that anybody who holds the same view that we do on the commercial value of ideas is not going to put their latest ideas into any journal. So, again, one has to be realistic about accepting what you read as the latest facts. (Electronic hardware, systems \& software: Grintek (2))

I think by the time something appears in a journal it is a little bit late. Because people don't publish things until they are well researched. So, I think journals help for more general information, rather than for more scientific insight. Scientific insight comes more from other teams of people working in the same field. (Chemicals: Plascon)

I think we use the Internet a lot. We find the Internet is key to our type of business model because what it has done is that it has put business based in South Africa on a [par] in terms of access to information compared to where business is based anywhere else in the world. When I first started my career, one of the big problems was that we would always get information later than an equivalent engineer, say, working in the US. It is a very difficult disadvantage to overcome if you are competing with a global market. So, we use the Internet a lot as a tool. (Electronic hardware, systems \& software: Azisa)

... it gives you the ability to scan what's happening in America, Europe, Japan and also Australia. (Fabricated metal products \& machinery: Delta Motor Corporation)

... most probably between the technical manager and myself we will spend three, four hours a week looking at research and development websites, university websites and really find out what are people are doing all over the world, because often, they may be working on something that gives you an idea for something else. (Manufacturing: Gelvenor Textiles)

You know I think these days the Internet has to a large extent taken the place of most of the journals that we consult. In fact, we did physically close our library earlier this year just because we found that the use of the Internet, as an information medium, was to a large extent supplanting the use of journals. (Electronic hardware, systems \& software: Tellumat) 
In summary, the R\&D agenda-setting process can be complex, involving a range of different stakeholders and drawing on diverse sources of information and ideas. On the one hand, companies try to ensure that the R\&D agenda responds to and is in line with the broader strategic objectives of the firm. On the other hand, R\&D priorities are also determined by the needs of customers, clients and other users, that is, trends in the marketplace.

Clearly, managing these different and sometimes contradictory needs and inputs into the R\&D agenda require negotiation and compromise and can present some real challenges. (See, for example, the problems created by the conflicting agendas of industry and academia in R\&D collaboration discussed in Chapter 10.) However, there is no doubt that the inclusion of all these stakeholders and inputs into the agenda is very important in terms of ensuring that the outputs of company R\&D are successfully utilised.

Therefore, whether R\&D is utilised and whether it is utilised to good effect are, in part, determined by the nature of the R\&D agenda: what R\&D will be done, by whom, and for what purpose. In addition, the R\&D agenda specifies the intended users of the results, ensuring a close fit between purpose and use.

Once the R\&D agenda has been set, company R\&D activities - the actual doing of the R\&D - can continue. The following chapter explores the nature of the R\&D activities undertaken by the companies surveyed in this study, with a specific focus on the modes of knowledge production. 
One of the basic precepts of research utilisation posed by Bailey \& Mouton (2005:47) is that the ways in which research (in this case, R\&D) can be utilised are "strongly influenced by the nature of the research/mode of knowledge production". We were therefore interested to know what modes of knowledge production R\&D units/functions engage in. In order to analyse these responses, we have taken as our point of departure, the Frascati Manual's (OECD 1994) classification of research into 'basic fundamental', 'basic strategic', 'applied' and 'experimental development' categories.

It should be noted, however, that respondents in the industry interviews used terms such as 'research', 'basic research', 'fundamental research' and 'development' in different ways. As Bailey \& Mouton (2005:36) observe, "Although practitioners, understanding the distinctions, do not have much trouble communicating amongst themselves, the broad range of activities encompassed by R\&D in its now-common usage sometimes leads to confusion among economists, policy analysts, and other observers." Some respondents provided their own definitions or interpretations of the terms 'research' and 'development', and examples of these are provided below. In other cases, which category the particular R\&D activity fell into had to be inferred from the data.

We also wanted to look at how companies differ in their involvement in and emphasis on the ' $R$ ' and ' $D$ ' in R\&D; in other words, do companies engage more in research or development? From the preceding discussion it is apparent that, overall, company R\&D is application-driven. From this we might anticipate that there is greater emphasis on experimental development and applied research, than on basic research as such. The industry data certainly supports this notion. Whether a company engages more in basic or applied research, or experimental development, depends largely on the purpose of the R\&D.

The following section provides a selection of respondents' comments and explanations regarding their own understanding of what is meant by R\&D, and the extent of their involvement in this range of activities. This is followed by examples of R\&D activities undertaken by companies in the survey, which have been grouped according to the Frascati classification outlined above.

\subsection{Different definitions of and emphases on 'research' and 'development'}

What we tend to do, if it's improving an existing product we just call it a development, and I'm not classifying any of those where we've already got the product, you've got the market all you doing now is just refining it, or bringing up an updated version. To me that's not research, it's really just developing an existing product. ... What we call research is into either a totally new innovation, coming up with a totally new concept of doing 
something, totally different from what you're doing at the moment. (Manufacturing: Gelvenor Textiles)

Development is stuff you would take ...(I don't know if you would call it technology transfer(?) that's taking the basic information and turning it into something that is practical. (Manufacturing: Tongaat-Hulett Sugar)

The research body basically will look at new technologies, basically decide on the pitfalls and then sort out all the problem areas, generate generally documents that the development side can use to actually implement the technology in the final product. We will just go to the prototype stage. (Fabricated metal products \& machinery: Conlog)

We do more fundamental research as opposed to developing products. (Fabricated metal products \& machinery: Circuit Breaker Industries - Reunert)

... the way we see ourselves is little ' $r$ ' and big ' $D$ ' ... (Electronic hardware, systems \& software: Spescom)

Basically in the classical sense of the word $R \& D$ - we don't do that. We are applying technology in the development of products, so a lot of the processes are really aimed at product development, and invariably that is trying to take advantage of whatever software or hardware technology particularly coming out of the commercial area - and seeing how we can turn those into products. (Electronic hardware, systems \& software: Altech Defence Systems)

I would say that the major portion is improving on existing products. (Chemicals: DPI Plastics)

It is definitely to improve or generate new products. We don't do a lot of research at this stage. (Manufacturing: Tiger Foods)

... in terms of if you take research and development as it is officially known, research is looking into something without knowing whether there would be any possible commercial application. We don't do any of that sort of thing. We really are far more in the development side where we are doing work with a definite commercial application. (Manufacturing: Anglovaal Industries - I\&J)

I would suggest that in the motor industry in South Africa there is no research as such. It is all development, but no research. (Fabricated metal products \& machinery: Volkswagen SA)

We do a limited amount of true research within our own companies, however, we do varying amount of development - improvement to existing 
products, improvements or modifications to products, which we might license from these overseas principles. (Chemicals: AECI Specialty Chemicals)

Some of it is very blue-sky - not a big percentage, but that is long- term very innovative stuff, which may or may not come off, through to short-term problem solving and support work. But I would say that most of it is medium-term really, for product development, process development, and a big area of our work is of the environmental waste reduction type. (Agriculture, forestry, fishing \& hunting: SAPPI)

\subsection{Experimental development}

The Frascati Manual (OECD 1994:5I) defines experimental development as "systematic work, drawing on existing knowledge gained from research and practical experience, that is directed to producing new materials, products and devices; to installing new processes, systems and services; or to improving substantially those already produced or installed." Development might therefore depend on knowledge and information generated through research, but also on any other information available, identified through environmental scanning, networking and consultation, for instance.

Many respondents indicated that either all, or a large part of their R\&D work was focused on development rather than research; in other words, R\&D is about improvements to or commercialisation of existing products and processes, or the development of new ones.

We like to call it 'technology development'. (Fabricated metal products \& machinery: Aberdare Cables)

... we use our own knowledge to tell the manufacturer this is what we think we want and we work with them in terms of developing that product to get what we want. (Mining: AngloGold Engineering)

What we're doing with this is we are attempting to put well-known pharmaceutical actives and then certain generic materials into this to develop a product that is more effective and has less side effects. (Chemicals: Meyer Zall Laboratories)

It is purely development. There is very little fundamental research done. It's more of what you call supplied research, taking a concept and commercialising it ... (Chemicals: AECI Fibres - SA Nylon Spinners)

Some of them are small changes from our range and some of them are totally new things. (Manufacturing: Food, drink \& tobacco - Anglovaal I\&J)

It is very much applied work and probably largely about incremental improvement, but from time to time we do get involved in what is regarded as a new product or new technology. We investigate to establish if a new technology is something we can apply, and if it requires different materials, 
we make sure that these can be bought locally against a suitable specification that we develop. (Manufacturing: Nampak - Megapak)

The drive and force would be to get a better fit to the customers' requirement here. When the overseas product would only set aside $60 \%$ of the requirement, you add something to it to get an $80 \%$ or $90 \%$ requirement fit. (Electronic hardware, systems \& software: Nanoteq)

\subsection{Applied research}

The Frascati Manual (OECD 1994:5 I) defines applied research as "original investigation undertaken in order to acquire new knowledge. It is, however, directed primarily towards a specific practical aim or objective." In terms of its practical application, applied research might closely resemble experimental development. According to the Frascati definition, however, the distinction lies in whether the knowledge is newly generated (applied research) or already existing (development).

In the context of company R\&D, applied research is often related to technological problem solving. It also involves understanding the raw materials one is working with in order to know how to use or apply them better. Other forms of applied research, which emerged in the data, include market research, as well as the clinical trials conducted by pharmaceutical companies.

... we do basic seismic exploration - the acquisition of seismic data offshore. There's, obviously when it comes to the interpretation of the data, there are various methods and processes to be interpreted, and process the data in order to delineate potential fuels or potential prospects - where we would like to drill. (Chemicals: PetroSA)

... micro-filtration was an existing technology, but you can't just put it anywhere, anytime and hope that it will work, so you do need to do some applied research ... (Chemicals: Keyplan Engineers)

... it is very ... much needs driven, so a lot of it is primary applied research ... (Services \& infrastructure: Eskom)

... there is also the sort of longer term studies which you are doing, which is basically once a year we will survey the breakwaters - do a helicopter survey of the breakwater - to determine long-term trends on shore protection. There is the gathering of data from the vessels: how many vessels are coming to port, what size, where do they come from, the wave interpretation of data ... (Services \& infrastructure: National Ports Authority)

We are often focusing on particular problems and problem solving, but we have $a$ brief and a function of longer-term work to develop instrumentation, new technologies etc. for the future in the industry. (Agriculture, forestry, fishing \& hunting: Sugar Milling Research Institute) 
It involves a whole lot of research from different people - things on fruit fly and other diseases that are considered by those countries to be $a$ problem for receiving fruit. (Agriculture, forestry, fishing \& hunting: Citrus Research Institute)

Silviculture is the research into an appropriate establishment. That will be your sites, your soil map, matching the appropriate species or clones to the sites, appropriate weed control, ensuring that you get canopy closure so that your weeds are then controlled, right through to harvesting. (Agriculture, forestry, fishing \& hunting: Mondi Forests Ltd)

... the study into crane behaviour research that Stellenbosch University has done, where really practical answers are coming out that are of benefit to our members. And, in fact, it is even going to alter our design loading codes on how we actually set about calculating the design loads for cranes. (Fabricated metal products \& machinery: South African Institute for Steel Construction)

... it would be different for different industries. Platinum is at a different stage of development. They will be doing a lot more fundamental research. In terms of the gold industry, I would say that we would be more interested in applied research from here on than fundamental research. (Mining: AngloGold Engineering)

\section{Market research}

A number of companies undertake market research, either to complement other R\&D activities, or as the only form of research that is conducted.

We have got a separate research centre (we call it Knowledgebase Centre) which essentially entails collation of primary data, primary sources of data into reports, which we would use as support tools. They also, from time to time, perform primary research. That primary research is for marketing purposes in order to either define or refine any product offering we are going to be making. An example of that primary research would be the whole research process we followed before we launched the four-year package last year - that entailed primary research in the form of interaction with teenagers all over SA. We got random samples of teenagers from various schools in the country, mostly in the big urban centres. They were interviewed at different stages, and then as time went on, during the initial interfacing with those kids, we selected individuals for follow through interviews once our concept started gelling. (Services \& infrastructure: Vodacom)

We do a lot of analysis of secondary data. We do a lot of primary research. The primary research is consumer-focused, segmentation, landscapes, so that we can input into forecasting. We do business research. We do new product development where we research our channels and we do 
competitive intelligence. We also do business intelligence, which incorporates things like GIS, and we do macro-economic services. We track what's happening on the international technological front, as well as specific international operators. And what else do we do? We've, obviously we also analyse our own subscriber data, looking for patterns in usage, mounted usage, etcetera, take up of certain products and features. (Services \& infrastructure: Cell C)

Our research is mainly focused on market research, and research in terms of services available out there, and how we can implement those services and our standard equipment. (Services \& infrastructure: Vodacom)

We typically don't do what one would call fundamental research. Generally the kind of research that we would do would be market research, more than engineering fundamental research. (Electronic hardware, systems \& software: Grintek (3))

... what we have got are habit and attitude studies particularly in FMCG, where we will have a look at habit and attitude studies and try and understand what people are doing. Are there any opportunities in their habits? (Chemicals: Lever Pond)

We research consumers and gain consumer insight from a marketing perspective, but we don't do true research from a technical/science perspective. (Manufacturing: Unilever Best Foods Robertson)

\section{Clinical research/trials}

The chemical industry - and especially the pharmaceuticals industry - engages in clinical research or clinical trials to test their drugs.

... we do get involved in drugs and medicines clinical research and various phases of clinical research. (Chemicals: Eli Lilly Pty Ltd)

In SA we do phase 2, 3 and 4 clinical trials. (Chemicals: Novartis - Pharma)

And we've done certain studies and trials on limited numbers of healthy patients, where the product works better. (Chemicals: Meyer Zall Laboratories)

\subsection{Basic fundamental and basic strategic research}

A few companies indicated that they engaged in basic research - occasionally in-house, but usually outsourced to, or in collaboration with, universities. The basic research side of company R\&D is more to do with long-term needs and objectives, than immediate practical applications.

There are two possible manifestations of basic research, namely fundamental and strategic basic research. In basic fundamental research, the scientist is motivated or driven by 
curiosity, or an interest purely in discovery and 'knowledge for the sake of knowledge'. In basic strategic research, the scientist - albeit first and foremost driven by curiosity and intellectual concerns - is also mindful of possible practical and economic and social applications/utilities in the future.

Because of the different ways in which respondents used the terms 'basic', 'fundamental' and 'blue-sky' research, it is often not clear exactly how these comments fit into our 'basic fundamental' and 'basic strategic' categories. One could argue that all company R\&D is ultimately aimed at having an application, even though it might be long-term and developed without that application in mind. Therefore, most 'basic' research is likely to be strategic rather than fundamental.

... the $R \& D$ that we do here is very fundamental.

(Mining: Impala Platinum Refinery)

[Name] was a knowledge-based $R \& D$ programme. A lot of fundamental research was done as well as a review of all of our current knowledgebase in terms of ultra deep-level mining. There was very little technology developed in [name], although there was some - but it was primarily a knowledgebased programme. (Mining: AngloGold Engineering)

The philosophy behind that is any level of basic work plus some of the applied work is not done in-house. We are not a research institute; we're a company that has to grow trees. We have to be very specific in terms of the processes we need. And we focus on the technology transfer, not on the basic research. We do have certain facilities in places where it's very easy to cross check the basic research and results that come in before large-scale tech transfer happens. (Agriculture, forestry, fishing \& hunting: Mondi Forests Ltd)

No, it does not always lead to a product. Sometimes it is a type of an exploring $R \& D$. We explore the possibility to make something to see if we can do it, and then we will look at the markets and all the rest. (Agriculture, forestry, fishing \& hunting: Kynoch Feeds)

Some of the longer-term stuff, within research itself we would feel it being fundamental research, so we interact with the universities on that. (Manufacturing: South African Breweries)

We would produce knowledge, which potentially might result in specific technology implementation. (Services \& infrastructure: Vodacom)

... we are working with University of Stellenbosch on a particular project where they are doing some fundamental $R \& D$ for us and putting an insecticide into Polymers, into our fibres. (Chemicals: AECI Fibres - SA Nylon Spinners) 
The modes of knowledge production inherent in company R\&D are clearly linked to the purpose of the R\&D. However, there are other ways of looking at when and why companies engage in research or development. Firstly, the mode of knowledge production, as applied to R\&D within industry, will differ depending on which aspect of the innovation process it is associated with. Therefore, basic research would be to do with the long-term vision of the company, looking to the future and planning generational changes in a product, for instance. Basic research might also inform the company's broader understanding of the environment in which the company, and its R\&D function, operate.'

Applied research, on the other hand, is likely to arise in relation to shorter-term needs, for example, generating new knowledge that is required to solve a technological or practical problem, or to provide practical, 'applicable' information. Applied research can also provide specific scientific or technical information, for example, around the raw or fabricated materials that are used.

Finally, companies are likely to engage in experimental development when they are seeking to make incremental improvements or new additions to existing products and processes. In this sense, Alic \& Branscomb (in Bailey \& Mouton 2005:36) suggest that it is better to use the term 'D\&D' (engineering design and development) to describe the commercialisation stage of the innovation process.

A second way of looking at when and why company R\&D engages in research or development is in terms of whether the company is part of a young or mature industry. According to Ralph Gomory (in Bailey \& Mouton 2005:35), young industries are characterised by the "Ladder paradigm" in which the innovation process begins with science (basic research) and culminates in the production and marketing of the innovation. The "Circle Model" on the other hand, is characteristic of more mature industries: "The cyclic development process is a process of repeated, continuous, incremental improvement. It is the process of following up what exists in manufacturing, put into production, and then in turn starts the next generation" (ibid).

Chapter 5 considers who conducts the company R\&D, with a specific focus on outsourcing and collaboration.

I This is similar to Carol Weiss's 'enlightment function' of social research (see Bailey \& Mouton 2005:25) 
Those companies, which do not have their own in-house R\&D facilities, invariably outsource all their R\&D needs. However, even those companies that do have their own in-house R\&D frequently outsource their R\&D needs (or aspects thereof), and/or collaborate with others. On the other hand, some respondents reported that they did not collaborate or outsource at all.

Companies collaborate with, or outsource to a range of partners, both locally and internationally, including higher education institutions (HEls) (notably universities), science councils and research institutes, other companies or companies within the group, and customers and clients. Through collaboration and outsourcing, companies seek to fulfil a variety of R\&D needs that they are unable to fulfil on their own.

Respondents also reported pros and cons of collaborating with different types of organisations. For instance, while there are many benefits to having a successful collaborative arrangement, competition and intellectual property rights can make some companies very cautious about entering into these kinds of agreements. (The difficulties experienced with regard to outsourcing and collaboration with academia in particular are discussed in Chapter 10.)

This section explores companies' motivations for, and the nature of R\&D outsourcing and collaboration. We also look more closely at who companies collaborate with or outsource to. ${ }^{2}$

\subsection{Motivations behind R\&D outsourcing and collaboration}

Speaking internationally, Howells \& James (2001:7-8) identify a number of 'push' and 'pull' factors, which encourage companies to outsource their R\&D needs, or to collaborate with others around their R\&D activities. Some of the push factors include "the increasing complexity of the research process and the cost and risks of R\&D"; the more challenging technical and scientific problems posed by increasingly sophisticated products and technologies; inadequate in-house resources; and, the multidisciplinary nature of many projects. Pull factors include the availability of specialised expertise, knowledge, equipment and facilities of potential partners, as well as "government policies and incentives to participate in collaborative research and technical projects” (Howells \& James 200 I:8).

2 It was beyond the scope of this study to investigate the nature of the collaborative agreements, what the interaction/relationship entailed, or how the partners participated. For a more detailed overview of industryhigher education collaboration and partnerships, see Carstens \& Mouton (2002) and Wickham (2002). 
Reasons for collaborating and outsourcing amongst the respondents in our industry interviews included:

$<$ To make up for shortfalls in human resource capacity

$<$ To access people with the appropriate tacit knowledge, as well as specific specialist expertise (especially in multidisciplinary projects)

$<$ To access additional funds, or expensive equipment and facilities

$<$ To get 'new blood' onto a project to help generate new and innovative ideas

$<$ To comply with funding requirements, such as THRIP

$<$ To seek out quality wherever it is available.

We outsource mostly. We really don't have the capacity. (Agriculture, forestry, fishing \& hunting: Mondi Processes)

Well, we like to make use of the expertise that is available in the country, so we have project coordinators or managers, and they are tasked to pull together the best team to solve the problem. ... And they pull together people from the varsities, or wherever, in order to solve a problem as efficiently and quickly as possible. So, depending on the nature of the problem, if it is more technological, then often the universities have more equipment or better budgets for capital expenses or have things that are available already and they can make use of students. So, some things are more suited to that. On the other hand if it's a project that is more applied and needs work done on the farms and field research, then we are more suited for that. So, the project coordinator will decide who is the best person to do the job basically. (Agriculture, forestry, fishing \& hunting: Citrus Research Institute)

Our policy is to firstly work with the best people, wherever in the world they are ... (Mining: Amplats Research Centre)

We tend to work closely with outside organisations because we believe we get more innovation using that approach, and it also gives us more flexibility because we are aiming at a certain need, and the technology base to meet that need could vary from year to year. (Mining: De Beers (I))

Most of it is very specific and focussed and, obviously, it's a high level of skills required, and there may be 7 or 8 different key research areas just in the geological field that one might want to address through projects or even on the operational side. To have every expert on the company's books doesn't really make sense. There's not necessarily a continuation of the need for such skills. So I believe it is sound practice. Yes, the people working for the company must be aware of the details, but having all the expertise I don't believe makes good sense. (Mining: Impala Platinum Exploration \& Projects) 
If it is a low-volume, high-value product and the technology is not available to manufacture, then we obviously wouldn't develop it in-house.

(Chemicals: Aspen Pharmacare)

We could either use them to make up a shortfall in capacity, engineering capacity, or it can be they have facilities that we don't have, or it could be they are located geographically where we are not. For instance, we have in the past used the Engine dymos at the SABS, because they are at the Reef, and we want to do power curves up at the Reef for instance. (Fabricated metal products \& machinery: Volkswagen $S A)$

We prefer the approach of rather contracting out the research to universities or research places because of the expense of equipment, and also you cannot keep all those specialists fully occupied on the right things, so we think it is more cost effective to use people to do your research. (Fabricated metal products \& machinery: Columbus Stainless)

What we do is we outsource stuff to meet peak requirements, especially on less-core type stuff. (Electronic hardware, systems \& software: Spescom)

\subsection{The nature of R\&D collaboration in general}

Companies engage in collaboration around their R\&D in a variety of ways. Amongst others, collaboration takes the form of:

$<$ Sharing R\&D activities and collaborative research

$<$ Tacit knowledge and skills transfer

$<$ Funding arrangements

$<$ License and technology agreements

$<$ Human resources development for the future (e.g. bursaries for postgraduate students, research funding, funding research chairs, and running training programmes at HEls).

Attempts are usually made to ensure that the relationship is mutually beneficial.

... we're working with a group from Holland now to develop a new way of identifying genes which switch on and switch off pre-maturation. ... We're not doing the gene matching and the gene analysis side of it, but we are doing all the fruit side of it, in other words, we determine the linkage between fruit maturity and the genes. (Agriculture, forestry, fishing \& hunting: Capespan)

The point is we have helped students at the Stellenbosch University, I give advice and I work with people at Stellenbosch University that is almost just to make sure that we get decent students. (Mining: AngloGold - Geochemistry) 
And we try and build a relationship with a couple of postgraduate students who then end up coming and doing practical parts of the actual contractual work at our site, and then eventually coming up with deliverables. (Mining: Impala Platinum Refinery)

... we are mainly interested working with them to ensure that their graduates service our needs. So, that is more collaborative type of thing - on their strategic committees, their curriculum planning, that type of thing. That is very important to us because we use in the order of about 60 analytical chemists, and they rotate through here at quite a high speed. (Chemicals: Aspen Pharmacare)

... 'Deepmine' was a collaborative research programme between 3 mining companies - AngloGold, GoldFields Ltd and Durban Roodepoort Deep; the CSIR Mining Tech and other collaborating research organisations and THRIP. ... So basically I/3 of the money came from industry, I/3 came from Mining Tech through its government grant, I/3 came from THRIP. We drew up a programme - a three-year programme and we managed - industry was really in the driving seat and CSIR was the lead contractor and we ran Deepmine on that basis. We've now got a successor programme called 'Futuremine' which is looking at modernising our current operations. Deepmine was looking at possible ultra deep operations. (Mining: AngloGold Engineering)

For instance, in our foundry group a year and a half ago we built a brand new cylinder head foundry in partnership with an Austrian company who are the leading cylinder heads producer in Europe - so we had a technology agreement with them. They supplied us with the design, the process, etc. and they would also supply us with people to train our engineers, our operators etc. ... That is quite a common way that we work. (Construction: Murray \& Roberts)

Because we have so many companies and we are a very diverse organisation, we have many, many products, many, many technologies. So typically we would find it better to enter into some licence agreement or technology agreement or even joint venture arrangement with an international company elsewhere in the world, companies which have much greater resources in their own R\&D and they might have many times more people working on the particular technologies, and we then are able to benefit from all of the work that is done there by the licence agreements being in place. (Chemicals: AECI Specialty Chemicals)

... we made use of a leading Japanese company and we put together a technology exchange programme and on this particular system, and their specialists would have come here after we have told them what our processes are and our capabilities. They would have looked at them. Our people would have gone over there and they would have been in their plant 
and then they would have transferred the applicable technology from the one plant to our plant. It would have been done from their people to our people, not just a piece of paper or a book telling you how to do it. They know how our plant does a specific process; they know what is needed and they tell us how to get our processes to get to the end result. (Fabricated metal products \& machinery: Huletts Aluminium)

\subsection{Who do companies collaborate with around R\&D?}

As already noted, companies collaborate with a range of organisations and institutions, both locally and internationally, around their R\&D needs. These include HEls, science councils, research institutes, other companies, industry bodies, hospitals and doctors. Of all these, companies appear to collaborate with other companies more often than they do with anyone else.

\section{Collaboration with other firms}

Companies collaborate with other companies for a number of reasons. In the first place, as one respondent observed, there is no point in 're-inventing the wheel'. In this sense, companies can benefit from the existing research base, expertise, skills and technology available in other companies, on which to base further R\&D. Companies also benefit from sharing costs with others, as well as scarce and/or expensive equipment and facilities. Some companies even choose to collaborate with other companies in order to overcome the competition between them.

What we tend to do is to collaborate with local suppliers. We ensure that the local suppliers can bring in the latest technology that is available overseas. (Fabricated metal products \& machinery: Volkswagen SA)

It's very difficult to get expertise on explosives off-the-shelf, so to speak, unless you are lucky and somebody from a military background applies for a job, or from an overseas company. What we used to do is to accept secondees from overseas explosive companies to strengthen the in-house $R \& D$ and broaden the base from which our people work. And vice versa, we also seconded people up. (Chemicals: AECI African Explosives)

We prefer to have people whose business it is to develop and sell machines coming along and being in partnership with us, rather than us being in competition with them, and having the in-house expertise to develop machines, which we certainly don't have anymore. (Mining: AngloGold Engineering)

We don't want to redesign the wheel from scratch. So if we know that there are experts outside there in the specific technology that we are interested in, we will rather look for an alliance with that specific supplier. (Mining: Iscor Mining Consulting Services)

... what we tend to do is collaborate with companies overseas because they are not direct competitors here. (Chemicals: $\mathrm{AECI}$ African Explosives) 
There is collaboration, but it tends to be on what I call pre-competitive technology. There is not really a lot of collaboration on the competitive edge between the companies because it affects your profitability and your costs. (Mining: Amplats Research Centre)

We get the manufacturers involved to a large degree. For example, when we look at installing new technology, the navigation equipment, we would certainly put our requirements on the table, get hold of two or three manufacturers and say to them, "Right, these are our requirements. We would want you to advise us what solution you would come up with." And in those instances, we would rely heavily on them to do their R\&D. (Transport: SAA)

\section{Collaboration with other companies in the multinational group}

Companies that are part of a larger multinational group often collaborate with their multinational partners in other regions of the world. A common premise for the collaboration is for the South African arm of the global R\&D to explore ways of developing and applying the technology in the South African context. There is also a lot of collaboration around technology and knowledge transfer through the exchange of human resources.

As it currently happens, typically it is a joint development, so the process would begin by sending South African engineers and software developers into the French teams, working alongside them for a period of time, and then establishing a duplicate development environment in the country. Until such time as we believe we have fully mastered all aspects of that technology and, subject to any export restrictions, we then basically are on our own. But it is mainly run in a fairly collaborative way, often on a programme of joint interest, with an exchange of people in both directions. (Electronic hardware, systems \& software: Altech Defence Systems)

There is a culture of sharing and we test this work for relevance in our markets. We get involved in the R\&D managers' meetings globally, so we are kept up to date with global technologies and trends. (Manufacturing: Unilever Best Foods Robertson)

As far as learning and training - one thing that we have done is we have about four people working in Sweden (that is from SA because of our joint ownership there) and we have about four or five of their people working here. ... you know, I believe technology goes on feet, not on paper. You have to have people working with each other and talking. (Electronic hardware, systems \& software: Grintek Avitronics)

\section{Collaboration with science councils and research institutes}

A number of respondents indicated that they collaborate with science councils and, to a lesser extent, with other research institutes. By far the majority of companies who mentioned collaborating with science councils identified the CSIR as the collaborating 
partner. Often the collaborating science council or research institute will do one or more aspects of the R\&D, for example, collecting or analysing of data, or testing technology, as well as provide specialist skills and expertise.

... we use a fair amount of the M+MTek division of the CSIR on, you know, their engineering facilities and skills. We also work together with CSIR in Pretoria on the polymer side ... (Manufacturing: Breathetex Corporation)

So, what we have had to do in instances is take that technology to the point it's been developed, on whatever scale, and look to check it or validate it on a pilot scale and, for example, use the CSIR Biochemtech to do that, in many instances. (Manufacturing: Illovo)

We have an existing relationship with the CSIR which dates quite far back. The CSIR have got the best database of information, and very much the research 'hat' on them as the research institute. ... There is a lot of skills development between the two of us, we fund a lot of their programmes, they provide a skills transfer back to us etc. (Services \& infrastructure: National Ports Authority)

\section{Collaboration with higher education institutions}

Overall within the higher education sector, companies appear to collaborate far more with universities than they do with technikons. It is encouraging to note that some respondents were very complimentary about the expertise available in certain university departments ("pockets of excellence"), or of specific individuals within universities. Some companies collaborate with only one institution, but many collaborate with a wide range, depending on their needs. In some cases, companies collaborate with universities overseas.

The most common form of R\&D collaboration with universities appears to be around longer-term and/or fundamental research, as well as the need for specific specialist expertise. Universities often benefit from the collaboration in the form of funding for research and bursaries for postgraduate students. In one case, a company funded the establishment of a technical centre at one of the technikons which ensured that the company had access to up-to-date equipment and technology, whilst at the same time building up the skills and expertise they needed to tap in to.

... we work with most of the major universities in SA. ... We do the policy work with South African universities and with some of them we have collaborative ventures, with overseas universities as well. (Mining: Amplats Research Centre)

... we also collaborate with universities and partially fund, together with other mining houses, a research unit at Pretoria University called Canmod, Centre for Agnatic Ore Deposits, for example, where one tries to direct them in certain areas that are of interest to us. (Mining: Impala Platinum Exploration \& Projects) 
We are directly funding various postgraduate research programmes to the tune of R200 000 a year, and that fluctuates. We do discuss this with the universities - what their needs are going to be. They do research along the lines that are going to be helpful to our industry and, where possible, we try and find the money to support the budget requesting. ... But typically, we have a very ulterior motive for supporting postgraduate research at universities in structural steel projects. When a person gets out of a university with an MSc or even better, a PhD degree in engineering that has been steel research based, we have a captive engineer who is going to become very competent in our field in our industry. So, it is almost a way of locking (golden handcuffs, I call it) the young people doing research back into our industry afterwards. (Fabricated metal products \& machinery: South African Institute for Steel Construction)

We actually collaborate a lot with universities. We took a strategic decision about 4 years back (1998), because we lost a lot of our people and we also went through what most of the other companies have gone through, a big reduction in numbers of people. And we lost nearly half our research capability, people-wise. We then made a strategic decision to maintain a core of people, which is the 25 I mentioned approximately, but then to identify opportunities outside our company, within and without SA, within an academic field, to assist us. And we built up research relationships with about five universities locally and one university in the UK. (Chemicals: AECI African Explosives)

Yes, we have some with the universities, not as much as I would like. We work quite closely with the University of Pretoria with some of the postgraduate students on defining some of their research projects. We present $a$ course at the university and it is something that we would like to expand as we grow. The other thing that we also do - we sometimes get requirements in fields where we don't have good domain knowledge in that field. (Electronic hardware, systems \& software: Azisa)

... the one with UCT is going to have much longer-term things. In other words, we are actually going to be helping them fund research (which you know that universities are desperate for funding for their research projects) so we are going to help with that. And it will have a spin off with postgrad students who will be employed and work on this research that we will be cofunding. (Manufacturing: Tiger Foods)

... that is project that we are busy running in collaboration with Cape Technikon, in actual fact. They are doing all the pumping trials and pumping models for us. (Chemicals: AECI African Explosives)

What we did about four years ago, or three years ago - we set up a technological agreement with the technikon and we have a battery centre at the technikon, which is basically an $80 \%$ ownership by Willard. We 
have supplied ... equipment to it, with regards to the battery testers, the particle-size testers and so forth. We actually fund all of the maintenance for the centre and the technikon then supplies us with the manpower ... That centre is actually where we carry out the majority of our really fancy research as such. (Fabricated metal products \& machinery: Willard Batteries)

\section{Collaboration with medical institutions and practitioners}

In order to carry out their clinical trials on new drugs, pharmaceutical companies collaborate with medical practitioners - whether they are doctors in hospitals or private practice - as well as patients.

In some cases, the companies simply use the hospitals as research sites. Others actually co-opt the doctors to participate in the research themselves.

They just act as sites. We ask them to do the research in a particular way and then they go ahead and do these trials for us. (Chemicals: Novartis - Pharma)

GPs, hospitals, private doctors, private specialists, whatever is the demand of the particular trial. You can imagine some very highly technical, innovative drug, which is going to be particularly expensive, we might not very well research in academia, because those specialists would probably never be exposed to it once it is registered. So there are a lot of considerations that we work right across the medical spectrum. (Chemicals: Pfizer Global R\&D)

\subsection{The nature of R\&D outsourcing}

Many companies outsource their R\&D requirements - in total or in part - to other organisations, both locally and internationally. In some cases, companies outsource R\&D requirements that are more specialised in nature - typically academic or scientific research. Others will outsource very large-scale R\&D that is beyond their capacity to undertake. In addition, as with collaboration, R\&D is outsourced to organisations or institutions that have particular expertise, or specialised equipment and facilities.

I would say about $15 \%$ is overseas, $15 \%$ is outsourced within SA and about $70 \%$ is internal expenditure. (Mining: Amplats Research Centre)

Virtually without exception on the mining side. Our metallurgy, I'm not sure about - but most pure R\&D is farmed out to research organisations. (Mining: AngloGold Engineering)

Larger scale R\&D is usually farmed out. (Mining: AngloGold Engineering)

... I think it's mainly local. There would, of the outsource we probably one third would go overseas. (Mining: De Beers (2)) 
The development work often goes to small companies in our vicinity ... so there are a range of small companies that would do specific development in their key areas. (Electronic hardware, systems \& software: Grintek (3))

Very little is outsourced due to the specialised nature and also the sensitive nature and the government military side. (Electronic hardware, systems \& software: Nanoteq)

We do $30 \%$ ourselves. The other $30 \%$ is either local test institutes or universities or CSIR, and then there's another 30\%, which is really overseas. (Manufacturing: Gelvenor Textiles)

... most of the buoys around the country which are picking up wave data and stuff are run by the CSIR, but funded by Portnet, the national port authority. We fund a lot of longer-term research as well ... (Services \& infrastructure: National Ports Authority)

\subsection{Who do companies outsource their R\&D to?}

Companies generally outsource their R\&D requirements to other companies - including those in the multinational group, or to universities and science councils. Companies also use individual consultants and specialists.

\section{Outsourcing R\&D to other firms}

For the most part, it appears that companies outsource to other companies around the use of specialised facilities and equipment. The more hi-tech and specialised the need, the more likely companies will have to source partners from abroad.

... with the acquisition of the data, we source that out, because those are the highly efficient international companies that actually have the type of vessels to do the acquisition. The processing is done internationally. ... but when it comes to the interpretation of the data, we do it. (Chemicals: PetroSA)

... we have a small agreement with [company name], who support us in our laboratory functions and for that we pay them a million a year. So there we can just cross check our standards and that sort of thing. (Fabricated metal products \& machinery: Huletts Aluminium)

Where we do have a lot of success is outsourcing of projects to other small businesses or individual consultants. I have had good success with outsourcing small projects to one-man businesses that develop electronics or write software or a combination. (Electronic hardware, systems \& software: Fuchs Electronics) 


\section{Outsourcing R\&D to science councils and research institutes}

Companies generally outsource their testing and evaluation needs, or entire research projects to science councils and research institutes.

... most of the research is done at local universities or research and development institutes like Mintek or CSIR. But then we also have some research in America like the Centre for Iron and Steel Research ... (Fabricated metal products \& machinery: Columbus Stainless)

We have used the SA Grain Laboratory to do evaluation of wheat quality. (Agriculture, forestry, fishing \& hunting: Pannar)

We make quite a lot of use of the ARC - to evaluate - ... The Agricultural Research Council, basically they are seen as the independent evaluator of agricultural seed, so we obviously make use of their whole evaluation system. We have sometimes made use of the CSIR. (Agriculture, forestry, fishing \& hunting: Pannar)

... because $a$ lot of the products we're working with are highly technical, we in fact, actually go overseas for a lot of it. We use overseas test houses or overseas research institutes. (Manufacturing: Gelvenor Textiles)

We have in the past worked quite closely with the CSIR to verify processes, heat penetration tests, and calculations. So, we use certain technical expertise and skill from the CSIR for verification. We develop the recipes, we develop the concept and they assist us with ensuring the safety. We have used the CSIR pilot plants as we do not have suitable pilot plants for all the technologies that we work in. (Manufacturing: Unilever Best Foods Robertson)

So, if you want quicker turnaround etc., you would go not to a university, but rather contract the work out to the CSIR, Mintek or one of those companies where a timeline is contracted and you don't have a two-year/three-year programme without the urgency of the results being delivered. It is an issue, and maybe universities suffer because of it, but I don't think it is a major issue if you understand how the universities operate. (Mining: Impala Platinum Exploration \& Projects)

\section{Outsourcing R\&D to higher education institutions}

As with collaboration, by far the majority of R\&D is outsourced to universities rather than technikons. Companies utilise universities to conduct research or they consult specialist expertise available in the institution.

We sometimes do, as we don't have expertise in every single area. We use your chemical engineering department quite a lot to get expertise on new processes on novel plans maybe. (Chemicals: Plascon) 
Occasionally we contract universities to do work for us. We had a contract with Stellenbosch. We have got a long-term contract with the University of Cape Town. We are supporting a lot of their projects. (Agriculture, forestry, fishing \& hunting: Pannar)

Whenever we have a particular task, we contract universities to do it. In other words, we place an order with them, if that is what it boils down to. (Fabricated metal products \& machinery: Circuit Breaker Industries - Reunert)

We outsource due to capacity constraints. We outsource depending on the availability of resources in the organisation. But, as well, specific programmes where we don't have the expertise, we outsource to universities. (Fabricated metal products \& machinery: Circuit Breaker Industries)

We also have used universities to investigate certain things for us like mechanical aspects, if we have failures we need to test, certain things like that. Generally, it would be in terms of the robustness of the product - what is going to break it down, what were the causes of something that went wrong - if we don't have the facilities in-house. (Fabricated metal products \& machinery: Conlog)

\section{Outsourcing R\&D to consultants and specialists}

Finally, companies also outsource some of their $R \& D$ requirements to independent consultants and specialists.

There are a number of clinical research associates who just do freelance contracting. (Chemicals: Eli Lilly Pty Ltd)

And we would look at specialists worldwide - they are normally retired people that are available as consultants and we've got on our books, about 42 different consultants that are specialists in various areas. (Fabricated metal products \& machinery: Huletts Aluminium)

In summary, companies depend to a large degree on the R\&D capacity, expertise, equipment and facilities of other companies, public institutions and even individuals. Whether or not to outsource and collaborate, and if so, with whom, are usually strategic decisions that a company makes. For instance, a company might choose to outsource rather than invest in full-time R\&D staff if their R\&D needs are ad hoc and limited. Who companies collaborate with or outsource to depends on what is needed and who has what to offer. Some respondents indicated that there are very few good collaborating partners available in South Africa and that they prefer to seek partners abroad. It has already been mentioned that a number of respondents perceived the capacity within the councils to be on the decline (see Chapter 10), while others felt that there were few organisations of a high enough calibre in South Africa, with whom companies could seek to collaborate. 
The challenge is not only about capacity, however. In the context of competition, companies are likely to be even more selective. On the one hand, they might choose to keep their most important discoveries and know-how a secret - either by avoiding any form of interaction at all, or by only outsourcing R\&D that does not relate to the core capabilities or technology of the company. Speaking internationally, Howells \& James (200I:8) comment, "Many companies are still reluctant to outsource 'critical' technologies to outside suppliers, but they are increasingly willing to contemplate the sub-contracting of more routine, low value-added research and technical activities." On the other hand, they might choose to 'co-opt the competition' in order to neutralise the effects of a competitive relationship.

Finally, while R\&D collaboration and outsourcing can play an important role in assisting companies to fulfil their R\&D needs, Howells \& James (200I:7) warn that too much collaboration and outsourcing can be to a company's detriment. They argue that some companies outsource "so much of their research and technical activity that they no longer have the internal capability to adequately deal with and absorb the knowledge and technology they are acquiring externally" (ibid). Howells \& James are essentially referring to the 'absorptive capacity' of firms, that is, the existing skills and knowledgebase, or 'tacit knowledge' within the company that enables the company to use the outputs of R\&D effectively. In this regard, Bailey \& Mouton (2005:39) note that in recent years "there has been an acknowledgement that users of research in fact require certain prior knowledge and skills in order to evaluate, translate and ultimately apply and utilise scientific information generated through research." Companies should therefore seek to combine the transfer of technologies and codified knowledge, with the tacit knowledge of how to apply these outputs.

The following chapter offers a brief overview of the outputs of company R\&D or, in Bozeman's (2000) terms, the 'transfer objects' of R\&D. 
Following the distinctions made by Bailey \& Mouton (2005:49), we can categorise the transfer objects or outputs of company R\&D into 'epistemic' and 'non-epistemic' outputs. According to Bailey \& Mouton (ibid), epistemic outputs include "all forms of new knowledge: theories, interpretations, insights, models, hypotheses, conjectures, facts, data as well as instrumentation."

The epistemic outputs can be categorised as either 'codified' or 'tacit'/'embedded' knowledge (see Bailey \& Mouton 2005:49 for definitions of these terms). As was highlighted earlier, companies depend to a significant extent on existing (codified) information in pursuit of their own R\&D. In turn, company R\&D can result in codified knowledge, for example, through publishing the findings of R\&D, or by developing codes and standards (see Chapter 7). R\&D also generates knowledge and information about these technologies and the market in which they are to be sold. The distinction between codified and tacit knowledge is therefore useful in that it highlights the importance of the skills, know-how and experience that people acquire about the R\&D process and, more importantly, about how to utilise and apply the results of R\&D in their own contexts.

Non-epistemic outputs refer to "all forms of application and technology that flow from the research process” (Bailey \& Mouton 2005:49). The Oslo Manual (OECD I99I), for instance, makes a distinction between new and improved technological product and process innovations. Non-epistemic outputs in the industry setting could also include instrumentation and methodologies.

This section describes some of the epistemic and non-epistemic outputs of company R\&D. We begin with the latter since they are usually the primary focus of R\&D activities.

\subsection{Non-epistemic outputs of company R\&D}

By far the greatest proportion of non-epistemic outputs includes newly developed or improved products and processes. To a lesser extent, company R\&D results in new instrumentation and methodologies.

The companies surveyed in this study cover the spectrum from those who only develop new products and processes, to those who only improve existing products and processes. More often than not it is a combination of the two, although more attention appears to be given to R\&D around products than processes. The following quote illustrates how company R\&D might combine work on new and existing products and processes.

I think what we do realise is that in order to keep up with the marketplace, you do need to plan generational changes in a product. What one might do in a product is every five years you do a technology upgrade of the same product, but maybe after ten years you actually launch a brand new product, still within the same product line, but disconnected from the past. 
So ten years is the life of a product. From three to five years, you continue to do technological evolutions to deal with obsolescence problems and things like that. (Electronic hardware, systems \& software: Altech Defence Systems)

The relative 'youth' or 'maturity' of the particular industry or company largely determines whether company R\&D focuses more on new or existing technologies.

We are quite a young company, so at the moment, the new projects seems to be the majority of that. (Chemicals: AECI Bioproducts)

The cable industry is fairly mature, so there aren't many new developments. (Fabricated metal products \& machinery: African Cables)

I think in energy, there is not much technology development going on. It is a very mature product and most of our work is about reducing cost of manufacturing. (Fabricated metal products \& machinery: Aberdare Cables)

\section{New, improved and modified product technologies}

Developing a new product technology means creating something unique - locally, if not internationally. Most experimental development, however, leads to incremental improvements in existing products, for example, by adding value or improving performance. Improvement can also involve solving problems associated with technology that goes into making products, or taking existing technologies and working on them in order to apply them in a new context. Finally, we introduced the idea of a 'modified' product technology to describe the results of R\&D that goes into developing generic drugs.

\section{$>$ New product technologies}

Okay, we have a fairly aggressive new product policy. Our policy is that at least $30 \%$ of our products that we are selling at any one time should be products that we have launched within the last two years. Within reason, we more or less keep to that, so that is an important part of our portfolio. In terms of improvement on existing products, we do that when there is a reason. (Manufacturing: Anglovaal Industries - I\&J)

We try not to invent something if we can build on someone else's platform or earlier investment. So in some cases that's the approach, and then in other cases, we have our own manufactured machines, which we have built from first principles, where it is completely an in-house development. (Mining: De Beers (I))

... we are looking at a requirement at the moment for a US-based customer that is in the biotechnology area and they are looking to develop software tools that will support research in the field of pharmacogenetics, developing pharmaceutical drugs which are based on genetic engineering research. (Electronic hardware, systems \& software: Azisa) 
Then on the data communication side, we do, in fact, have a product, which is ... a ground-air link for unmanned aerial vehicles. It is a military product that we finished developing 2 or 3 years ago, and we are still well ahead of anyone else in the world. No-one else has made a link of that nature. (Electronic hardware, systems \& software: Thales Advanced Engineering)

Probably, the most notable of the lot is the launch of the first functional food in South Africa. The cholesterol-lowering margarine called Flora Proactive. (Manufacturing: Unilever Best Foods Robertson)

... we started a lot of research on getting a very comfortable fabric which basically every single person can wear in the hospital. It's like a scrub suit, that they can wear, your nurses, your doctors, everybody can wear it. It's non-linting, antibacterial, so if blood or anything gets on to it or if the person perspires and their perspiration gets onto the garment, and they then work with the patient, the garment had to kill whatever comes in contact with it, but also mustn't infect the person's skin. So, you need a non-leaching product. And then also you want a very high level of fluid repellency so it wouldn't absorb anything. So, we started lot of work in researching chemical products. We eventually found a product in Spain that would basically provide most of the information that we needed. We then engineered a product, using yarn from America, using the chemicals from Spain, using our know-how in weaving products very tightly, so that they would hold out, but at the same time be very comfortable. So, there was a lot of breathable fabric technology that had to go in to it. And putting all of that together, we developed a product, which was then put into hospitals for evaluation. (Manufacturing: Gelvenor Textiles)

\section{Improved product technologies}

... it's a bit like a Lego set. We have all these building blocks, and we put them together in different ways to generate a product with a whole new set of attributes. (Fabricated metal products \& machinery: Aberdare Cables)

We are proactive in terms of when we are testing parts, we make recommendations on those parts. How they could be improved based on our technological knowledge of those parts. (Fabricated metal products \& machinery: Toyota)

... one that WITS are doing at the moment is light-framed structures that will stand up to twelve metres apart, using very light steel structures, and that they will actually be able to be bought in kit form and bolted together by very unskilled people. (Fabricated metal products \& machinery: South African Institute for Steel Construction) 
We have unique requirement in SA, which we make sure that our vehicles will meet. We have a far higher percentage of our customers who will be driving on dirt roads than in Europe. We have the altitude problems that they don't have in Europe. We have stone damage that they don't have in Europe. So there are quite a few unique requirements in SA that we will test for and ensure that our vehicles are okay with. (Fabricated metal products \& machinery: Volkswagen SA)

LHD is a load haul dump machine found throughout mining throughout the world. Ours was uniquely designed for great depth and heat. It's electrohydraulic which means it's electrically driven. No company was prepared to develop that machine for us, so we developed it ourselves. (Mining: AngloGold Engineering)

The electronic detonators in open cast mining, where they see a large reduction in the number of holes that they have to drill ... (Chemicals: AECI African Explosives)

So we're trying to improve on maybe some of the older range products with regards to filtration and drainage and transmit the flows to make combination products that do result in a better performance. (Manufacturing: Kaytech)

\section{Modified product technologies}

We will not necessarily improve on it, but it would be a copy of that. (Chemicals: Fine Chemicals Corporation)

It is just that when we develop a product, we use the identical of a chemical, so we purchase the chemical from the world market. What we then do with the chemical is our art. It is how to get that chemical into a tablet or a cream or an emulsion or whatever it is. That is efficacious and at the right quality, that is equal to the product on the market, but going through our processes. (Chemicals: Aspen Pharmacare)

\section{New and improved process technologies}

Often a new process will accompany a new or improved product technology. In other cases, a new company will need to develop new processes from scratch. Improved process technologies, on the other hand, are frequently the result of the (routine) maintenance undertaken by the R\&D or equivalent function. In this sense, the improved process technology is closely linked to the ' $D$ ' in R\&D. 
In the companies we surveyed, the improvements made to processes had to do with:

$<$ Improving the durability of the product

$<$ Making the process more cost-effective

$<$ Improving the sustainability and economics of the process

$<$ Understanding the process better in order to improve it.

\section{New process technologies}

... as a new company, a lot of it has to do with process and the need to get things to market very quickly. You have to have a number of processes around that. (Services \& infrastructure: Cell C)

... we're looking intensely at developing a different mineral resource management system. It is a IT system, but it enables us to do electronic mine planning and scheduling designs and do iterations on different business plans, using different mining methods, different layouts. And at the end of the day, it will be a tool that will go out to the production guys that will enable them to maybe increase their extraction rate or increase the production from a half level. (Mining: Impala Platinum Mining)

\section{$>$ Improved process technologies}

... what happens when innovation comes in is we will look at the component and we will say that, you know, our method of assembly is different to Europe's, for example, they have more robots, and we find that we don't need all the technicalities of the holes, etc. And, so we can reduce on the tooling costs as well, okay? But we end up with a component that fits in the same place and does the same functions what we want it to do and, with our labour-intensive assembly practice, the part delivers one hundred percent, as per the source plant. (Fabricated metal products \& machinery: Delta Motor Corporation)

We've changed processes to make them more effective and give higher quality products and become less reliant on labour. (Chemicals: AECI African Explosives)

I think through the R\&D we've developed certain operating practices that have allowed us to take almost double the amount of chrome that we could previously. (Mining: Impala Platinum Metallurgy)

We managed to get one type of steel - we struggled to cast it - but we managed to set up control parameters and that sort of thing, and now we can cast like six of them without clogging. Now we can do 600 tons without a problem. (Fabricated metal products \& machinery: Columbus Stainless)

... it is a plant that we bought and we developed it further and we bought it with a capability of 8000 tons a year and we are actually putting 
12000 tons a year through that, through further development. (Fabricated metal products \& machinery: Huletts Aluminium)

I think it's more taking existing technology and trying to use them in slightly different ways. You know, really trying to push efficiencies further and optimise them further. We're still basically using flotation, and milling, and smelting for that matter, which is probably a hundred years and older technologies. But, there have been some huge advances quite recently in improving those efficiencies further. (Mining: Impala Platinum Metallurgy)

That would often result, possibly, in either correcting an engineering aspect of the process or correcting details in either a process or a specification and resulting in an updated or a revised specification, or making improvements to the way a process flows. (Manufacturing: Anglovaal Industries - National Brands Ltd)

\section{New and improved instrumentation and methodologies}

... we have devised new instrumentation and methodologies and our Internet-based systems support those methodologies. So, I think what we try to do is capture our experience of the market we work in, in terms of well defined methodologies and processes, best practices, which we then capture in our systems and that is the way we run our business. (Electronic hardware, systems \& software: Azisa)

Mainly in-house we have found some modification of tests and equipment to suit our needs and to do specific specialised analysis like diesel aromatics analysis by HTLC. It has found its way into the refine lab eventually and now it's used as a routine tool. (Chemicals: PetroSA Mossgas)

We have just pure research where we look at tools and methods ... (Electronic hardware, systems \& software: Grintek Avitronics)

\subsection{Epistemic outputs of company R\&D: Knowledge, skills and know-how}

Company R\&D produces information and knowledge on the one hand, and on the other, skills and expertise. The knowledge might be scientific, or it might be more general, relating to the product and the environment within which it is to be applied. The information and knowledge generated through company R\&D is often documented either for internal or for broader public interest and use. These codified forms of R\&D output are discussed in Chapter 3.7 in relation to the dissemination of R\&D outputs.

At the same time, by engaging in R\&D and technology transfer, company staff acquires a variety of skills and expertise - the tacit knowledge we spoke of earlier. This might include specialised competencies and skills relating to both the R\&D process and business 
operations. Not only does this expand and strengthen the skills base in R\&D, but it also facilitates the effective transfer or utilisation of other R\&D outputs.

... we build up a base of skills and equipment that can be used for years and years to come. (Fabricated metal products \& machinery: Toyota)

Just remembering back from the group that actually developed the technology for our precious metal refinery, most of those people then graduated into line roles within the company, often at very senior positions, and that knowledge is being kept in-house. (Mining: Impala Platinum Refinery)

This project is a little different in that formulating the product that you require; to apply on the field is one thing. The knowledge of how you apply it and the dosage rate is another whole gambit because you simply don't throw the stuff on the field and hope it works. It varies from soil to soil, it varies from crop to crop, it varies from season to season in parts of the world and you need to build up all that knowledge, which is what we have been doing and are still presently doing now. (Manufacturing: Illovo)

And then we provide a quality centre of excellence. We are the group's experts in quality management. For example, if we build a new factory, then we will take the Quality Systems manager and we will bring them here to work for six months and then we will send them off to go and put the new system in. (Chemicals: Aspen Pharmacare)

In some cases, we don't necessarily create technology evolution, we create technology leverage, if you want to call it that. That knowledge is not necessarily exclusively leverage. In some cases it resides in people's heads or in people's guts or whatever you want to call it. It just makes the launch of the next product much easier. (Services \& infrastructure: Vodacom)

You know a lot of the research we are doing we are probably adding to the body of knowledge, specifically in stuff we do with the CSIR. The wave dynamic processes in Table Bay, the ... all that database information, that is a database which we have built up that no one else has ... (Services \& infrastructure: National Ports Authority)

What we are building is an excellent understanding of the consumer. So, what is important for us to develop on a more strategic long-term level is, who is the consumer, what are they doing, what are they thinking, why are they thinking this way, what trends are impacting there, how do they shop, how do they consume media ... ? (Chemicals: Lever Pond) 
In summary, the R\&D of the companies surveyed usually culminates in innovations in technological products and processes, and instrumentation and methodologies. The extent to which companies focus on developing new or improving existing technologies is in part related to whether the industry is young or mature.

In the process, company R\&D might also add to the pool of knowledge, and develop invaluable skills, know-how and expertise in the firm's staff. The question is: how are these R\&D outputs disseminated to intended and unintended users? The following chapter documents the various ways in which the results of company R\&D - both epistemic and non-epistemic - are transferred to those who wish to use them. Issues that arise in relation to intellectual property are also considered. 


\section{CHAPTER 7}

\section{THE DISSEMINATION OF R\&D OUTPUTS}

Respondents highlighted the various ways in which their companies' disseminate the products of R\&D to intended and unintended users. The outputs of company R\&D might be transferred via:

$<$ Licenses and patents

$<$ Design codes and standards

$<$ Protocols

$<$ Internal reports and communication

$<$ Training and consultation

$<$ Networks

$<$ Publications.

These transfer media might be further grouped according to commercialisation activities (e.g. patenting and licensing) and information exchanges (e.g. training and consultation, publishing, etc) (see Bailey \& Mouton 2005:31).

\subsection{Licenses}

Selling technology or design licenses is a common, albeit limited form of dissemination. No doubt, companies only enter into license agreements if they can benefit financially, and if it does not create a conflict of (competitive) interest, and therefore select recipients carefully. In one case, a company no longer wished to remain in a particular aspect of their business, and so sold the license to someone who did.

We've licensed our designs to people overseas. (Manufacturing: TongaatHulett Sugar)

India is the second largest producer of peanuts in the world and that's the first registration we obtained in South Africa for our product. And the plan would be that we sell the licence technology as royalty, and produce the product locally, and sell it and export it to India. (Manufacturing: Illovo)

... we have license agreements with companies overseas where we, in fact, sort of came to say exporting the know-how. (Manufacturing: Breathetex Corporation)

We sold the design to Kenwood in Japan, we sold the design to Anam in Korea and also at one stage Daewoo used our design. So we have done quite a few design transfers to other companies ... (Fabricated metal products \& machinery: Altech UEC Multimedia) 
As far as sharing technology goes, we have actually sold technology to Siemens in Germany in an area that we no longer wish to do business. So what we did is we took the intellectual property and we sold it to them and they have continued to develop it and made business out of it. (Electronic hardware, systems \& software: Spescom)

\subsection{Patents}

Some respondents indicated that they patented some, if not all, of their products or processes. Others indicated that they were less likely to patent their processes since it effectively gives the 'recipe' away to the competition. Companies are therefore strategic about whether they patent or not.

Some companies do not patent at all, particularly if they are not involved in producing any new products or processes.

We tend to see patents as a way of protecting our access to that technology, as opposed to a way of earning money by selling technology ... (Agriculture, forestry, fishing \& hunting: SAPPI)

... we find, because we are not geared for patenting, because of the complexities, we find it a hell of a lot easier to enter into a deal with someone who has got the patent rights. So, at this point in time, we prefer to work with people and secure patents by virtue of the fact that we work with them. We are a small staff and we are not geared for a higher admin load. (Agriculture, forestry, fishing \& hunting: Capespan)

If you developed a piece of equipment and wanted to sell that to a number of people, then a patent would be perfect. But if it is in process development and you patent it, then everybody in the world can pick up the patent, go to their plants, and modify their own thing and take your market advantage. (Agriculture, forestry, fishing \& hunting: Mondi Processes)

... we have patented a lot over the years globally. We have got global protection for most of our newer products and systems. (Chemicals: $\mathrm{AECl}$ African Explosives)

Your patent is an open invitation for people to reverse engineer. Then it is up to us to go and prove that they have reversed engineered, which is quite difficult with our law conditions. (Chemicals: AECI African Explosives)

... we've found in the past that patenting and copyrighting things was very expensive and very difficult to enforce. We think the value lies within your specific understanding or utilisation of that data and trying to protect it. (Mining: Impala Platinum Metallurgy)

Very many things we do not patent clearly because the patents do not give adequate protection, not in our kind of business. If you have a very simple 
product which can be easily copied, then the best protection we believe is the patent. And some of the things that we have are of that nature but many of the things are of a complex nature so the best protection that we have is definitely not to make it known how we do it. (Electronic hardware, systems \& software: Grintek (3))

You might find yourself patenting stuff and the guys are marching past you anyway, and then you get into these litigations, which are very expensive, and there is often no clear winner. (Electronic hardware, systems \& software: Spescom)

It is not the case that we patent or copyright everything that we do. In some instances, it is the last thing that we do. In other cases, we try and assert our rights simply by implementing the design in a way that makes it very difficult to copy and then keep key elements out of the public domain. (Electronic hardware, systems \& software: Grintek (2))

... we have developed a lot of patents over the years. Some of them of course lie, and nothing happens, which normally happens. But there are a number of patents that I have non-exclusive licence for (and some exclusive licence, which I don't particularly like doing) and that have generated some royalties for us. (Services \& infrastructure: Eskom)

\subsection{Design codes and standards}

Design codes are a form of transfer media insofar as the results of R\&D are translated into codes, which can then be used by others in their own work. Some company R\&D also constitutes the industry standard for a particular technology or process.

Part of it I think is distributed within the industry, like some of the SABS standards and that, that we deliver an input into that as well - coming up with new rules - just generally developing a better standard for the safety of the industry as a whole that everyone benefits from. (Fabricated metal products \& machinery: Mitek)

... we could actually change design codes. Now, this would be SABS codes. We get to do it every five years and our loading codes (that's how we determine wind loads and what sort of factors to use when designing our structures) are being rewritten at the moment. And the impact of a whole lot of that research is affecting a couple of parts to that loading code. So the first thing is by actually changing the documents that engineers have to use legally and to do that by altering design codes. (Fabricated metal products \& machinery: South African Institute for Steel Construction)

... the STS standard, the security standard, came from Conlog and became a standard. And now all the pre-payment industries use that. We also have a base that meters plug into which came out of Conlog that has become a standard. (Fabricated metal products \& machinery: Conlog) 


\subsection{Protocols}

The R\&D in certain industries can also result in the development of protocols, for example, in the chemical or agricultural sectors, which can then be used by others.

It's protocols for different types of fruit determining those protocols and establishing them and also developing protocols with technologies and handling processes. (Agriculture, forestry, fishing \& hunting: Capespan)

Since then, there've been a number of, let's call it, incremental advances that have taken place in respect of modified atmosphere packaging formats that have been developed by the unit to address particular weaknesses or issues relating to certain grape varieties, or to the development of protocols that we have exercised exclusively. For example with plums and other stone fruit varieties we developed protocols with extended shelf life preferentially, so that has given us the edge. (Agriculture, forestry, fishing \& hunting: Capespan)

\subsection{Internal reports and communication}

When the company R\&D is for internal use only, companies adopt a range of strategies by which to transfer the findings of R\&D, and the associated tacit knowledge, to the users within the organisation.

We have informal types of technology transfer like newsletters and internal reports and then the production areas have their own technical groups, study groups. P8I (Agriculture, forestry, fishing \& hunting: Citrus Research Institute)

The way that we're handling it at the moment is basically to use communication as a tool of technology transfer. What we would have is an in-depth prolonged communication process, which will initially sensitise people to some of the issues, and then systematically build on their knowledge and do so at various levels within the organisation. (Mining: Impala Platinum Mining)

\subsection{Feedback to and ongoing consultation with user groups and clients} For those companies that conduct R\&D on behalf of user groups or clients, transfer to users might involve feedback and ongoing consultation with users, throughout the implementation phase. An important feature of these interactions is the transfer of tacit knowledge - in other words, the knowledge required by users in order to evaluate and apply/utilise the technology.

In some industries, such as agriculture and mining, feedback and consultation with users is institutionalised. For example, agricultural R\&D is transferred to the intended users (farmers) via a system of agricultural extension. 
Extension work, in general, seeks to facilitate the dissemination, uptake and implementation or utilisation of research findings by the user group. Where these resources are limited, utilisation is also likely to be limited.

What we do with the results is we get students to come and give feedback to the other engineers that work in the production area. (Fabricated metal products \& machinery: Columbus Stainless)

... e-mail or mail shots and that sort of thing. We have a database of 4600 people directly interested in our business. (Fabricated metal products \& machinery: South African Institute for Steel Construction)

What we do there is usually we have some part of our team go on site to our customers, usually outside of SA, and work with them through the final integration and acceptance of that technology into their environment. Through that process, they pick up the knowledge to then further sustain the product. But we also have another model where we provide the ongoing sustaining services. So, with some of our customers, they have said that they don't want to transfer the technology back into themselves, they want it to stay with Azisa and then Azisa in a way owns that technology, and we continue to provide enhancements and so on. (Electronic hardware, systems \& software: Azisa)

And if they had brought up this particular research topic, then the researcher will go back to that field when the research is complete, and present the results and tell them how to implement it. (Agriculture, forestry, fishing \& hunting - Citrus Research Institute)

We conduct our R\&D on a weekly basis with our key clients. We are involved in their operational meetings. So anything that we find out of our $R \& D$ - you know, it may be observational, it may not be ... statistically evaluated - anything that is of interest is immediately fed through to the company so that they can decide whether or not to use it. So it is an ongoing process. Twice a year, on an interim feedback, we give them feedback of the data evaluated, full conclusions and recommendations and once we have had time to evaluate the matter, we would then give them a final for the year, a final overview of the R\&D and also their recommendations. But because we are doing it for a client who requested it, you find that there is a tremendous pull- factor so we don't have a major problem with implementation. (Agriculture, forestry, fishing \& hunting: Capespan) 


\section{7 $\quad$ Training}

The knowledge and know-how generated by R\&D is transferred to others via training either to clients or internal staff (informally or through workshops, seminars and courses), or through the training and supervision of postgraduate students. Knowledge transfer is a core feature of technology transfer.

As a member of the Vodacom group we have got these Best Practices Quality, and those best practices there are sessions that happen at specific points in the year, where operating companies within the Vodacom group get together. And there are specific workshops along specific technologies or product clusters or what have you. ... So, yes we do see adoption from companies within the group, the Vodacom group of companies. (Services \& infrastructure: Vodacom)

... that knowledge is documented by way of specifications as far as we can, as well as through training programmes that we have for our staff. (Manufacturing: Anglovaal Industries - National Brands Ltd)

... we would typically send some of our staff up and they would work on the process for a number of weeks or whatever how long it takes to actually transfer that and then they would bring it back. So, we would actually get our people trained up on site, so to speak, and then bring them back with that knowledge. (Chemicals: AECI Aroma \& Fine Chemicals)

And then at the Pharmacy School, we run ten lectures a year with them, where we give them professional augmentation of their course material with expert lectures. We run the practical sessions. We have been doing that for 13 years. We run practical projects, we run four projects a year. So, students come and do their projects in our factories, 4th year projects. And then we support their project evening and that type of thing and we have had about five or six MSc graduates go through there. (Chemicals: Aspen Pharmacare)

... at our materials centre at the technikon, we actually train new graduates. (Fabricated metal products \& machinery: Willard Batteries)

I think we are in the process of now, with the students coming in on the membrane project, we will further train graduates, for postgraduate degrees.

(Manufacturing: Breathetex Corporation) 


\subsection{Forums, conferences and other networks}

Companies also disseminate information arising from their R\&D activities more widely to stakeholders within the company or the wider industry via industry or professional forums, conferences and other networks. Some companies have designed special software and systems that can be used to share information internally. In some cases, R\&D outputs are used to inform industry standard setting or benchmarking exercises.

We have just started a national planning forum where we try and meet once in every two months... so, yes, there is some transfer as well between the various ports ... (Services \& infrastructure: National Ports Authority)

We are represented on two international organisations: IEC is one of them, the International Electrotechnical Commission. That is an international body that controls international standards and we influence that proactively. Predating that by about 5-7 years, is the work of another organisation called Cigre. It is an international council for large high-voltage electric systems.... So we represent South Africa on that council as well, and we contribute and we learn from the rest of the world, in terms of their general direction. (Fabricated metal products \& machinery: African Cables)

We have what we call technical forums, and we meet twice a year with a very broad agenda to share information. (Fabricated metal products \& machinery: Aberdare Cables)

We participate a lot in industry forums, especially on new technologies. We participate and contribute to them. And that benefits us as well, because we pick up knowledge out of those forums that we can then use to add value for our customer. (Electronic hardware, systems \& software: Azisa)

There are many people with networks and I think especially where it is information of a non-competitive nature. (Manufacturing: Unilever Best Foods Robertson)

We have just within the group set up what we call 'knowledge management technology', which is obviously a software IT-driven system. What we are doing there is we are trying to reflect learnings, from the different units, let it be $R \& D$ or the breweries around the whole group, in the most cost effective and most efficacious way. (Manufacturing: South African Breweries)

But I guess our biggest contact area is international conferences. We really take time to try and send people to the best international conferences around the world and try to bring the papers and proceedings back and distribute it amongst our engineers and try and drive knowledge down that way. (Mining: Impala Platinum Metallurgy)

I gave a paper in America last year at the Society of Plastics Engineers on our technology, on our modified PVC pipe. (Chemicals: DPI Plastics) 


\subsection{Publications}

The results of company R\&D are sometimes also published more widely than in internal or contract reports, for instance, in journal articles, popular articles, masters or doctoral theses, manuals and handbooks.

... we read and contribute to a number of scientific journals. (Electronic hardware, systems \& software: Grintek (2))

... we have our own steel construction journal which we issue every two months. We also have the SA Institute of Civil Engineers journal. Most of our design engineers are civil engineers and they would belong to the SA Institute and we publish stuff in their journals. And this crane loading stuff we will actually print in the Structural Engineer - any structural engineer who believes anything worth anything is a member of the Institute of Structural Engineers in England, and quite a few of our papers get published through their documentation on an international level, so we keep our recognition up. (Fabricated metal products \& machinery: South African Institute for Steel Construction)

Then we publish handbooks that actually make it easy to use those design codes and have tables calculated using all the formulae and the design codes and so these get published and we are just about to issue our fourth edition of that handbook, based on some new changes that are happening in all these codes. And we're running 20000 of them when we print it in about a month's time. So, we really are getting to the people who need it. (Fabricated metal products \& machinery: South African Institute for Steel Construction)

Since one of the primary objectives of much company R\&D is to contribute to the company gaining and maintaining a competitive advantage, the dissemination of R\&D results (technology transfer) is usually limited, both in nature and extent. For example, licenses and patents are reserved for a select group of users, and the former comes at a fee. Knowledge transfer might only occur within the organisation, while training and consultation may be limited to specific user groups. Conferences and publications, on the other hand, especially in public access media such as journals or the Internet, imply much wider access to information. It is quite likely, though, that in these cases, companies retain their most important 'secrets', which give them a competitive edge for internal use only.

In this regard, patents are an interesting case. One normally associates patents with protecting one's invention or innovation. In this sense, patents represent a very limited form of transfer - either only to the company itself (in that the patent protects the company's access to that technology in the future) or to the select others whom the company authorises to use the technology. Consequently, patents offer very restricted opportunities for utilisation. Interestingly, however, respondents in the industry interviews pointed out that sometimes patenting could give too much away. This is particularly so with regard to the patenting of processes. In this sense, instead of protecting technological 
advances, patenting inadvertently becomes a form of communicating or sharing knowledge and technology with others. Intellectual property issues are raised again in Chapter 10.

Up until this point in the report, we have considered the typical R\&D activities undertaken in the companies we surveyed, and some of the inputs into and outputs of these activities. This leads us to ask a number of questions. For instance, are the results of company R\&D utilised? Are they utilised effectively? Who utilises company R\&D, and in what ways do they benefit? When is R\&D not utilised, and why does this happen? What other factors contribute to promoting or inhibiting successful R\&D activities and effective utilisation of the results? The remainder of this report is dedicated to addressing these issues. A discussion of the various benefits and beneficiaries of R\&D introduces the following chapter. 


\section{CHAPTER 8}

\section{THE BENEFITS AND BENEFICIARIES OF COMPANY R\&D}

Utilisation implies much more than dissemination. In other words, utilisation requires that users not only acquire the results of R\&D, but that they also adopt, take up and implement or apply them. One way of exploring how R\&D is utilised, and to what end, is to look at the benefits experienced by both intended and unintended users. This chapter considers what kinds of benefits there are from R\&D, and specifically the utilisation of $R \& D$ in the industrial sector, and who benefits from this $R \& D$, and how.

If the R\&D is successful, then the benefits are likely to reflect the factors that motivated the R\&D in the first place (demand environment). In some cases, however, there might also be unanticipated benefits.

Largely who benefits from the R\&D depends on whom it was intended for in the first place. It almost goes without saying that the company stands to benefit directly from the $R \& D$ (not least because it initiated it) - either through exploiting the results itself, or through earning revenue from licenses or from having conducted the R\&D on behalf of others. Other beneficiaries of company R\&D include other companies, the industry as a whole, clients and user groups, and the broader scientific community.

\subsection{The nature of the benefits of company R\&D}

And to varying degrees, the benefits of company R\&D may be seen to include the following:

$<$ A positive impact on the performance and competitiveness of the company in the market

$<$ Improvements in the quality of products, processes or overall performance of the company

$<$ Advancements in knowledge

$<$ The expansion of the skilled human resource base

$<$ Improved sustainability of the environment

$<$ A positive impact on the wider society.

\section{Market impact}

Not surprisingly, the majority of respondents reported that an immediate benefit of successful R\&D efforts was an improvement in the company's market impact that, in turn, generated greater profits and financial gains. In this sense, R\&D contributed to or resulted in:

$<$ An improvement in the company's competitive advantage locally and/or globally

$<A$ reduction in the costs associated with production, thereby saving the company money

$<$ Access to new markets, thereby increasing exports opportunities 


\section{$<$ International recognition for the company \\ $<$ The creation of spin-off firms.}

Selected quotations from the industry interviews, which illustrate these kinds of benefits, are provided below.

\section{$>$ Competitive advantage}

This product ... has given us the competitive edge. It's made the difference between our company surviving and dying. It has put two of our oppositions out of the marketplace in the last year and a half. (Fabricated metal products \& machinery: Genwest \& Hansen)

... we've used our R\&D efforts to come up with technology that will keep us in the market from 2004/5 onwards. We already have the technology in place to make sure that we will still be doing business. (Fabricated metal products \& machinery: Willard Batteries)

But the biggest thing is that [R\&D] gives you the ability to control your future, as against other people having to provide you with products for your the future. ... We are $70 \%$ of the generic market in SA, and that is an awesome percentage, so we have got to stay there. (Chemicals: Aspen Pharmacare)

... we see the value because, both because it keeps us competitive, and also because a lot of these developments are more long-term, so we are looking two or three years hence, where we can replace older products with new generation products, hence keep it competitive in the long term. (Chemicals: DPI Plastics)

Implemented by the growers and the agents that market fruit from the growers is enabling them to stay competitive with other countries selling citrus. (Agriculture, forestry, fishing \& hunting - Citrus Research Institute)

I think (work) on our tree breeding side has definitely given us a hell of an competitive advantage. We are now the cheapest pulp producer in the world because of the way in which we were able to clone and develop and breed trees specific for use in the pulp industry. So that has been a major significance to us, millions of Rands. (Agriculture, forestry, fishing \& hunting: Mondi Processes)

We've got products that we can sell into different sectors of our market, so it has given us better edge technically. The products perform better in these cases than competitors' products, and that has given us competitive edge. (Manufacturing: Kaytech)

... it improves the public image of the business within the market, and it also ensures that the business remains world class, because a lot of the 
systems and procedures that you apply, really they go together with the technologies that you're researching. (Manufacturing: Gelvenor Textiles)

Well, it has definitely helped us to shorten the design cycle, and by doing that we have been able to keep ahead and even have an advantage over our competitors, because all of the recent production is based on new designs and having a shorter design cycle because of the setting systems has actually meant that we are more competitive ... (Electronic hardware, systems \& software: Fuchs Electronics)

\section{Cost reduction and cost-effectiveness}

We lowered the traditional cost of cabelling by use of innovative design and materials. (Fabricated metal products \& machinery: Aberdare Cables)

The high-grade, low-grade flotation circuit that we've adopted has allowed us to increase the capacity of our UG circuits by about $20 \%$ - very, very cost effective capital-wise, probably half the cost it would have been if we'd gone the conventional way. It also had a benefit in that the operating cost was lower. (Mining: Impala Platinum Metallurgy)

The electronic detonators in open cast mining, where they see a large reduction in the number of holes that they have to drill, which is a big cost to a mine. I think it is about R5000 a metre. They drill up to about $60 \mathrm{~m}$ per hole and probably about 500 holes a day. So, if you reduce that by $30 \%$ alone, that's a lot. (Chemicals: AECI African Explosives)

The application in that sphere, you can use less active ingredients, make the product cheaper ... (Chemicals: Meyer Zall Laboratories)

\section{Exports and accessing new markets}

We have been addressing items on things like citrus black spot, and just the fact that we've still kept that market open, has been a big success. And then gaining access to the States, where we did not have access in the past, a very lucrative market that we have now got access to. That is also a big breakthrough. So, just from a monetary value to the grower, those are the biggest achievements, all related to market access and getting into new markets and the like. And there are a lot of markets, places like Korea that we have got into recently, as well. It involves a whole lot of research from different people - things on fruit fly and other diseases that are considered by those countries to be a problem for receiving fruit. And one way or another we have been able to get around those. (Agriculture, forestry, fishing \& hunting - Citrus Research Institute)

... in doing that, we've actually taken over, or bought, a business in the USA. We're making coloured fibres. We didn't buy the technology, we just bought the customer base and we've managed to commercialise that product, in 
particular in the USA, but we are now expanding it to other parts of the world. (Chemicals: AECI Fibres - SA Nylon Spinners)

... within two years of manufacture, we were leading in the American market. We took over $20 \%$ of their market. (Fabricated metal products \& machinery: Huletts Aluminium)

... this new metal development has really boosted the export market ... (Electronic hardware, systems \& software: Impro Technologies)

... we export $30 \%$ of our technology and we compete with everybody around the world. We have long-term supply agreements with Siemens, Cisco the voiceover IP - so we are one of the players. (Electronic hardware, systems \& software: Spescom)

The products have definitely given us export capability, because five years ago we had virtually no export, and we have now grown to where we export of over $75 \%$ of our business. (Electronic hardware, systems \& software: Grintek Avitronics)

\section{$>$ International recognition}

It will also have international recognition by the way. It is going to make a lot of people out there sit up and think. (Fabricated metal products \& machinery: South African Institute for Steel Construction)

... one of the things [R\&D] has done for us is that it has put us on a world stage which allows us then access to other people. If you are seen as innovative, people are more willing to talk to you, whereas if you are not involved in anything, not publishing much, not doing much exciting work, it limits your access to other research institutes. No one knows who you are or what you are doing. (Agriculture, forestry, fishing \& hunting: SAPPI)

... [R\&D] gives the business a certain standing worldwide. So, it has huge face value, in terms of how the business is perceived. You're perceived as a global player, you're perceived as a world-class business and that immediately provides you with a lot of openings into areas in the world that normally you wouldn't be able to go. We are ISO 9002 and ISO I400I. (Manufacturing: Gelvenor Textiles)

\section{New firms}

And then certainly, I think the biggest one is probably the chrome white that we can deal with in the furnaces now. That has allowed us to take on a lot of secondary concentrates from other people, mainly UG2 concentrates. In effect, what it has allowed Impala to do is to start a new business called Impala Refining Services, where we are refining for other people. (Mining: Impala Platinum Metallurgy) 
In fact, we've also created a new company now like this. It's called Priontex, this joint venture company down in Cape Town. (Manufacturing: Breathetex Corporation)

In one way or another, all of these market-related benefits can result in financial gain for companies.

\section{$>$ Financial gains/generating profits}

Surviving, in the first instance, and then obviously, pushed us into a profit mode. (Fabricated metal products \& machinery: Genwest \& Hansen)

The effect of the R\&D work is that we have improved our sales, our turnover. (Manufacturing: Kaytech)

... they are niche market products, and so there are, there's a monetary gain for the company, increased revenue ... (Chemicals: PetroSA Mossgas)

You know, we are in the business to make money. So our R\&D will always be focussed to reach that goal. But also to improve the environment. To make sure we will be sustainable. Both of them with the aim of making money. (Agriculture, forestry, fishing \& hunting: Mondi Processes)

So, that is one product that has sold millions and millions of Rand around the world. (Electronic hardware, systems \& software: Spescom)

I would guess from the value of the business that has derived from them, both developments, are worth somewhere between fifty and a hundred million Rand each. (Electronic hardware, systems \& software: Tellumat)

\section{Improved quality of products, processes or performance}

Another primary benefit of company R\&D often inherent in the other benefits is the improvement of products, processes or the general performance of the company. Ultimately, this gives the company access to new markets, makes them more competitive etc.

The notion of 'improvement' is applied to a range of factors, such as:

$<$ Producing more and better quality products

$<$ Improving the structural integrity, reliability and effectiveness of the product

$<$ Shortening the time taken to produce a product

$<$ Producing more environmentally-friendly products or processes

$<$ Giving a product a longer lease on life (e.g. medicines or the shelf-life of fresh produce)

$<$ Improving the nutritional value of food

$<$ Improving safety (for staff and for end-users). 
Its benefit is to have smaller products which are more power efficient which is a desirable thing for our customers. So it is a customer advantage. (Electronic hardware, systems \& software: Grintek (3))

Particularly with the crane loading - we are going to have less structural problems on structures that support cranes in the future. We don't have these things falling down but what happens is they start showing signs of distress in time and then there are expensive repairs and a lot of this is going to eliminate a lot of that expensive, costly repair in the future. So it is giving us more confidence in what we are doing ... (Fabricated metal products \& machinery: South African Institute for Steel Construction)

... we also had good R\&D done in the past, certain processes was developed. And that does assist us in improving our accuracy and our exploration efforts. (Chemicals: PetroSA)

We have patented a system, which is an ultra-sonic detector, which is quite unique in the world. You put it on metal and it can look at the fatigue and blemishes in metal ... So, if you are in a power station and you have to work on boiler tubes, normally what you do is cut these tubes out and that particular part of the plant doesn't operate and, of course, there is an incredible amount of loss in sales and time down. But what you can do with this is you can just take this ultrasonic system and you can move it along the various areas that you want to inspect and there is no time down whatsoever, so you can look at fatigue. (Services \& infrastructure: Eskom)

... In the case of moisture absorbing material which we use on table grapes - it is also a quality linked thing - where you reduce the amount of free moisture in the carton and we also reduced the amount of damage caused by sulphur dioxide - so that is a quality thing. (Agriculture, forestry, fishing \& hunting: Capespan)

We have developed in-line turbidity measures specifically for use in sugar factories, and they are fairly widely used in the industry now. They are important for sugar quality, the quality of the final product. (Agriculture, forestry, fishing \& hunting: Sugar Milling Research Institute)

We actually developed a medical fabric for South Africa, because of the AIDS problem. What you need is that staff do not have sufficient protection in our hospitals against blood-borne pathogens and basically body-fluid protection. People wear cotton and poly cotton garments. They have two problems. One is they are absorbent, secondly they are linting, in other words you get fibres that come off, and specifically in a operating theatre post operative infection levels are very high where fibres have linting. So, we did a project whereby (it was one of the Pietermaritzburg clinics) we gave them completely lint-free fabrics and said to them, "Okay, use this in the 
operating theatre. It was all filament and fabrics. The postoperative infection levels dropped by 35\%. (Manufacturing: Gelvenor Textiles)

\section{Advancement or improvement in knowledge}

The process of undertaking R\&D and utilising the outcomes of the process inevitably generates new knowledge or information for the users. For some firms, generating new knowledge is part of the core business of R\&D; for others, it is a positive spin-off of R\&D activities. The knowledge is either codified or tacit.

The benefits of this knowledge and information manifest in various ways, for example:

$<$ The knowledge and information generated about products, processes and operations can be used to add value to the performance and competitive edge of the firm (best practices), for example, by enabling firms to make improvements in the future, or through informing strategic decision-making.

$<$ It might also assist companies to develop in-depth specialised knowledge of a particular technology, and what goes into its development and application, as well as greater understanding of the market. This gives companies a competitive edge.

$<$ Finally, R\&D can generate knowledge that is unique, and which can be utilised by others.

I think we might have created new pools of knowledge or we are custodians of pools of knowledge, which no one else will have. In that way we are quite unique. The analysis of water samples that we do on a yearly basis, stuff like that, the wave data that we collect - that really isn't collected by anyone else as far as I understand. So if anyone wants to come and build a new marina or something like that, they would benefit from the knowledge which we have funded and the research that we have funded and done in the past. (Services \& infrastructure: National Ports Authority)

I think a large component of that has been just allowing people to make informed decisions. So, if I look specifically at the amount of work we've done segmenting our markets, this has provided a roadmap for us for the next eighteen months in terms of just going into further layers. So, this provides a very good backbone for the effective release of products in innovation. (Services \& infrastructure: Cell C)

... the biggest value is now being able to get a depth of knowledge you would not get otherwise, and in your people. And that is impressing on our customers and future customers - that we are the people that know how to provide these solutions. (Electronic hardware, systems \& software: Nanoteq)

... now in Europe we are providing R\&D support from Cape Town. This will extend into our Africa operations and we believe is a significant advantage to have both customer product knowledge and broad packaging experience. (Manufacturing: Nampak - Megapak) 


\section{Increased scientific and technical human capital}

The R\&D process, and especially technology transfer activities, can lead to an increase in the company's capacity to perform and use R\&D by building the skills, knowledge and experience of its staff. The human resources capacity of other organisations can also be improved through participation in collaborative arrangements or personnel exchanges.

The latter is particularly easy within multinational corporations.

... one thing, which I noticed there on the sideline, is staff development. So we have a lot of in-house build up of expertise here, which guys cannot gain anywhere else, but they can take it somewhere else. (Chemicals: PetroSA Mossgas)

When a person gets out of a university with an MSc or even better, a $\mathrm{PhD}$ degree in engineering that has been steel research based, we have $a$ captive engineer who is going to become very competent in our field in our industry. (Fabricated metal products \& machinery: South African Institute for Steel Construction)

Sometimes we give work to students to do their dissertations, on the testing of certain products and materials, and then we have got access to those dissertations and it helps us in our research.

(Manufacturing: Kaytech)

At the moment we have got one of their students here who's sort of furthering his skills and getting a feel for industrial research. He is at the post-doctoral level. And similarly, in reverse, we have got one of our students who is doing an external Ph.D. with Stellenbosch. He is registered there and spends some time here doing research, and a smaller time doing research that complements that in Stellenbosch. (Manufacturing: South African Breweries)

\section{Environmental impact}

Some companies dedicate part of their R\&D activities to finding ways either to utilise raw materials more efficiently, or find alternatives to scarce raw materials and natural resources. Others have focused on developing products and processes that are more environmentally friendly or environmentally sustainable.

... we drive our cost through raw material evaluations, because materials are a high cost of our product. So we evaluate alternative raw material sources. (Chemicals: Aspen Pharmacare)

The other one is a lot of work on the environmental side - water reduction, water utilisation - we are probably world leaders in that. And I think the one that SAPPI' s most... it goes back about five years - is oxygen bleaching which is an environmentally friendly oxygen bleaching process. So that has now been implemented worldwide and is a requirement of just about any new mill that is built. (Agriculture, forestry, fishing \& hunting: SAPPI) 
The biotechnology is one issue, but the whole forest sustainability is always a key issue, but continued improvement in terms of utilisation of the resource use in biotechnology which is a more environmentally friendly process than the current fairly harsh chemical processes, and then using bio-techniques for recycling of process systems to reduce water consumption, has been something that we have been fairly good at and are fairly advantageous. (Agriculture, forestry, fishing \& hunting: SAPPI)

In the recovery process, in the pulp mill, we have a recovery process. To recover the chemicals and regenerate them and re-use them. (Agriculture, forestry, fishing \& hunting: Mondi Processes)

We strive in growth, in growing the value, for our limited raw materials, resources. We try to get the best out of that material, the best money out of that material, so we have produced new products that will increase the value of the raw material. ... We are also trying to look at now is what more can we do to the raw material that will give more money to the company. (Manufacturing: Food, drink \& tobacco - Anglovaal I\&J)

\section{Social impact}

There were very few examples of company $R \& D$ resulting in a positive impact on the wider community/society. Perhaps this is not surprising, given that company R\&D is usually directed towards improving the position of the company itself.

Cases where R\&D impacted directly or indirectly on some broader social issue included developing drugs for AIDS and tuberculosis, improving the nutritional value of food, developing crime prevention technologies aimed at improving safety and security in the country, and making a product cheaper for the poorest of the poor to use.

But Glibec is one of our drugs for leukaemia. And it is a really good drug. The FDA approved it in record time. (Chemicals: Novartis - Pharma)

On the other hand we sit here with the realities like Aids and TB, where you try and deliver what you call a social product. And that is one of the reasons why we started off with the TB project, it is the social responsibility thing. (Chemicals: Meyer Zall Laboratories)

It's reduced the installation costs for a very small consumer right in the rural areas. (Fabricated metal products \& machinery: Aberdare Cables)

... we have developed ... a microwave sterilising unit, which is part of our rural development programme. So, instead of throwing your needles and everything that is hazardous away, you put it in this microwave system. It is almost like a portable washing machine, which is single phase, and not three-phase. It crosses to a microwave and it steams it up to the appropriate temperature. It then sterilises the stuff so that it becomes nonhazardous, so that you end up with a non-hazardous product, and what you 
do is put it in a normal white bag and dispose of it as normal. (Services \& infrastructure: Eskom)

So, not only was there a benefit to the consumer, but there was definitely an increase in the nutritional value of the products throughout the country. (Manufacturing: Pioneer Foods)

You can't call them products for AIDS sufferers, but in fact that is exactly what they are. It would be a balanced diet looking at their requirements, loss of body weight and there are things that we can do to actually help them out as well. So, it is a matter of putting our minds together, and marketing would help to get those products on the market, without placing a negative connotation to them. So, it would be a general product - it will be good for you and me, but it will also help to alleviate the problem elsewhere. (Manufacturing: Pioneer Foods)

\subsection{The beneficiaries of company R\&D}

Since the purpose of much of the R\&D conducted within the industry setting is to further the competitive edge or market impact of the respective companies, it is not surprising that in most cases, the R\&D benefits the company directly. Where the company conducts R\&D on behalf of user groups, the multinational or clients, these are also direct transfer recipients and beneficiaries of the research. Knowledge spillovers, licenses and exports can benefit other companies within the industry or beyond.

It is seldom the case that company R\&D is seen to benefit the broader scientific community. This is only likely to occur when companies publish the results of their R\&D in public resources such as journals, or when they collaborate with academics or scientists from universities or science councils. Moreover, as with any R\&D, there are always possible unintended beneficiaries too.

This section considers how each of the beneficiary groups benefits from, and therefore utilises, company R\&D.

\section{Benefits of R\&D to the firm}

Much of the preceding discussion pointed to the benefits of R\&D to the company in particular. A number of respondents described how the R\&D function - whether it is in-house or outsourced - was of immense value to the firm.

We consider R\&D to be part of our life-blood. We are committed to sustaining our own capability, to generating our own intellectual property. It is the absolute cornerstone of our business. (Electronic hardware, systems \& software: Grintek (2))

$\{R \& D$ has] been an absolutely incredible benefit to the company. It's changed the way we have done business. We've changed the complete strategy of the company and, in fact, and I've got to be perfectly frank, I think it's why we're still in business. (Mining: Impala Platinum Refinery) 
... really having a full understanding of the impact of new technology and having a better perspective of what competitors are doing and in what context they're doing it. Whether they've got a really tight approach on what they're doing, or whether they are just throwing caution to the wind, I think that in terms of the effect that it has, at this stage, is informing things that we've done and informing things that we're not doing yet. (Services \& infrastructure: Cell C)

They are satisfied that the return, not only in Rand, but also in customer goodwill and support to the operations, has more than justified the expense. (Manufacturing: Nampak - Megapak)

... the R\&D enjoys a high level of support from our Executive, who see and believe in its value. (Mining: Amplats Research Centre)

Well the justification is easy. We show financial valuation of $R I$ billion, as compared to our budget, which is a small fraction of that, and that's only for two of our deliveries and we've got more. So, we are working quite strongly towards having a financial model behind our technology to demonstrate that its not a leap of faith into putting money into research and development, that there's actually some tangible evidence for our contribution to the bottom line. (Mining: De Beers (I))

We have companies that are real market leaders - especially if they are a technology or engineering company - they would value it very highly. If they are a company like our industrial and mining division, which would do a lot of market research and application of technology - they would value R\&D quite highly and spend appropriately. I mean Consani spends about I\% of their turnover on R\&D. Murray and Roberts Engineering Solutions, which is our industry and mining division would probably spend about $0.5 \%$ on the application of technology type research. (Construction: Murray \& Roberts)

In many cases from that point of view we can justify our existence by quantifying the testing we do versus the implication had we not done the testing and things have gone wrong later on ... (Fabricated metal products \& machinery: Toyota)

This unit was the unit that founded the Lennon generic range. The Lennon generics were the pioneers of generics. You could argue that without the unit, you would not have had Lennon. So it was able to pioneer a thing. Now it is used mainly as a strategic tool for the company. If you can buy something cheap, well, why develop it. That is the type of usage that it is at. (Chemicals: Aspen Pharmacare)

It is very clear. Our benefit is one of competitive advantage. That's the reason why we have a research centre. To continually have that competitive 
advantage in a very competitive market and innovation, is the key to success. That is our belief. (Chemicals: Plascon)

$R \& D$ is very much seen as a core of the business and critical for growth. If money is required and the returns are there then money is allocated. (Manufacturing: Unilever Best Foods Robertson)

What I'm saying is there's a second value proposition of having an in-house $R \& D$ which most companies don't appreciate - that is that you have the tool of knowledgeable people who disseminate that knowledge in a tacit manner into the operations, and being a phone call away, people who understand the operation and the problem, and can give people advice. So there is a significant value contribution, and I have made it a personal mission for myself to communicate this and to get the recognition of that contribution. (Mining: De Beers (I))

\section{Benefits of R\&D to industry}

Company R\&D can benefit the wider industry directly or indirectly. Examples of the direct impact on industry include, for example, when research institutes work on behalf of members or clients within the industry; when improvements or innovations in a product and process (reliability, structural integrity, safety, cost-effectiveness etc) are of general benefit to the industry; or, when R\&D results in new standards or regulations which affect the industry as a whole. Company R\&D can benefit industry indirectly when knowledge spillovers etc filter through to other companies (even competitors) within the industry.

First of all the design codes that are rubber-stamped today by the SABS are actually written into the National Building Regulations, which is the overall governing set of rules for building in South Africa, but that design code has to be used to design steel structures. We are legally recognised at every level and the guys are not allowed to operate without that information. (Fabricated metal products \& machinery: South African Institute for Steel Construction)

... we actually hope to get the whole South African Feed lot and dairy market to perform better, and also all feed lots and potential dairy producers in the world. We are at the moment looking at the USA as a start. (Agriculture, forestry, fishing \& hunting: Kynoch Feeds)

... one of the breakthroughs and developments that this unit did ... was the development of the $\mathrm{SO}_{2}$ sheet machines for the export of grapes. It played a major role in that and it's a widely used technology in South Africa today, but it was not patented because it was done for and on behalf of the industry as a whole. (Agriculture, forestry, fishing \& hunting: Capespan)

In 1996, or shortly thereafter, we introduced 2-piece DWI metal can manufacture for food cans. ... This change had a considerable impact on the local canning industry through production of cheaper cans because of 
improved material and process efficiency. (Manufacturing: Nampak Megapak)

I sit on the advisory board for the South African Bureau of Standards on edible oils. Part of the industry and members of the board come from our competitors, and we have input in developing the common standards for the country. (Manufacturing: Unilever Best Foods Robertson)

\section{Benefits of R\&D to other companies}

The R\&D activities of one company can benefit other companies in a number of ways, for example, via exports or the selling of licenses, through knowledge spillovers, or through networking and personnel exchanges.

Of course, those firms that are part of a multinational corporation can benefit the other companies within the group through their R\&D. In some cases, the South African branch of the company offers something unique in terms of R\&D capacity and/or outcomes.

Spillover of knowledge at the moment to other firms - it happens all the time, because we work together and collaborate with other companies. People leave us and go elsewhere and carry that knowledge with them. (Electronic hardware, systems \& software: Tellumat)

Products, yes but very much at arms length. It would usually be products, as far as I can think now, which are out of patent, or products that we acquire for example through merger, and that becomes rather foreign to our portfolio. So something that is very much in another area of expertise that we would then consider selling out. (Chemicals: Aventis)

We have also links with other packaging companies worldwide, so we do exchange information under technology. (Manufacturing: Nampak Megapak)

... we have actually been exporting more $R \& D$ to $S A A B$ than they have been to us, because we are actually more experienced than they are in this field. (Electronic hardware, systems \& software: Grintek Avitronics)

It will be the first medical fabric, for general hospital-wear, which will be FDA approved and it will then become the standard for all American hospitals. (Manufacturing: Gelvenor Textiles)

[We] developed infrared drying pads systems [for the textile industry]. By using electricity, which has actually increased their drying capabilities of their fabrics, Mooi River and Da Gama Textiles have increased their productivity in drying by something like $60 \%$, reduced their energy requirements by something like $40 \%$, and their whole production line, the whole flow process, has increased something like 55\%. (Services \& infrastructure: Eskom) 
We are the global R\&D so all that we do is for the international company. (Chemicals: Pfizer Global R\&D)

... as an affiliate we assist in the global clinical trial programme. So, it is really a global $R \& D$ programme, and we are one component of that. Within that, obviously, we assist in producing information that is required for registration of those products in various countries and including in SA. We are not solely responsible for it but we are an important part of doing that. From a track record point of view, SA has produced a significant number of, or significant percentage of, that global research content that is required for registration. So from that point of view, yes, it is a value to the organisation in getting products, in discovering new products and getting them registered for marketing. (Chemicals: Eli Lilly Pty Ltd)

\section{Benefits of R\&D to clients and user groups}

Clearly, when a company specifically does research or development on behalf of user groups (such as farmers or sugar millers) or customer groups (such as banks), these groups benefit insofar as they are the primary users of the R\&D.

And if they had brought up this particular research topic, then the researcher will go back to that field when the research is complete, and present the results and tell them how to implement it. (Agriculture, forestry, fishing \& hunting: Citrus Research Institute)

... we get the right report and bringing it back to the mill, report back, and motivate if the process should really change, that's in the plant. (Agriculture, forestry, fishing \& hunting: Mondi Processes)

... we have instances where we deal with banks and so on, where they've got an internal competence that can actually ... where we can transfer some of the knowledge. (Electronic hardware, systems \& software: Nanoteq)

You know effectively just about everything we do is used by someone else because we specifically design it for use by other companies. So $90 \%$ of what we do is in some way or another used by other companies to meet their customer's needs in terms of building the technology. (Electronic hardware, systems \& software: Azisa)

\section{Benefits of R\&D to the broader scientific community}

There are a few instances in which the broader scientific community is seen to benefit from company R\&D. More of than not, this would include either the institution itself, in terms of research funding or funds for research chairs and bursaries, or the academics/postgraduate students involved in any of the project work.

The only spin-off really is the collaboration with the universities. They obviously gain. They sign confidentiality agreements, so the idea is not to spread the knowledge around. But they obviously benefit in some way out of 
it - there is no question. Not financially. They discover new techniques and things like that. (Fabricated metal products \& machinery: Circuit Breaker Industries - Reunert)

We try and benefit the university by funding a project with their 4 th year students. We occasionally try and employ the 3rd year students during the holidays and give them small tasks to perform with development and stuff like that. (Electronic hardware, systems \& software: Thales Advanced Engineering)

The only one I could actually really see out of that that we do often is we give students work, and obviously a lot of that technology then gets transferred to them when they go away knowing much more on how to do RFID and that sort of thing. (Electronic hardware, systems \& software: Impro Technologies)

\section{Unintended beneficiaries}

Despite the user-focused and selective dissemination of R\&D outputs, there are also unintended beneficiaries of company R\&D. Other companies or organisations might benefit from company R\&D through, for example, using or copying the technology once the patent has expired; knowledge spillovers and the results of environmental scanning; or even reverse engineering.

If it is used by other companies we will generally find a paper in literature. For instance some of the work we have done at Wits there is a paper in Nature. So the other companies would have picked that up. And I have just been to a conference in Australia and that paper was probably referenced about 20 times, by 20 different speakers at the conference. (Mining: AngloGold - Geochemistry)

We were the first in the world to do that with the success that we have had. And it is now being copied by a lot of other people around the world. (Manufacturing: Anglovaal Industries - I\&J)

In summary, companies enjoy a range of benefits from their own R\&D activities and, whether directly or indirectly, others benefit too. Clearly, to benefit from company R\&D implies that the R\&D was successful in achieving its objectives and that there was uptake and implementation or utilisation by the intended users.

However, it is not always the case the R\&D activities come to fruition; in fact, it happens more than we realise that R\&D is unsuccessful and no utilisation takes place. The following section considers some of the reasons given by respondents for instances of no utilisation. We will return to this issue in the concluding section of this report. 


\subsection{Instances of 'no utilisation'}

There are certainly times when R\&D activities do not come to fruition and hence no utilisation takes place. Some of the reasons for this provided by respondents include:

$<$ Difficulties associated with technology transfer

$<$ Technological problems that the R\&D cannot solve

$<$ The R\&D does not produce the desired or intended output

$<$ Insufficient funds might lead to the termination of an R\&D project, or to only a partial completion of the intended R\&D, for example, the company might not have the money to take the product to the stage of commercialisation

C The technology is not successful in the market, the market collapses, or someone else gets there first.

We have had products like that were put onto the market, that we did spend time and research on that eventually were not very successful. But it is not very often. We try and limit ourselves or try and do an assessment on the practicalities of it before we spend too much on it. (Fabricated metal products \& machinery: Mitek)

Ja, sometimes the problem of "resistance to change", is one of the problems. The other thing is that our current operations are very capital intensive and you have got equipment, so it is not so easy to change ... (Mining: Iscor Mining Consulting Services)

We had projects developed that for various reasons have been turned off, that have never been introduced, certainly. ... Could be a shift in the market. If I think of a classic one, we developed just about up to about the point of going into production, a 5-cylinder syncro bus, but then we realised that the market was collapsing for syncro buses and so we cancelled it at the last minute. (Fabricated metal products \& machinery: Volkswagen SA)

That is if R\&D is successful. It is not always successful. We might go through the whole process and find out that idea was not great from the start. (Agriculture, forestry, fishing \& hunting: Mondi Processes)

Sometimes we can be working on a product, for example a machine that can mark fish and grill the fish, and we were busy and it was taking too long and we could not make a decision. Then the competitors bought a machine that made the product. (Manufacturing: Food, drink \& tobacco - Anglovaal 1\&J)

That does sometimes happen. Perhaps a new can coating material or a new polymer for a plastic bottle, and it doesn't turn out to have the desired performance, then we abort the project. (Manufacturing: Nampak - Megapak) 
We have that problem all the time, ja. I would say our fallout rate in terms of new projects and new product development is probably between fifty to seventy percent. In other words, a new idea comes up and we start working on it. Of those new ideas, only thirty to forty percent actually become final. The reason for that would be a cost problem or a technological problem. (Manufacturing: Anglovaal Industries - I\&J)

Now that was a combined research development, where they produced the stuff according to our specifications, they would then feedback to us saying this is what they have developed. We'd have a look at it and maybe send a test unit out and we'd try out a simulator or a desktop version and we'd say, "No, hang on a sec. That doesn't work, that doesn't work." And we went backwards and forwards with them for about a year and a half on that particular project. And it was right, right there that we were about to start installations of the stuff and then we decided to buy these Airbuses. So, we had to cancel the project, which was a pity because the product was developed specifically and only for SAA. (Transport: SAA)

There are undoubtedly many more reasons why the outputs of R\&D are not transferred to or utilised by the company or other intended users. In addition, while there are clearcut cases of no utilisation, there are also ranges of other factors, which can limit the success of the R\&D activities or the realisation of technology transfer. The following chapter considers the various challenges, which companies face with regard to undertaking $R \& D$ and ensuring that the results of R\&D are effectively utilised. 
CHAPTER 9

FACTORS THAT LIMIT R\&D AND TECHNOLOGY TRANSFER

Respondents reported a range of factors that limit R\&D and technology transfer, including:

$<$ The lack of appropriately skills human resources in the country

$<$ Inadequate financial resources

$<$ The lack of certain equipment and facilities locally

$<$ Inadequate sources of knowledge or information

$<$ The secrecy around intellectual property

$<$ The difficulties associated with technology transfer

$<$ Inadequate government incentives, resources and support

$<$ The conflicting agendas of industry and academia in the context of R\&D collaboration and outsourcing

$<$ Limited or stagnating local markets

$<$ Negative attitudes towards innovation and R\&D.

\subsection{Lack of appropriately skilled human resources}

By far the biggest problem reported by respondents with regard to R\&D in general is the shortage of skilled human resources in South Africa. For many companies, the brain drain in South Africa is contributing to and exacerbating the skills shortages. Others attributed the lack of skills to what they perceive as the declining R\&D capacity in HEls and science councils, or low participation and throughput rates amongst school and higher education students, especially in mathematics and science. For most, the greatest loss is the invaluable tacit knowledge that is only acquired through years of experience.

$R \& D$ is not about buildings and it is not about specific locations, it is about people and accessing people. My main worries are the overall available skills level in SA to service South African industry generally, and at the quality of the average graduate coming out of university. A lot of the literacy and numeracy skills are not there, and that shows in the way they conduct themselves when working. That is not an issue with a five-minute solution. (Mining: Amplats Research Centre)

I think the largest prohibiting factor that I face in terms of the application of research is the overall skills base available in the country. (Mining: Amplats Research Centre)

And it's hard to sometimes get the specialised skills. I guess that the world opening up with the globalisation has helped, in that you can go to Australia and Canada for assistance if you want to. But certainly, as far as South 
Africa is concerned, there is a definite lack of the skills that we need. (Mining: Impala Platinum Metallurgy)

And this is not a peculiarly South African problem. ... the net capacity in the world has gone down. South Africa is one of the few places that has retained what it had, but it has not increased it. This was largely a result of the policies during apartheid time, when SA was trying to be reasonably selfsufficient. So, it kept going, but it didn't really expand the capacity that it had. (Mining: Amplats Research Centre)

There are lots of qualified people but very few competent ones, if I can put it that way. (Manufacturing: Tongaat-Hulett Sugar)

We do battle to find very strong, capable chemists, and I think in our case, it is about strong chemists who not just do research in the laboratory, but who have the ability to apply, application of, technology in a multinational type culture, that is why we get so limited. (Chemicals: Unilever)

... the people in the operations out in the field seem to have a decline in competence level. The gap between what the technology, in principle, can do and what the real life people out in the field can absorb is a forever-growing gap, and that makes the transfer of technology incredibly difficult... (Mining: De Beers (I))

\section{The brain drain or a general loss of skills}

Many respondents reported that they had lost skills through emigration, by staff being poached by other companies locally or abroad, by people leaving the industry and moving into a new occupation altogether, or by people who leave in order to set up their own businesses. Part of the difficulty with retaining staff is that companies are often unable to compete with the attractive salary packages offered elsewhere, and especially by other companies abroad. Significantly, respondents reported that it is often their top quality staff, the 'cream-of-the-crop', who leaves for greener pastures.

In addition, the investments made by companies in the education and training of their staff is effectively wasted when people move on. There is also something paradoxical about the fact that the training and work experience that people gain is ultimately what makes them more mobile and in demand in the long run.

We have, as a company, lost senior people - it is an ongoing problem. Both people moving abroad although largely to people working within local industry. (Electronic hardware, systems \& software: Fuchs Electronics)

Say if you are a youngster doing minerals processing in a South African university, you get reasonably well qualified. You have got to be quite marketable and that is in addition to the shortage of skills in the country right now. That is going to make those people more mobile, which is going to add to the problem that we have (Mining: Amplats Research Centre) 
People have become mobile and you know people can lift their anchors very easily and move and earn very big salaries, because there is worldwide, even in this field there is a scarcity of highly qualified, experienced people. (Manufacturing: Breathetex Corporation)

I think there has been a bit of a drain, especially in the cereal science field. There are really only a handful of real experts left. (Manufacturing: Pioneer Foods)

We have had this problem in SA of training really top class people here and losing a lot of those investments by people moving. (Electronic hardware, systems \& software: Azisa)

That is certainly a problem, as soon as people become specialised they are very marketable, not only within South Africa but outside South Africa as well. And we regularly have our people approached directly by employment agencies in the States, Germany and in the UK, so that is fairly common. (Fabricated metal products \& machinery: Volkswagen SA)

I would say that probably one of the biggest is that when people get good in a certain field, they get stolen - not really by South African people, but by overseas people. ... let's say, their package is R240 000 to R300 000 here. These guys get triple that when they go overseas and we have lost a half a dozen good people like that. Believe it or not - two or three of them have come back.... You put a lot of effort into training people and then they become very marketable in the world. (Electronic hardware, systems \& software: Grintek Avitronics)

... recognising that many of these very creative, particularly young people, have quite an entrepreneurial flair, we are quite used to a certain amount of it - where they actually come through the company for four or five years and eventually end up setting up their own specialist business. And we generally - if they are being realistic enough - we try to continue our relationship with them otherwise we don't try to induce them to stay beyond what we consider to be economically practical. (Electronic hardware, systems \& software: Grintek (2))

To overcome that, we actually started recruiting younger people and just trained them through the ranks. We also found that it is not as debilitating as we thought to not have total expertise in everybody. You need only to have expertise in a small core group, because new people bring new ideas. (Chemicals: AECI African Explosives)

Staff turnover, unfortunately, tends to be a bit high. I can hold the older guys but younger guys tend to - more of our previously disadvantaged people - and they come in here, get some training... The Eastern Cape salary levels are not that good, so for a new guy coming in the salary levels 
are down, and as soon as he has got two to three years' exposure, the people go off to better pastures. ... The effort we've been putting into the young guys, we haven't been getting a return on it. (Fabricated metal products \& machinery: Willard Batteries)

... because the youngsters ... as soon as we have got them up to a level where we happy, the other guys are pinching them from us. But if you look at SA in general, if all of the businesses operated like that then we will actually grow our skills base, so we shouldn't look too negatively at this. (Fabricated metal products \& machinery: Willard Batteries)

\section{Inadequate skills' replacement}

Replacing these lost skills is not always that simple: there are insufficient numbers of graduates, especially those with maths and science, coming through into certain industries. In addition, it can take a long time to train new employees, and for them to gain the experience to the required level. The high cost of recruiting much-needed skills from abroad is also sometimes prohibitive.

$\ldots$ it is the number of science students coming through and engineering students coming through, that are prepared to remain on the scientific side. (Chemicals: AECI African Explosives)

I think it should be targeted at schools. I've got sons in Std 8 and Matric and they are not interested in sciences, so that is, obviously, where it starts. You need to start targeting there and show it as a career path, and everything is material and money-driven nowadays, so there is an opportunity to get to the top even on that side. (Chemicals: $\mathrm{AECl}$ African Explosives)

If they are coming to us fresh out of university they have to accommodate their knowledge to a new specialist field fairly quickly. He has to make the investment in time before we are fully productive. (Manufacturing: Nampak - Megapak)

And we find we have to make our own cable experts. Even taking an BSC graduate - we incorporate such a wide range of technology, it's plastics, its metal, it's electrical. It takes three years to produce a good technical guy in our industry. (Fabricated metal products \& machinery: Aberdare Cables)

... it takes a long time to train up people from university level to really become skilled in this innovative sort of field. (Manufacturing: Breathetex Corporation)

We have tried to recruit people last year from overseas and it was shocking. The salaries was round about a million Rand to try and recruit, let's say, polymer scientists from overseas. (Manufacturing: Breathetex Corporation) 


\section{Declining or inadequate capacity in universities and science councils}

A number of respondents indicated that they have major concerns about what they perceive to be deterioration in the capacity of universities and science councils in South Africa to support company R\&D. In part, this is attributed to the decline in funding and available resources in these institutions. Mostly, however, there is concern about the ageing and shrinking scientific workforce in the public sector. Amongst others, the ageing of the scientific workforce can result in what one respondent referred to as "technological lock-in"; in other words, when older academics and scientists get stuck in a particular way of thinking about technology. At the same time, the lack of young blood coming into the system means that there is a dearth of new, fresh and innovative ideas.

One of the big problems in SA is the quality of South African geology departments. The staff is aging and it is a serious problem because in the '80s they were brilliant people and we see very few young people coming in and they have gone and locked in the technology and we can't get it out of them. It is so impossible to change these guys. (Mining: AngloGold - Geochemistry)

I don't think we have probably, as a country, enough research innovation development capacity out there for organisations to easily tap into. (Mining: Impala Platinum Mining)

I see great difficulty. I see with the despair how the research capability of the universities is declining and generally the salary levels in research and development - I'm working with university professors who have a lower pay packet than my secretary and that is obviously not sustainable. (Mining: De Beers (2))

I am absolutely convinced in my working with the universities that in ten years time there will be no capacity for us to - how they can gainfully contribute. We might still work with them, with some sort of means for finding opportunistic talent in the early days, which we would have to train. In the universities, I see a bleak future for them as a partner, and they don't seem to have - they might intellectually claim that that is a problem - but they don't seem to emotionally have accepted that in terms of a change in practice - that is how to deal with it. Similarly in our own situation, I also see the difficulty in the next generation researcher. We've got extremely competent PhDs and Master degreed people who have ten years of experience, but we've got very little influx of freshly graduated MDs who seem to have the capabilities to replace their more experienced colleagues. (Mining: De Beers (I))

We did a survey the other day that had a look at the average age of our engineers are and they are probably in the high forties. So we have a lot of the near-retiring age group and not too many people of the lower ages, even though we have things like bursary schemes. (Construction: Murray \& Roberts) 
My biggest concern since we became involved in universities is the lack of succession planning at university that we are slowly but surely running out of human capital there. People are all close to retirement age and there is nobody following up. I think industry has got a role to play there ... (Chemicals: AECI African Explosives)

Recent research (see, for example, Mattes \& Richmond 2000) has shown that among the reasons why South Africans emigrate are the cost of living and poor economic growth rates, deteriorating standard of public services - especially health and education, and rising crime rates. At the same time, the skilled labour force is globalising. Like professionals around the world, skilled South Africans are increasingly mobile and in demand, and can compete in the global market for better career opportunities and salary packages. This poses a tremendous challenge for local employees, many of who cannot compete with companies abroad.

However, while companies may be losing skilled people through skills migration (either emigration to another country, or mobility between companies), South Africa is also part of this global 'brain circulation', which is an opportunity we can exploit. Firstly, South Africa would benefit from an immigration policy that enables recruiting skilled personnel from abroad. Not only do these immigrants bring with them much-needed skills, they also provide access to valuable networks, facilities and funding, etc. Secondly, the loss of skills can, in fact, help to develop the local skills base since it compels companies and public institutions to increase staff development opportunities, and to accelerate the throughput rate of students, respectively. It also makes way for the younger generation of skilled people to gain experience.

\subsection{Inadequate financial resources}

The costs involved in company R\&D are frequently very high - one just needs to look at the gross expenditure on R\&D in many of these companies that frequently runs into millions of Rands. Respondents indicated that the highest costs are usually associated with outsourcing, other technology, or special facilities and equipment. This is particularly so in certain industries. At the same time, in the current economic climate, companies have less and less capital (internal and external) available to spend on R\&D. Financial constraints can limit company R\&D significantly, especially in the smaller firms, and are often the reason why R\&D activities are terminated, or do not come to fruition.

The classic example that restricts research from turning into useful products is capital... (Electronic hardware, systems \& software: Grintek (2))

... I would find it to be an item which is quite easily cut from your budget. ... you know, research is typically a soft target. If it is directly linked to the expansion of something and I have to do that technical study otherwise I can't do the expansion, then I will get it. But if it is sort of a softer long-term issue, then I want to determine the trends of the lesser spotted mud prawn on the bay and we might develop there in fifteen years, the chances of being cut year after year are quite good. (Services \& infrastructure: National Ports Authority) 
We are one of the smaller players and, as such, we do not spend a large sum of money on $R \& D$, comparatively speaking. Resources for $R \& D$ are always a problem. (Mining: Impala Platinum Metallurgy)

I would say financial constraints. We would develop say ten products and maybe one of those would end up being commercialised. Maybe one is a bit harsh - maybe two or three would end up being commercialised ... Commercially, there might be ten other suppliers out in the market and we just can't compete on a financial point of view. So, the whole cost involved in $R \& D$ is very high compared to the number of products that are actually commercialised. So, I think a number of companies are starting to say; well it's difficult to justify the financial cost involved in new product development where we could perhaps source the technology from overseas. And, in fact, we are also going that route. (Chemicals: Fine Chemicals Corporation)

The amount of money that is put into research, and I would say industrial research, has to be linked to the probability of getting something back for that investment, and in South Africa, being a relatively limited market, I think there are fewer opportunities to invest heavily and get heavy returns. The international companies, multinational companies, of which there are very few in South Africa, but SASOL would be a good example, I think they still invest heavily in research ... They have enough critical mass to see the return on that, coming not only in South Africa but also in the world. Now for us to invest heavily when we have the option of licences or technology agreements with bigger companies doesn't really make too much sense. (Chemicals: AECI Specialty Chemicals)

I would say that because of sugar prices, the amount of funding available for research has declined in real terms. (Agriculture, forestry, fishing \& hunting: Sugar Milling Research Institute)

... one of the most limiting things is prices - of equipment, staff that we require. For instance, if you want to do the TB trials in a TB hospital, we become involved as outsiders, you have to pay for beds up front. If it could be arranged that we could use their facilities, beds, nurses, etc., that would bring the price of the research down considerably. At the moment we have to pay for all those aspects out of our own pockets. Also equipment is very expensive. We have one or two pieces of equipment that we desperately need, like flow cell tytometers, but the moment you talk of those things, it is in the region of R2, 5 million. What small company can afford that sort of stuff off hand? And the assistance given by people like the Innovation Fund is limited. If one looks at what it costs to develop a new chemical entity, it is in the order of $\$ 350$ million. And the maximum grants that we get may run to R3 million for five years. It is insignificant. (Chemicals: Meyer Zall Laboratories) 


\subsection{The lack of certain equipment and facilities locally}

Respondents reported that equipment is often not up-to-date or cutting edge. In addition, certain materials, equipment and facilities are simply not available locally and, as a result companies are compelled to seek these overseas.

The CSIR have the only wind-testing facility and unfortunately, they are closing that down. And it doesn't look like that is going to pass into private industry hands either. So, that is very sad news for our industry. We are going to have to get that work done internationally. (Fabricated metal products \& machinery: South African Institute for Steel Construction)

I think there is probably a limitation in R\&D facilities and development capabilities in this country. There is no question, I mean if you want to do fundamental research and you want decent facilities - I'm talking about industrial chemicals in general - then the CSIR and Biochemtech is probably one of the few places you can turn to. (Manufacturing: Illovo)

I think there is a dearth of decent $R \& D$ facilities in this country. I really do. It could be $a$ hell of a lot better but you know it's a function of the demand too. I think if you look at the whole chemical industry, other than maybe Sasol, the rest are struggling I would say. (Manufacturing: Illovo)

I think an inhibition at this point in time is really lack of infrastructure in SA in terms of sophisticated equipment and know-how to use it. I think it is not only the availability. Sometimes it is really getting service for that equipment locally. If one of our instruments breaks down something that is relatively simple like a gas analyser, it may take us six months to a year to get it fixed because we have to send it offshore. (Agriculture, forestry, fishing \& hunting: Capespan)

There are certain things that we just cannot make. For instance, we were approached by a certain automotive manufacturers saying, "Listen you guys have got to make aluminium sheeting for the outside panels of motorcars". And we did our analysis and said, "Okay, we can do it, but we need to install this and this and this. We'll have to spend (I can't remember the amount, but we are talking in the region of R/00 million on equipment), and we'll have to get the know-how". We know where we can get the know-how, but we wouldn't touch that product. It is not feasible; it doesn't fit in with our capabilities unless we spend the additional money to put it in. (Fabricated metal products \& machinery: Huletts Aluminium)

\subsection{Inadequate sources of knowledge or information}

Company R\&D is sometimes limited by the lack of information, prior research and/or particular specialist knowledge in South Africa. In part this has to do with human resource capacity and the status of research in a particular field. In addition, journals are often considered to be out-of-date, to provide irrelevant information, or are too expensive to purchase. 
However, the unavailability of research or technical information in the country also has to do with the need for companies to keep some, if not all their intellectual property a secret from the competition.

... getting information on the picture in this country. Very little research has been done in the aviation sector in South Africa. (Transport: SAA (2))

In terms of prohibitive things, it is not an exact science that we are dealing with. The methods that you use don't have an unique answer, so you always try to increase your changes of success when drilling. It is really an uncertainty and there is quite a big risk associated with this thing, so there's not anything that I can ascribe as prohibitive. It is just a matter of not having enough technical information or technical data to be one hundred percent successful. (Chemicals: PetroSA)

... often we don't have the right amount of information to actually take a good decision and sometimes you have to take a bad decision in that field. (Electronic hardware, systems \& software: Nanoteq)

If I were to be doing the latest and greatest, would I go out there and publicise it [in a journal] before I have done it? So essentially, what you are finding there is old news. ... So, we get results talking about the average Fin and the average German or average Italian. How valuable are those results in comparison to the uniqueness of the environment that we face here because of socio economic differences, because of all sorts of things? (Services \& infrastructure: Vodacom)

I think one of the things that inhibits us locally is the lack of a strong chemical industry - outside of petro-chemistry and mining, we really don't have a strong chemical industry. We have a lot of agents who make chemicals, but with limited knowledge, and that is a huge inhibitor. (Chemicals: Unilever)

\section{Intellectual property: secrecy vs. open sharing}

It was mentioned earlier, unlike the (apparently) open access to publicly-funded research outputs, the results of company R\&D are usually only disseminated to a limited number of recipients or users, and often only in limited ways. In addition, companies adopt various strategies to protect their intellectual property, to guard their secrets from the competition (e.g. via patents or non-disclosure agreements). In many ways, this makes good business sense.

However, the secrecy has a number of somewhat paradoxical implications. One is that it limits the possibilities in terms of outsourcing and collaboration, since companies are likely to be highly selective about who they reveal their secrets to. Another is that it decreases the availability of the very sources of information and know-how that companies rely on to inform their own R\&D agenda and activities. It can also limit the advantages gained from sharing information in, for example, industry forums. In this sense, intellectual property is 
a major issue in the broader R\&D process, where competition with other companies gives rise to secrecy rather than open sharing.

In other cases, we try and assert our rights simply by implementing the design in a way that makes it very difficult to copy and then keep key elements out of the public domain. (Electronic hardware, systems \& software: Grintek (2))

If I have to look sort of on a more sort of broad level, I think one of the things lacking in the South African environment, and this is particular so in the cellular industry ... there is this kind of paranoia about information, about technological innovation, and I think that what's missing in South Africa is a strong forum for the development of these things. (Services \& infrastructure: Cell C)

Of course, quite clearly as a business, we are not going to put everything in a journal, because it will impact on our future capability on certain things. (Services \& infrastructure: Eskom)

Slightly inhibiting compared to previous years is the competition between sugar companies, which has some inhibitory effects on what we can do because unless we can keep it confidential, we are often not asked to do the work. (Agriculture, forestry, fishing \& hunting: Sugar Milling Research Institute)

There are networks, but the competitive nature of the industry doesn't make a pool database of knowledge a practical reality. I think this is another one of the debates we've had over many years and with respect, with many academics who have tried to convince us that we should put all our cards on the table and we all share it and all live happily ever after. This is not the reality of business. If we have an edge over one of our competitors, we keep it within our deepest pockets and make sure that we retain the edge. (Electronic hardware, systems \& software: Grintek (2))

$99 \%$ of the stuff is openly exchanged. There are one or two things that people try and hold closely to their chests. But you only have to see one and you get to grips with it: "Oh, that's a good idea. How am I going to plagiarise it?" And we tend not to fight each other on this information. We send them copies of our journals and all the kinds of things we get and we get letters back saying, "That's a great idea. We are going to use it, thanks." And we do the same sort of thing. There is an open exchange. (Fabricated metal products \& machinery: South African Institute for Steel Construction)

Well, one would hardly say "sharing" because it's a highly competitive business that we're in, and to tell you the truth, we sort of guard our technology and our know-how quite seriously. (Chemicals: DPI Plastics) 
I believe that there is generally an atmosphere of secrecy about technology in this country. (Chemicals: Plascon)

The aluminium industry is very much a closed industry. They don't really talk to each other ... (Fabricated metal products \& machinery: Huletts Aluminium)

There has been increased competition in the worldwide sugar industry and locally between sugar companies, and so in terms of by-products of research, where there are limited markets there has been an increase in confidential work to develop by-products for limited markets. ... The sugar industry has always shared and, in fact, we act as a strong collating and collaborating body in that we get factory performance parameters each week from our 23 member mills, and we collate this and put it back to the industry as a benchmarking exercise. So, there is huge sharing of those benchmarking issues, but also sharing of technologies and development of technologies, which are of benefit to the industry as a whole. But as soon as the market becomes a limiting one, then there is less sharing in those areas. (Agriculture, forestry, fishing \& hunting: Sugar Milling Research Institute)

... I think in the biscuit industry a lot of the knowledge of the processes is fairly generic and it's fairly open knowledge too. I think when it comes to recipes and specific settings, in terms of the way one sets up a plant and runs a product, that knowledge is kept very confidential. (Manufacturing: Anglovaal Industries - National Brands Ltd)

\subsection{Difficulties associated with technology transfer}

As was pointed out earlier, the effective transfer of technology (utilisation) involves much more than the dissemination of R\&D outputs. It requires that users actively engage with the technology or new knowledge/information and, more importantly, it requires that they possess the relevant prior knowledge and skills necessary to apply or implement the findings. The following quotes reflect some of the lessons learnt by respondents with regard to the importance of communication and tacit knowledge in the process of technology transfer.

You are dealing with external people; you know that they are spending a hell of a lot of money on development work so they are not going to wait. They prefer, irrespective of risk in many cases, go ahead commercially as soon as they can. There is no problem in technology transfer - it goes very rapidly. (Agriculture, forestry, fishing \& hunting: Capespan)

I would just stress the people side of relationships. ... until people get to know each other, it is pretty difficult for technology to flow. So, you've got to spend time to let people get to know each other, and then you will find it escalates, but it does take time. (Fabricated metal products \& machinery: Aberdare Cables) 
Our experience of the problems of putting innovation into practise, if you go too far down the road with the innovators, and then they come to the factory and say: "This is what you must do" and the people in the factory haven't been involved in it, you would never get across that line successfully. But if each party is involved from square one you do that and I think we have a fairly good record of getting innovation into our plant. ... When things fail, ninety percent of the time it is a personality clash and not a technical problem. So that's the way we do it. Communication and number one everybody is invited to come up with ideas - we don't have a person who comes up with good ideas, and everybody is invited to gives their views from square one. They don't get handed it at the end of a process and told to put it in their factory. (Manufacturing: Anglovaal Industries - I\&J)

\subsection{Inadequate government incentives and support}

Except for funding mechanisms such as THRIP or the Innovation Fund, respondents reported that companies are offered no incentives by government to pursue R\&D. In addition, for some, the support offered by government left a lot to be desired, particularly the bureaucratic nature of the process that can result in the company missing a window of opportunity. For others, the criteria and conditions associated with government funding are problematic. Moreover, funding programmes such as THRIP require collaboration between HEls and industry. This can raise intellectual property issues, which might make a company reluctant to participate.

There are no incentives in place by the government to promote $R \& D$. We don't get any extra tax benefits, although they are talking about that new programme now. And that would make a big difference, if you could get some incentive for R\&D work. (Manufacturing: Tongaat-Hulett Sugar)

You know we've looked at some of the funding operations - you've got to get your applications in six months ahead of time and it takes forever for somebody to make a decision, by which time the opportunity is either gone or you disclose too much information to people that you don't want to have it. (Chemicals: Keyplan Engineers)

There are just too many obstacles, too much paperwork. Whenever you visit them it is so complicated that we just spend the money and do it ourselves. (Manufacturing: Gelvenor Textiles)

One of the concerns we have had is that the people who are responsible for assessing the value of the proposals that have been made, seem to be becoming much more bureaucratic than they used to be and we are experiencing a lot of new people coming into the process. So, if there is anything that $I$ think maybe interesting to poll the industry on this is how they are experiencing the interface to these government initiatives and whether they feel it is changing. I think from my viewpoint, we have definitely seen that it takes a lot more effort to actually become involved in these programmes, than it did, for instance, two or three years 
ago. I am not saying that it is all wrong. I think that they are being a lot more careful, but it is almost getting to the point where we can't wait for them. An idea must get turned into a product - and if it takes six, to nine or twelve months to convince the project manager of the value of what you are trying to do, often the idea is timed out by the time you get an answer from them. And this is somewhat of a frustration. (Electronic hardware, systems \& software: Grintek (2))

You know the one thing that I feel quite strongly about is that although there is some government support as far as, let's call it the research and development component, in our view that sometimes that represents only a small percentage of the cost involved in getting a technology based product into international markets. And by the time your development funding stops, maybe you've actually spent $25 \%$ of what you need to really launch an internationally successful product. ... So, I think there needs to be more emphasis on taking products to market and a national effort to help bright ideas actually succeed in the world market rather than just the generation of bright ideas. (Electronic hardware, systems \& software: Tellumat)

... the government wants about $5 \%$ of the turnover that is eventually generated as a sort of payback, which is nuts. You must understand that this business typically runs on about 10-I I\% net margin, so $5 \%$ is about half the profit. (Fabricated metal products \& machinery: Altech UEC Multimedia)

We have now and again applied for money from the Innovation Fund and we got it, but then we saw all the intellectual property stuff and then we thought, no. I understand why people put that in and I understand that it is the government's view that it has to be done, but sometimes we lose good projects because of that. We don't expect to do competitive research on government money, but on the other hand, sometimes we seem to argue so much about intellectual property that we don't actually get the work done. I guess that is one of my major issues. (Fabricated metal products \& machinery: Columbus Stainless)

I think as I said to you before that government has to decide: are they serious about R\&D or not? We have a major problem with a lot of our competition and our competition in certain areas of our business, and aquaculture is one. The government is pouring millions of Dollars into this country, and they are the people we have got to compete with. So at the moment, all the R\&D we do in that area is effectively not funded at all by government. And we are suffering because of that, which is number one. The number two issue is that on the fishing side, and it may just be on the fishing side, but they are so obsessed with the control of the resource, which has been their job up to now. Their job is to control these fishermen who are trying to take as much out of the water as they can. And I understand that, and they now need to change - for aquaculture they now need to change that attitude, encourage people to start aquaculture 
and they seem to be unable to do that. In fact, in the aquaculture area business we have been constrained by ridiculous controls that nobody else in other countries have. And that is a problem that they have to resolve. (Manufacturing: Anglovaal Industries - I\&J)

\subsection{Conflicting agendas of industry and academia around collaboration and outsourcing}

In current times, there are many compelling reasons for HEls and industry to collaborate around R\&D. Industry's motivations for collaborating and outsourcing were discussed in Chapter 5. Within the higher education sector internationally, collaboration is increasingly becoming an imperative for the survival of HEls. More than ever before, HEls are dependent on external funding and contracts for research, as their own budgets shrink. At the same time, they are under pressure from governments to develop partnerships with, and be more responsive to the needs of business and industry. This is reflected in the emphasis on programmes in science and technology, as well as research collaboration and contracts. This new university form has been termed the 'market' or 'entrepreneurial' university (see, for example, Orr 1997:46 and Subotzky 1998:2).

These trends are increasingly evident in South Africa, as our own universities and technikons are compelled to seek partners with whom to collaborate. These collaborative relationships are not without their challenges, however. A recent study by Wickham (2002), for instance, which investigated industry partners' experiences of partnerships with $\mathrm{HEls}$, revealed that a critical issue facing HE-industry partnerships is the apparently conflicting agendas of the two.

Respondents in our own industry interviews also highlighted these kinds of problems. They reported that the 'cultural differences' between industry and academia often pose a challenge in terms of R\&D outsourcing and collaboration. For instance, respondents complained that:

$<$ Academics are unable or unwilling to take their research to a practical application level

$<$ Academics do not understand or appreciate the way in which business operates, and

$<$ The different timeframes, priorities, standards and commitments (e.g. to postgraduate students) within HEls often conflicted with the company's own agenda.

In my opinion, one of the issues or problems is a lack of practical understanding on the part of a lot of researchers, and vice versa, a lack of understanding of people within the industry (what would the word be professionals?) about research and issues within research, such as statistics and the ability to verify, you know, do scientific research and then make scientific conclusions. ... Those understandings aren't necessarily what they should be within practitioners in the field. So, you have these two groups talking different languages and bridging that gap is difficult. Communication is difficult there. So, it is difficult at this stage and it would be of assistance if 
more of the researchers had more practical inclinations and experience, and had a better feeling for what's going on in operations, and vice versa. (Mining: Impala Platinum Mining)

You know, universities are incredibly theoretical, but there's not a lot of practical innovation coming out of a lot of the projects that students do. We're saying, "Well, let us have a look at those papers and we'll see what can be applied as a technology in textiles". (Manufacturing: Gelvenor Textiles)

The researchers like doing the research. They don't like writing it up. And they really don't like turning it into something practical. And we actually have, not quite, but we actually demand our pound of flesh along those lines. We say that coming from a contracting background, the contract is never finished until the paper work is done: "Mr Researcher, your research is not finished until your paper work is done and you've told us the practical uses of it". (Fabricated metal products \& machinery: South African Institute for Steel Construction)

... our experience is that universities are not commercial institutions. They generally don't understand commerce and that is why we prefer to keep it nice and simple. (Electronic hardware, systems \& software: Grintek (2))

Universities particularly focus on making a molecule, whether it gives a 5\% yield, whether it is factory friendly, it doesn't matter, as long as you can make it and then you have achieved your goal. Where for us it is really making a product, where you take into account environmental aspects, whether it can be done in production. You take into account the costs obviously involved. Often projects will be discontinued, because either from a cost point of view or an environmental point of view, whereas at a university, they don't take that into consideration. (Chemicals: Fine Chemicals Corporation)

And then if you look at universities, I guess the only complaint is that they take a lot of time. As the departments start to realise that things are changing, they pick up their administration and you know, previously universities did things sort of at their own pace that suited them but, fortunately, you find now that departments are starting to realise that they need to get going, get proper feedback going and put structures in place to ensure efficient research without giving away their freedom. I think it is a difficult thing for them to manage and I feel sorry for them, but that is how it is. (Fabricated metal products \& machinery: Columbus Stainless)

It is a concern. I have tried, for instance, to approach our universities to do projects but the university agenda is at odds with the industrial agenda. My requirement is to have projects done very quickly and almost on a fulltime basis, whereas the university agenda is to stretch something over a student's 
career, over a year or maybe two years. So there is a conflict of interest there. (Electronic hardware, systems \& software: Fuchs Electronics)

The key component in that was ensuring that we didn't target an institution because it was labelled as a good commerce or biotechnology. The key issue there was to look for productive individuals, productive academics, who were moving ahead, who were rated, who were attracting students, who could get the work done for us. (Agriculture, forestry, fishing \& hunting: Mondi Forests Ltd)

\subsection{Limited or stagnating local markets}

Limited or stagnating local markets can reduce the demand for particular R\&D activities, or they can impact on the company's success in getting their products to market.

On the hindering side I suppose like all businesses is orders. Some of our work is directed to Spoornet and they haven't placed new orders for a long time ... In other words that market hasn't really grown. (Fabricated metal products \& machinery: Dorbyl Engineering (2))

I don't think that the need has diminished. I think that there has been a significant down turn in our industry. ... Locally there has been a huge down turn in the last 10 years, to the extent that this whole industry was under serious threat and much of the effort has gone into rather product development for application in the export market, and downscaling the staff has been quite common. So for that reason very little has gone into research-type work, which is a pity but due to the down turn one understands it. (Electronic hardware, systems \& software: Grintek (3))

But, we still can't sell a metre in South Africa.

(Manufacturing: Gelvenor Textiles)

\subsection{Negative attitudes towards innovation/R\&D}

Finally, respondents indicated that sometimes either company management or end-users (internal or external) exhibit a negative attitude towards innovation and/or the role of R\&D in contributing to the overall performance of the company. This can inhibit the successful uptake of $R \& D$ results.

Respondents reported that sometimes management have little appreciation for the real or potential value of R\&D to a company's growth and competitiveness. In part this has to do with a lack of understanding about exactly what goes in R\&D and how it functions within the broader business operations. As a result, management can be resistant towards and unsupportive of proposals for R\&D to be undertaken. On the other hand, end-users can also be resistant to accepting and adopting the changes suggested by R\&D that can lead to no utilisation taking place at all.

Some sort of a higher technical literacy among the management would have been very helpful. Say it's in a sense, you could argue, it's an 
internal problem to the company, but I think it's a symptom of the South African economy. We find great difficulty in it. There's very poor appreciation of what the R\&D's role is in the company and what it should be doing. (Mining: De Beers (2))

One of the other issues is more on the technology transfer side, is getting the growers to implement the results of the research. Even if you go to a lot of trouble in technology transfer and making sure that they know what the results are, it doesn't mean to say that they will implement them. ... It is perhaps just the conservative nature of a lot of the growers in doing what they know rather than trying something new. So in the past we used to have extension officers who could virtually show that person on the farm how to do things, but we don't have that personnel any more and it is up to the farmer to grasp from the various means of communication what he needs to do and implement it himself. Some do and some don't. (Agriculture, forestry, fishing \& hunting: Citrus Research Institute)

There is also a tendency amongst many, many organisations to suffer from the 'not invented here' syndrome. They don't like other people's ideas. In fact when I put forward the idea that we have a research centre, nobody liked it. So, I think the people and their past education, and perhaps the fact that they used to work in a very different world - not the global village that we have become so familiar with - I think those are some of the constraints in utilising knowledge that is readily available. (Chemicals: Plascon)

In summary, company R\&D is a complex and costly process. It involves a diverse range of stakeholders who have a variety of (sometimes conflicting) needs. R\&D also makes enormous demands in terms of finances, highly skilled human resources and specialised equipment and facilities. It is therefore not surprising that companies experience so many challenges along the way. What this means, however, is that factors which will inhibit the ultimately successful uptake and utilisation of R\&D can arise throughout the R\&D process. These are summarised in the concluding chapter of this report.

While companies are faced by many challenges in seeing their R\&D undertaken and brought to fruition, there are some factors, which put a positive spin on company R\&D locally. The following chapter considers some of the strategies that companies have adopted in order to stimulate R\&D and ensure that it is effectively utilised, as well as some of the valuable resources available to individual companies, or that are specific to South Africa, which promote company R\&D. 
Respondents reported a range of factors, which contribute positively to company R\&D. Some of these factors relate directly to the circumstances of and approaches adopted by individual companies. For instance, some companies are simply well endowed in terms of finances, human resources and a solid knowledgebase. Others attribute their success to a positive attitude towards innovation and R\&D within the company, and incentives for their own staff to develop their skills in conducting R\&D and implementing or applying the results. Other promoting factors were more indirectly related to characteristics of the South African context that were particularly advantageous in terms of R\&D.

All in all, respondents offered useful insights and ideas about how to stimulate company R\&D in this country.

\subsection{Adequate financial, human and knowledge resources}

Some respondents indicated that they are adequately equipped in terms of financial and human resources, and access to knowledge and information. The government's contribution to company R\&D, via funding mechanisms such as THRIP, was also acknowledged and appreciated.

Something which maybe promotes is... we do get resourced. Unilever provides the means or human capital to make it happen. So that is one thing that we have, a very strong - we have the availability of cash and resources in our hands ... (Chemicals: Unilever)

... we have great appreciation for a number of initiatives that the government has put in place to provide funding for local development. (Electronic hardware, systems \& software: Grintek (2))

I must say, from our industry's point of view, an additional Rand-for-Rand has really been able to make a programme like the Stellenbosch one work, by not quite, but almost doubling the sums they are able to get in industry. And that is making the difference between just another bit of research and a really meaningful approach. (Fabricated metal products \& machinery: South African Institute for Steel Construction)

Quite a bit of our work at the research centre has been supported by government funding. We haven't always spent only our money - we spent our money and government funding. We have out of this been able to bring benefit to the university. Stellenbosch has benefited from the money we have spent at the university. Trips have been made possible for the Department of Polymer Science out of our participation. I am very pleased at the kind of availability and accessibility of government funding. I think they're doing a great job. (Chemicals: Plascon) 
We value this calibre of person very highly in our group of companies. We have $a$ very high portion of technically qualified people in our main staff complement. (Electronic hardware, systems \& software: Grintek (2))

... what helps us is that we've got an extremely innovative team of people that work for us. (Chemicals: Keyplan Engineers)

We have that some of our highly skilled people leave and some of them have emigrated, but I don't think it seriously held back by that. It's not a genuine inhibiting factor; there are other good people coming available out of the universities and in general we have been able to get the people we need. (Electronic hardware, systems \& software: Tellumat)

We've got a very big library here on geosynthetics. It's probably the biggest library on geosynthetics in the whole of the southern hemisphere, because we've been going for twenty-seven years now. There is a lot of knowledge here. I've got colleagues with a lot of knowledge on geosynthetics and so I do draw on their information. (Manufacturing: Kaytech)

One of the things we do have is a strong international network. We do have sister institutes in all developed countries in the world. We have big brother institutes in America, Canada and UK. We have similar size institutes in most European countries, in Australia, New Zealand and we have a very good international network of passing information on. (Fabricated metal products \& machinery: South African Institute for Steel Construction)

\subsection{Company geared towards innovation and R\&D}

Certain companies are entirely focused on change and innovation within their business operations that means that they respond proactively to the innovation imperative, and offer incentives to their staff to be as innovative as possible. It also means that management values the role of R\&D in the company, and provides adequate funding and strong support to the R\&D function. One company in particular appears to have taken great strides towards 'institutionalising' R\&D and innovation by, amongst others, developing an intranet system which facilitates and integrates communication and the sharing of new ideas and findings around R\&D within the company.

Promoting factors: our company is quite active, quite proactive in actually getting people on the floor to come up with creative ideas, the idea being that people who know the business best are the people who can innovate best. They come up with the most preferred solution. So, there are drives towards, you know, idea boxes, a reward principle for people who come up with innovative operational techniques or ways to save money and stuff like that. (Services \& infrastructure: National Ports Authority)

What we have done there is we have developed on our intranet what we call 'R\&D IQ', which allows us and people (we particularly want to stimulate innovation in the organisation) to put innovation ideas. They will be able to 
$\log$ on, go into the system and then at the click of a button, it would go through to a number of appropriate R\&D managers, via email. And then we would almost develop a chat line, and we would see what it is and how we should expand it further. (Services \& infrastructure: Eskom)

[R\&D] is very integral to our main line of business and I think what is important as well is that it has extremely strong support from the managerial board and the organisation. (Services \& infrastructure: Eskom)

I think what is very important to know is that every year I go to management board and I have to say to them, "Mr Chairman, I need so many million a year for next year", or the next five years. And what we normally get is, in principle, support for the five-year period, which I believe is absolutely crucial for the sustainability of any research organisation. There is no way that we can plan from one year to the next, because some of our projects last for five, six or seven years. If an organisation believes they are going to be competitively advantaged to technology and they have a oneyear window frame, they are going to lose it. I think this is why it is so important that our technology roadmap highlights those issues and I believe the role of the technology roadmap is key and paramount in the way we do things. (Services \& infrastructure: Eskom)

So, what we are saying is that our overheads are extremely low and we need to do that to ensure that we spend money on $R \& D$, rather than wasteful administration. ... I have a staff complement of 13 , including myself, but I have six research managers, operational managers, who each look after a budget of around about $R 30 \mathrm{~m}$. And the reason why they and their assistants can do it is that we have developed an intranet software system that manages it, all our projects. ... So, everything is online, so that any contractor or researcher within Eskom can log on every day and he can see exactly what his needs are in terms of the project process. So, it makes life a lot easier and the management side, in terms of nitty-gritty admin, is all on the system. Every report or every product that is developed goes to the steering committee; it goes out and it is all logged on the system. We are in the process of having a voice interactive system so that even the steering committee members don't even have to go onto the computer. They just phone in and talk on the telephone - using voice-recognition - it is automatically put on our database. So it's all there, all logged and we know exactly what each product means to each of our internal customers, which is very important. So that, in actual fact, pays a lot on the daily administration of the projects, makes life a hell of a lot easier. So that is why our overhead costs have been and will not go above round about $6 \%$ per annum. It is extremely efficient. (Services \& infrastructure: Eskom) 


\subsection{Good human resources management}

Some firms have been successful in implementing strategies to attract and retain key R\&D staff, through incentives and opportunities for development and promotion.

... there are incentives. We've got a separate, what we term a technical ladder, for technical advancements, which is parallel to the management one, which is normally the one that people jump on to get quick promotions. So there is a career path for scientists up to the highest level in the company. And it totally relies, like an academic institution, on peer recognition and superior recognition and fulfilling certain criteria on this ladder. It is a very scientific, technologically driven ladder. (Chemicals: AECI African Explosives)

... our normal financial incentives - like share options and those things, golden cufflinks that tie people down that little bit longer. (Electronic hardware, systems \& software: Nanoteq)

... these people have quite a stimulating environment. There are opportunities, so if they get bored they can change into other technologies; opportunities to go and work overseas for a few years. So, I think there are a lot of personal development opportunities for them, and that is why we are able to actually keep people. And if someone wants to go overseas or move or something, he is in a global network, so he can still get $a$ job overseas. We are not against it if someone wants to move to Germany - we will actually try and arrange it, because it is still part of the same network of people. (Electronic hardware, systems \& software: Siemens Telecommunications)

We actually also see our research facility as a training ground. We tend to use a number of young graduates, skill them up and move them into the operational areas, and so this provides good training ground ... (Agriculture, forestry, fishing \& hunting: SAPPI)

\subsection{Evaluating the outcomes of company R\&D}

One respondent spoke of the system of evaluating the outputs and outcomes of R\&D activities in his company. The company evaluates their numerous R\&D projects via customer feedback and a "return-rate on investment" (RRI) exercise. Clearly, this kind of evaluative exercise can play a significant role in ensuring that R\&D is effectively utilised in the long run. It is also a way of demonstrating the real and potential value of R\&D to the firm.

... all those RRI's of our seven hundred projects would be audited twice a year. We have just gone through one audit now, and that would be the discounted flow rate, the flush flows, projected over the next five years. We would do that twice a year. Every audited RRI would then be completed; documents would be put out and I would actually them present this to my board, and what is happening generally is that for every buck that I spend, I 
am showing a R5 return. So it is a 5:I RRI, and because of the robustness of the audit in the process that we utilise, it seems pretty well accepted that it has been very key in increasing our R\&D expenditure over the last ten years. (Services \& infrastructure: Eskom)

\subsection{The 'South African advantage'}

While a number of respondents highlighted the disadvantages associated with conducting R\&D in South Africa (e.g. the limited skills base or the lack of adequate funding), others indicated that these factors could in fact be viewed as advantages. In particular, respondents reported that South Africa is regarded as a quality but inexpensive site for R\&D for companies abroad. In other words, skilled labour is comparatively cheap but, as a few respondents indicated, overseas companies find South Africans to be hard workers and, therefore, comparatively more productive. This is possibly easiest within multinational corporations since the necessary linkages are already there. This is an opportunity to be exploited: if local and overseas companies were to invest more in R\&D in South Africa, this would generate additional funding and contracts, and help to build our $R \& D$ capacity in the future.

In our experience we have found that at least process development in SA is very cost effective worldwide. (Chemicals: $\mathrm{AECl}$ Bioproducts)

I think that what is good is that we have very capable multidisciplinary, generalists type people in the country and that means that we can get by with generally smaller teams equivalent programme internationally ... We are also a lot more specific, especially currently with the Rand having a low value so when it comes to non-recurring type work, customisation for low volume systems is competitive which is good. (Electronic hardware, systems \& software: Grintek (3))

There are certainly incentives for the group for VW in Germany to use us as a development facility, certainly. Our rates are dramatically lower than European rates; we are far more cost effective. (Fabricated metal products \& machinery: Volkswagen SA)

We have a huge cost advantage, so work done here is roughly $20 \%$ to $25 \%$ of doing work in the US or so. So, it makes a lot of sense to move more $R \& D$ to $S A$. Companies have tried this with other developing countries, like India, for example, but I think we have a specific niche in being able to provide the kind of customer communications and interfacing, which is on a parallel on what you would get in First World countries, but combined with a lot of costs as well. (Electronic hardware, systems \& software: Azisa)

I do feel the South African climate does create a lot of ... we are fearless enough, we are not worried to innovate and create things, even if we sometimes reinvent the wheel. And out of that sometimes comes a lot of good and new ideas ... (Electronic hardware, systems \& software: Nanoteq) 
It is much cheaper for them to do it here, so currently there is a worldwide trend to look for cheaper countries, but with skilled staff. (Electronic hardware, systems \& software: Siemens Telecommunications)

In summary, some companies have been successful in overcoming the challenges surrounding company R\&D in this country. Internally, companies have found ways to tap into and retain highly skilled staff, or to leverage adequate funding to successfully pursue R\&D and ensure its effective utilisation. Largely, these measures are a function of a positive and proactive attitude towards R\&D and innovation.

Externally, some companies have recognised that South Africa has a unique advantage which can be exploited: our 'competitive edge' internationally is rooted in the combination of so-called 'first' and 'third world' attributes, for example, top class infrastructure but cheap skilled labour and overheads. Certainly, if we encourage companies abroad to bring their R\&D requirements to this country, this could amount to a considerable investment in R\&D in South Africa. It could expand the skills and knowledge bases in the country, and create important links with companies and organisations abroad. This is an opportunity to put South Africa on the global R\&D map. 
This report has documented and discussed a range of information concerning company $R \& D$ in South Africa, generated from the industry interviews. We have considered the factors, which drive company R\&D, and how these are translated into an R\&D agenda. We have also considered the modes of knowledge production inherent in company R\&D, as well as the involvement of others in the R\&D process through collaboration and outsourcing. The nature of the outputs of company R\&D, and the way in which these are disseminated to users, was also explored.

The report then turned to the question of the utilisation, or otherwise, of R\&D outputs. We began by looking at the benefits derived from the utilisation of R\&D, and who the users are. We then turned to an investigation of the factors that either limit or result in no utilisation. Finally, we considered respondents' ideas and insights into how to ensure that company R\&D is successful and, more importantly, that the outputs are effectively utilised.

By way of summarising the factors that impact on company R\&D and, in particular, those which inhibit or result in no utilisation of R\&D outputs, we have attempted to match each of these factors to the particular stage in the process of innovation in which they are likely to occur. Some of the major themes running through this analysis have included issues to do with human resources, funding, intellectual property and the importance of tacit knowledge in the process of technology transfer. In many respects, these factors cut across all stages of the innovation process.

\section{Table I I.I: Factors that limit utilisation}

\begin{tabular}{|c|c|}
\hline $\begin{array}{l}\text { Stage in the } \\
\text { innovation process }\end{array}$ & Limiting factors \\
\hline $\begin{array}{l}\text { Setting the R\&D } \\
\text { agenda }\end{array}$ & $\begin{array}{l}\text { - Inadequate information can lead to the poor conceptualisation of an } \\
\text { R\&D project, which later might result in a product that is } \\
\text { inappropriate and which cannot be used } \\
\text { - A lack of proper consultation with intended users at the start can } \\
\text { lead to problems with utilisation later on (cf the fit between purpose } \\
\text { and intended user and users) }\end{array}$ \\
\hline R\&D activities & $\begin{array}{l}\text { - The quality and ultimate success of R\&D might be compromised by } \\
\text { a lack of skills, equipment, information or funding, or by political } \\
\text { pressure } \\
\text { - Longer-term, basic research is under greater threat than short- } \\
\text { term, application-driven R\&D of not being utilised, or pursued in the } \\
\text { first place }\end{array}$ \\
\hline
\end{tabular}


Table II.I Continued

\begin{tabular}{|c|c|}
\hline $\begin{array}{l}\text { Stage in the } \\
\text { innovation process }\end{array}$ & Limiting factors \\
\hline Dissemination & $\begin{array}{l}\text { - Dissemination of R\&D outputs is usually restricted (e.g. patents, } \\
\text { licenses, keeping it internal) which reduces the amount of } \\
\text { information or knowledge available to South African industry as a } \\
\text { whole } \\
\text { - Wider dissemination (e.g. in journals or at conferences) is also } \\
\text { limited and is usually too general or out-of-date to be of much } \\
\text { immediate use }\end{array}$ \\
\hline Commercialisation & $\begin{array}{l}\text { The more theoretical orientation of many academics and public } \\
\text { sector scientists can lead to results which are too impractical to } \\
\text { properly commercialise } \\
\text { - A lack of funds can result in the product not being commercialised } \\
\text { (note that government funding does not cover commercialisation) }\end{array}$ \\
\hline Technology transfer & $\begin{array}{l}\text { - When the tacit knowledge associated with the R\&D process and } \\
\text { outputs is not transferred, this can result in limited or no utilisation } \\
\text { on the part of users (cf the absorptive capacity of firms) } \\
\text { - In cases where technology transfer is institutionalised, e.g. in } \\
\text { agricultural extension, a lack of resources, both human and financial, } \\
\text { can result in very limited utilisation or implementation. } \\
\text { - When users are sceptical about the value of the change suggested } \\
\text { by the R\&D, do not have the skills to apply R\&D outputs in their } \\
\text { own contexts, or who are simply resistant to change, they are likely } \\
\text { to not use the R\&D at all }\end{array}$ \\
\hline Product launch & $\begin{array}{l}\text { - The outputs of R\&D will not be effectively utilised if there is no } \\
\text { market for product, or the product turns out to not be competitive. } \\
\text { To some extent, this could be because the company did not do its } \\
\text { homework properly! } \\
\text { - R\&D activities might not be realised if a competitor gets to the } \\
\text { market first }\end{array}$ \\
\hline $\begin{array}{l}\text { Evaluating the } \\
\text { outcomes of R\&D }\end{array}$ & $\begin{array}{l}\text { - Companies would do well to implement a system of ongoing } \\
\text { monitoring and evaluation of the process, outcomes and utilisation } \\
\text { of R\&D }\end{array}$ \\
\hline
\end{tabular}

Finally, the industry data suggests a number of ideas on how to optimalise the effective utilisation of company R\&D:

I) In the interests of industrial and economic development in the country, the government could consider some form of incentive for companies to pursue R\&D.

2) Human resource capacity is a major issue. Already many of the 'solutions' are on the national agenda (science and maths graduates, improved participation and throughput rates in $\mathrm{HE}$, etc). Nevertheless, many of these are very long-term solutions. A short-term option to consider is recruiting skills from abroad. The 
government's 'restrictive' immigration policy is an issue in this regard (see, for example, Crush, McDonald \& Williams 2000:2; Mattes, Crush \& Richmond 2000:12). We also need proactive policies to address the ageing/shrinking scientific workforce in the public sector.

3) Government funding policies and processes could be improved. For example, the process could be streamlined to ensure that the 'turnaround' is quick enough for companies to pursue their opportunities. Government funding could also be extended to ensure that company R\&D reaches the stage of commercialisation.

4) Both companies and their collaborating or contractual partners could consider the process of technology transfer itself. This might involve, for instance, training and other forms of knowledge transfer between producers and users of R\&D to ensure effective utilisation, or the use of networks and software to facilitate communication and transfer internally.

5) Finally, both the public and private sectors could usefully exploit the fact that South Africa is considered to be a cheap site for R\&D (particularly in terms of labour), but that it is also considered to have some quality expertise available. This would help to grow our own capacity. 


\section{LIST OF REFERENCES}

Bailey TG \& Mouton J (2005) A review of models of research utilisation. Centre for Research on Science and Technology: University of Stellenbosch.

Barre R (200I) The agora model of innovation systems: S\&T indicators for a democratic knowledge society. Research Evaluation, 10(1): I3-18.

Bozeman B (2000) Technology transfer and public policy: A review of research and theory, Research Policy, 29:627-655

Carstens A \& Mouton J (2002) Industry-higher education partnerships: Literature review. Centre for Interdisciplinary Studies, University of Stellenbosch.

Crush J; McDonald D \& Williams V (2000) Is South Africa losing its minds? In Losing our minds: Skills migration and the South African brain drain, (ed) J Crush. Cape Town: Idasa.

Etzkowitz H \& Webster A (1998) Entrepreneurial science: The second academic revolution. In Etzkowitz H; Webster A \& Healey P (eds.) Capitalizing knowledge: New intersections of industry and academia. Albany: State University of New York Press.

Etzkowitz, H, Webster A \& Healey P (1998) Introduction. In Etzkowitz H; Webster A \& Healey P (eds.) Capitalizing knowledge: New intersections of industry and academia. Albany: State University of New York Press.

Gibbons M; Limoges C; Nowotny H; Schwartzman S; Scott P \& Trow M (1994) The new production of knowledge. The dynamics of science and research in contemporary societies. London: SAGE Publications.

Hellström T \& Jacob M (2000) Emerging issues in R\&D evaluation: The case of universityindustry partnership networks. In Jacob M \& Hellström T (eds.) The future of knowledge production in the academy. Buckingham: Open University Press.

Hemlin S (1998) Utility evaluation of academic research: Six basic propositions. Research Evaluation, Vol. 7(3): 159-165.

Howells J \& James A (200I) Corporate decision-making on the sourcing of technological knowledge. PREST Discussion Paper 0 I-0 I. Policy Research in Engineering, Science \& Technology, University of Manchester.

Huberman M (1994) Research utilisation: The state of the art. Knowledge and Policy: The International Journal of Knowledge Transfer and Utilisation. Vol. 7 (4): I3-33.

Leydesdorff L \& Etzkowitz H (1998) The Triple Helix as a model for innovation studies. (Conference Report). Available online at http://home.pscw.uva.nl/lleydesdorff/th2/spp.htm

Leydesdorff L \& Etzkowitz H 200I. The transformation of university-industry-government relations. (Electronic Journal of Sociology). Available online at http://www.sociology.org/content/vol005.004/ht.html

Machlup F (1993) Uses, value and benefits of knowledge. Knowledge: Creation, Diffusion, Utilisation. Vol. 14(4): 448-466.

Mattes R; Crush J \& Richmond W (2000) The brain gain: Skilled migrants and immigration policy in post-apartheid South Africa, Migration Policy Series, No. 20. Cape Town: Idasa/South African Migration Project. 
Mattes R \& Richmond W (2000) The brain drain: What do skilled South Africans think? In Losing our minds: Skills migration and the South African brain drain (ed) J Crush.

Migration Policy Series No. 18. Cape Town: Idasa/South African Migration Project

Mouton, J (2000) Patterns of research collaboration in academic science in South Africa. SA Journal of Science Vol.96 (Nrs. 9 \& I0): 458-462.

Mouton J (200I) Between adversaries and allies: The call for strategic science in postapartheid South Africa. Society in Transition.

OECD (199I) Oslo Manual: Proposed guidelines for collecting and interpreting technological innovation data. Paris: Organisation for Economic Co-operation and Development.

OECD (1994) Frascati Manual 1993: Proposed standard practice for surveys of research and experimental development. Paris: Organisation for Economic Co-operation and Development.

Orr L ( 1997) Globalisation and universities: Towards the 'market university'? Social Dynamics, 23(I):42-67.

Rich RF (1997) Measuring knowledge utilisation: Process and outcomes. Knowledge and Policy: The International Journal of Knowledge Transfer and Utilisation. Vol. 10 (3): II-24.

Rogers J \& Bozeman B (200I) "Knowledge value alliances": An alternative to the R\&D project focus in evaluation. Science, Technology and Human Values, Vol. 26 (I): 23-55.

Salter AJ \& Martin B (200I) The economic benefits of publicly funded basic research: A critical review. Research Policy 30: 509-532.

Scott A; Steyn G; Geuna A; Brusoni S \& Steinmeuller E (200I) The economic returns to basic research and the benefits of university-industry relationships: $A$ literature review and update of findings. Brighton: SPRU.

Subotzky G (1998) Alternatives to the entrepreneurial university: New modes of knowledge production in community service programs. Paper presented at the Annual ASHE International Conference, Miami, Florida, 4-7 November 1998.

Wickham S (2002) Unlocking intellectual knowledge: External partners' views of research partnerships with selected higher education institutions in the Western Cape. Report for the International Development Research Centre / Trade and Industry Policy Secretariat. Cape Town: Research \& Academic Development. 

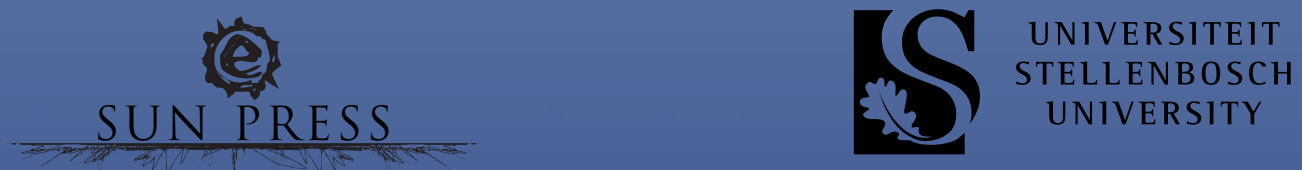